\title{
Maternal smoking during pregnancy and birth defects in children: a systematic review with meta-analysis
}

\section{Tabagismo materno na gestação e malformações congênitas em crianças: uma revisão sistemática com meta-análise}

\section{El tabaquismo materno durante el embarazo y las malformaciones congénitas en niños: una revisión sistemática y meta-análisis}

\author{
1 Faculdade de Medicina, \\ Universidade Federal do Rio \\ Grande, Rio Grande, Brasil. \\ Correspondence \\ L. Zhang \\ Faculdade de Medicina, \\ Universidade Federal do Rio \\ Grande. \\ Rua Visconde de Paranaguá \\ 102, Rio Grande, RS \\ 96200-190, Brasil. \\ zhanglinjie63@yahoo.com.br
}

\begin{abstract}
This systematic review aimed to investigate the association between maternal smoking during pregnancy and birth defects in children. We performed an electronic search of observational studies in the databases ovid MEDLINE (1950 to April 2010), LILACS and SciELO. We included 188 studies with a total of 13,564,914 participants (192,655 cases). Significant positive associations were found between maternal smoking and birth defects in the following body systems: cardiovascular (OR: 1.11; 95\% CI: 1.031.19), digestive (OR: 1.18; 95\%CI: 1.07-1.30), musculoskeletal (OR: 1.27; 95\%CI: 1.16-1.39) and face and neck (OR: 1.28; 95\%CI: 1.19-1.37). The strength of association between maternal smoking and birth defects measured by the OR (95\%CI) is significantly related to the amount of cigarettes smoked daily $\left(\chi^{2}=12.1 ; d f=2\right.$ $p=0.002)$. In conclusion, maternal smoking during pregnancy is associated with congenital malformations in children and this association is dose-dependent.
\end{abstract}

Smoking; Pregnancy; Congenital Abnormalities

\author{
Dilvania Nicoletti 1 \\ Leilane Droppa Appel 1 \\ Pedro Siedersberger Neto 1 \\ Gabriel Waihrich Guimarães 1 \\ Linjie Zhang ${ }^{1}$
}

\section{Resumo}

Esta revisão sistemática teve como objetivo investigar a associação entre fumo materno na gestação e as malformações congênitas em crianças. Uma busca eletrônica dos estudos observacionais foi realizada nas bases de dados ovid MEDLINE (1950 até abril de 2010), SciELO e LILACS. Foram incluídos nesta revisão 188 estudos com um total de 13.564.914 participantes (192.655 casos). Foram encontradas associações positivas significativas entre fumo materno e malformações dos sistemas: cardiovascular (OR: 1,11; IC95\%: 1,03-1,19), digestivo (OR: 1,18; IC95\%: 1,07-1,30), musculoesquelético (OR: 1,27; IC95\%: 1,16-1,39) e face e pescoço (OR: 1,28; IC95\%: 1,19-1,37). A força de associação entre fumo materno e malformações medida pelo $O R$ (IC95\%) está relacionada significativamente com a quantidade diária de cigarros consumi$\operatorname{dos}\left(\chi^{2}=12,1 ; d f=2 ; p=0,002\right)$. Concluímos que fumo materno na gestação está associado com maior risco de malformações congênitas em crianças e essa associação é dose-dependente.

Hábito de Fumar; Gravidez; Anormalidades Congênitas 


\section{Introduction}

Birth defects are the cause of high mortality and morbidity in children. It is estimated that about $5 \%$ of live births present some abnormality in their development 1 . Over the past decades, birth defects have increasingly contributed to child mortality 2,3. In Brazil, the rate of child deaths due to birth defects rose from $9.7 \%$ in 1996 to $18.2 \%$ in 2008 , representing an annual average increase of $0.71 \%$. This increase may be due to a better management of infections and contagious, and nutrition-related diseases, which reduced child deaths from these conditions 1,3 .

Most birth defects are of multifactorial etiology. In addition to the genetic component, their occurrence may be related to exposure of the child, even before birth, or the parents to toxic substances, including tobacco ${ }^{4}$. While this investigation was being carried out, a systematic review with 101 observational studies was published, and showed an association between maternal smoking during pregnancy and different birth defects in children 5 . This review, however, did not include a considerable number of relevant studies 6,7,8,9,10,11,12,13,14. Moreover, defects of the abdominal wall, such as congenital diaphragmatic and inguinal hernia, gastroschisis, and omphalocele, which should be considered musculoskeletal abnormalities, according to the $10^{\text {th }}$ revision of the International Statistical Classification of Diseases and Related Health Problems (ICD10) 15 were classified as gastrointestinal defects.

The purpose of this systematic review is to investigate maternal smoking during pregnancy and birth defects in children. The possible doseresponse relation in that association was also studied.

\section{Methods}

A systematic review with meta-analysis was conducted. The procedures for the review and reporting of the results were based on the recommendations by MOOSE (Meta-analysis of Observational Studies in Epidemiology) 16. The protocol for the review was assessed and approved by a panel that included two experts in Pediatrics and one in Epidemiology, in 2010.

Studies that investigated the association between maternal smoking during pregnancy and birth defects in children were considered eligible for the review. Studies that contemplated the association between maternal smoking and chromosomal abnormalities were ruled out.

The electronic search of the studies was made on databases Ovid MEDLINE (1950 until April
2010), SciELO, and LILACS. The strategy to search potentially relevant studies for the review on the databse Ovid MEDLINE is composed of two parts (Figure 1): the first (from line \#1 to line \#4) is the search strategy to identify studies on maternal smoking, and the secons part (from line \#5 to line \#20) is the strategy to find birth-defects-related studies. The bibliographic references of articles whose full text was obtained were reviewed, in order to identify additional studies. The Google Translator (https://translate.google.com.br/) was used to translate two articles, one in Lithuanian and other in French.

Study selection was independently made by four investigators (two teams of two). Selection process was made in two stages: in the first, the title and abstract of the articles identified during the electronic search were reviewed to select potential studies for this review. The full text of articles was obtained for which information from the title and the abstract met the inclusion criteria, or in cases where there was not enough information to decide about their inclusion. In the second stage, the articles were read in full for a final selection of the studies, with the inclusion and exclusion criteria being checked. Discrepancies among the investigators were resolved by consensus. Data extraction was performed by four investigators using a standard form. The extracted data were checked by the investigators.

Meta-analysis was performed using the software Stata, version 11.0 (Stata Corp., College Station, United States). A random effects model was applied. The association between maternal smoking during pregnancy and the presence of any kind of birth defects in children was evaluated by means of odds ratios (OR) and $95 \%$ confidence intervals $(95 \% \mathrm{CI})$. When the original studies indicated the presence of more than one defect, the results of each defect were combined to obtain data of any type of defect. Whenever possible, adjusted OR was used.

The pre-defined sub-group analyses were performed to investigate the association between maternal smoking during pregnancy and birth defects in children, according to the organ systems involved. The classification of birth defects was based on the ICD-10. The pre-defined sub-group analyses were also used to assess the potential influence of the following methodological aspects in the results of the meta-analyses: design of the investigation (prospective $v s$. retrospective); size of the sample (cases) $(\leq 200$; 200-1,000; 1,000-5,000; > 5,000); adjustment/ matching of confounding factors, including age of the mother (yes $v$ s. no). Two post hoc subgroup analyses were performed to assess the potential impact of exposure definition (maternal smok- 
Figure 1

Search strategy of studies in the Ovid MEDLINE database.

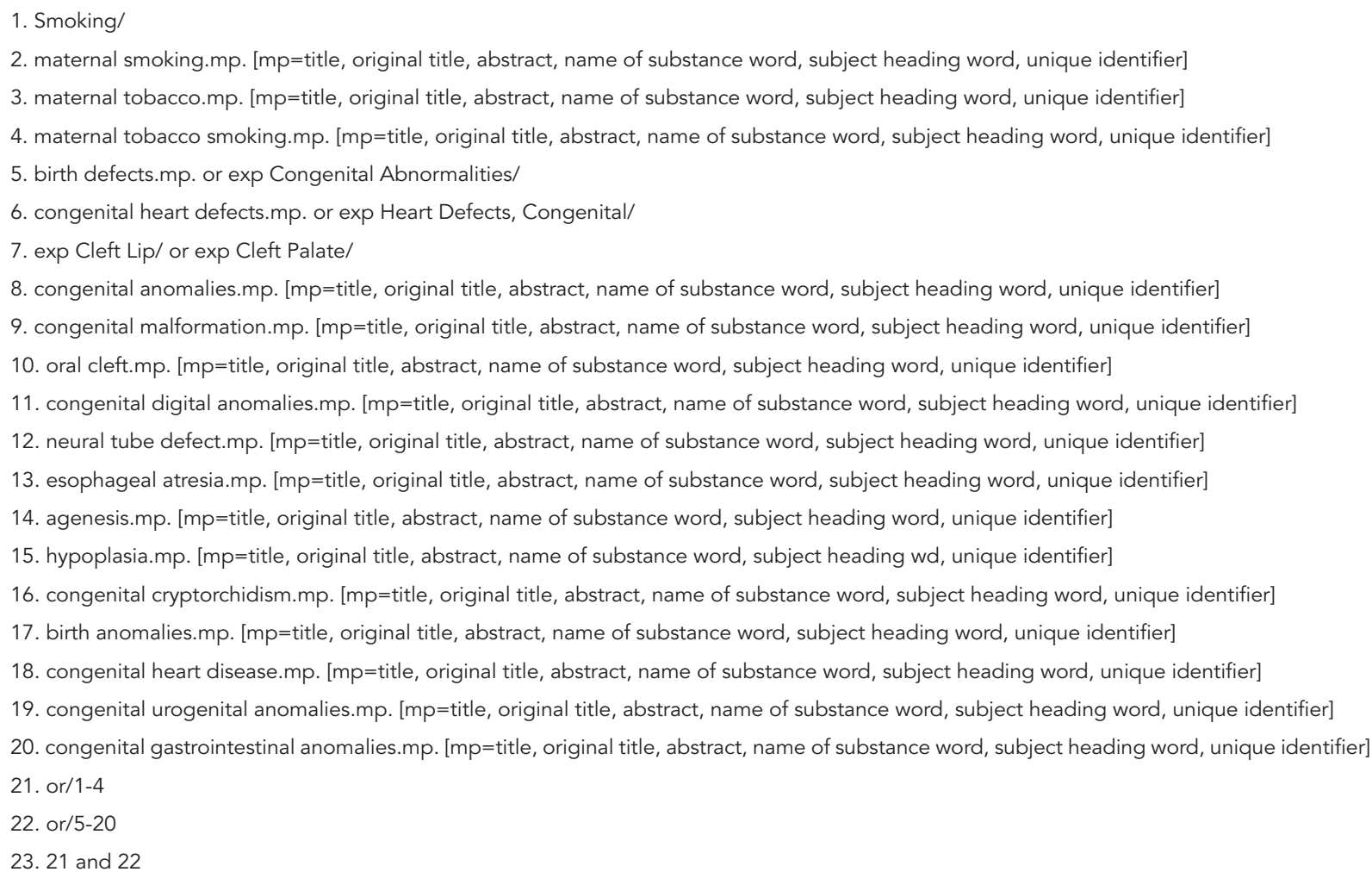

ing), and the period of exposure during pregnancy in the meta-analysis results. To investigate the dose-response relation between maternal smoking during pregnancy and birth defects in children, the analysis was stratified in three categories according to the number of cigarettes smoked per day (1-9, 10-19 and > 20).

Heterogeneity of results among the studies was assessed through the $\mathrm{I}^{2}$ statistic. $\mathrm{I}^{2}>75 \%$ indicates significant heterogeneity 17 . Possible causes for heterogeneity were examined through the above mentioned sub-group analyses. The publication bias was investigated with the use of the funnel plot and the Egger test 17.

\section{Results}

Out of the 1,043 citations identified by the electronic search, 129 studies were selected. Fiftynine additional studies were included, found in reviews of original articles and from the systematic review. Therefore, a total of 188 studies (153 projects or independent databases) $6,7,8,9,10,11,12$, $13,14,18,19,20,21,22,23,24,25,26,27,28,29,30,31,32,33,34,35,36,37$, $38,39,40,41,42,43,44,45,46,47,48,49,50,51,52,53,54,55,56,57,58,59$, $60,61,62,63,64,65,66,67,68,69,70,71,72,73,74,75,76,77,78,79,80,81$, $82,83,84,85,86,87,88,89,90,91,92,93,94,95,96,97,98,99,100,101,102$, 103,104,105,106,107,108,109,110,111,112,113,114,115,116,117,118, $119,120,121,122,123,124,125,126,127,128,129,130,131,132,133,134$, $135,136,137,138,139,140,141,142,143,144,145,146,147,148,149,150$, $151,152,153,154,155,156,157,158,159,160,161,162,163.164,165,166$, $167,168,169,170,171,172,173,174,175,176,177,178,179,180,181,182$, $183,184,185,186,187,188,189,190,191,192,193,194,195,196$ with a total of 13,564,914 subjects (192,655 birth defect cases, and 13,372,259 controls with no defects) were included in this review (Figure 2). Twentynine were prospective studies (cohort, or nestedcase control studies), and 159 were retrospective (case-control, or cross-sectional studies). The overall characteristics of the 188 studies included are shown in Table 1. 


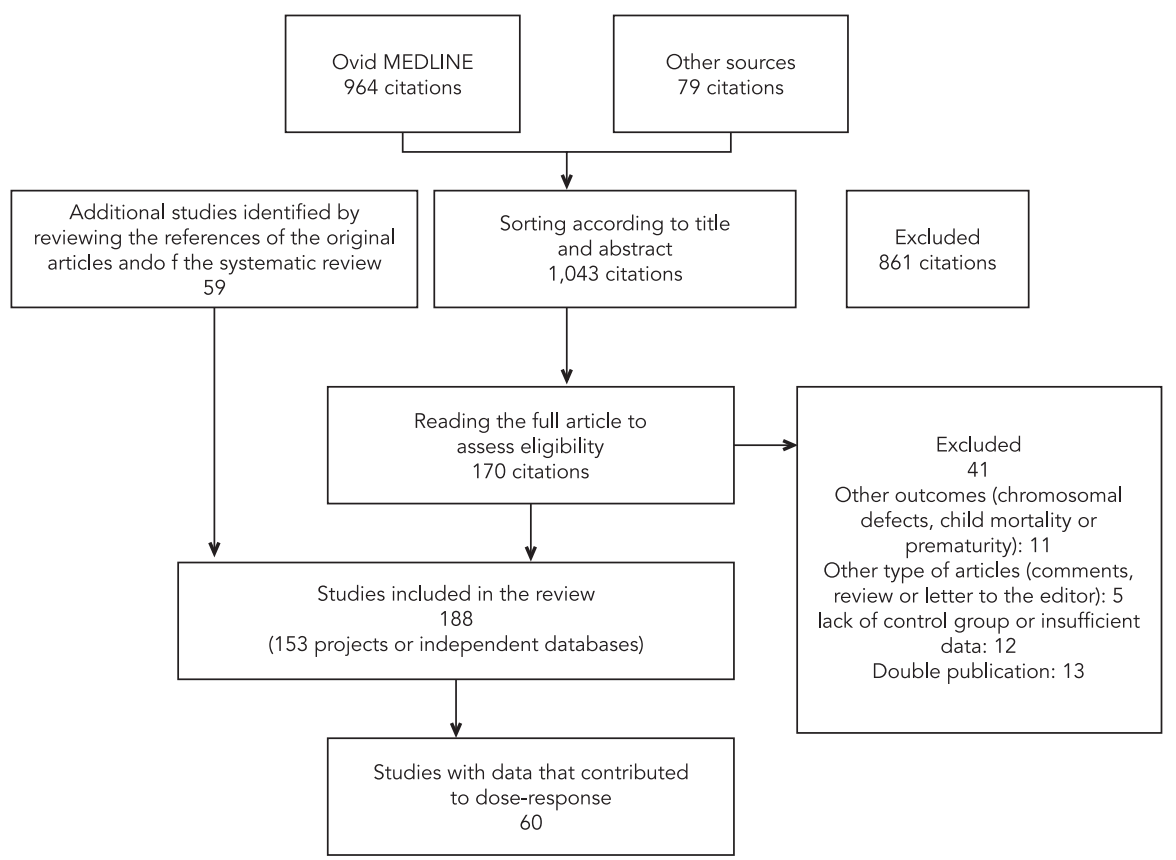

Table 2 presents individual and combined results of the 188 studies about the association between maternal smoking during pregnancy and birth defect of any type in children. The meta-analysis of the 188 studies showed that children of smoking mother had a higher chance of presenting any type of birth defects (OR: 1.18; 95\%CI: 1.14-1.22; $\mathrm{p}<0.001$; $\mathrm{I}$ : 77.2\%).

In the sub-group analyses, according to the organ systems involved, there were significant positive associations between maternal smoking and defects in the cardiovascular system (OR: 1.11; 95\%CI: 1.03-1.19), digestive system (OR: 1.18; 95\%CI: 1.07-1.30), musculoskeletal system (OR: 1.27; 95\%CI: 1.16-139), and face and neck (OR: 1.28; 95\%CI: 1.19-1.37) (Figure 3). Other subgroup analyses showed that retrospective studies and those with smaller sample size ( $\leq 1.000$ cases) has higher combined OR values. Using or not adjustment/matching in the original studies to control confounding factors, particularly the age of the mother did not significantly affect the meta-analysis results (Table 3). Two post hoc sub-group analyses were performed to assess the potential impact of the definition of maternal smoking, and the period of pregnancy the pregnant mother was exposed to smoking in the meta-analysis results. There was no statistically significant difference between studies in which maternal smoking during pregnancy was explicitly defined as daily smoking $(\mathrm{n}=91$; OR: 1.21; 95\%CI: 1.16-1.26) and those studies with no clear definition $(\mathrm{n}=97$; OR: 1.17 ; 95\%CI: 1.11 1.23) $\left(\chi^{2}=1.0 ; \mathrm{p}=0.32\right)$. In addition, there was no statistically significant difference between studies in which exposure to smoking occurred in the first quarter of the pregnancy ( $\mathrm{n}=80$; OR: 1.22 ; 95\%CI: 1.17-1.29) and those studies with no clear definition ( $\mathrm{n}=108$; OR: 1.16; 95\%CI: $1.10-1.21$ ) $\left(\chi^{2}=2.1 ; \mathrm{p}=0.15\right)$.

Figure 4 shows the dose-response relation between maternal smoking during pregnancy and birth defects in children. Sixty studies $6,7,8$, $9,11,12,16,21,24,32,43,44,47,48,49,51,57,58,64,65,69,74,80,82$, $85,88,89,90,91,92,99,100,101,103,104,107,108,113,115,119,121$, 122,123,124,132,135,144,150,151,157,163,169,172,173,187,188,189, 190,192 with a total of $12,137,944$ subjects $(103,107$ cases) contributed their data to the analysis, of which 11 were prospective studies. The power of association between maternal smoking and defects measured by OR (95\%CI) is significantly related with the daily amount of cigarettes smoked 
Table 1

General characteristics of the studies included.

\begin{tabular}{|c|c|c|c|c|c|c|c|c|}
\hline \multirow[t]{2}{*}{$\begin{array}{l}\text { Reference } \\
\text { (year) }\end{array}$} & \multirow[t]{2}{*}{$\begin{array}{l}\text { Type of } \\
\text { study }\end{array}$} & \multirow[t]{2}{*}{$\begin{array}{l}\text { Site/Source } \\
\text { of data }\end{array}$} & \multirow[t]{2}{*}{ Type of defect } & \multicolumn{2}{|c|}{$\begin{array}{l}\text { Exposure (maternal } \\
\text { smoking) }\end{array}$} & \multirow[t]{2}{*}{ Case } & \multirow[t]{2}{*}{ Controls } & \multirow{2}{*}{$\begin{array}{l}\text { Control of confounders } \\
\text { (adjustment/ } \\
\text { matching) }\end{array}$} \\
\hline & & & & $\begin{array}{c}\text { Data } \\
\text { collection }\end{array}$ & $\begin{array}{l}\text { Stage of } \\
\text { pregnancy }\end{array}$ & & & \\
\hline $\begin{array}{l}\text { Adams et } \\
\text { al. } 18 \text { (1989) }\end{array}$ & $\begin{array}{l}\text { Case- } \\
\text { control }\end{array}$ & $\begin{array}{c}\text { Five } \\
\text { metropolitan } \\
\text { areas of Atlanta } \\
\text { (United States) }\end{array}$ & $\begin{array}{c}\text { Conotruncal heart } \\
\text { defect }\end{array}$ & Interview & First quarter & 83 & 1,303 & $\begin{array}{l}\text { Matching: race, month } \\
\text { of birth, place of birth }\end{array}$ \\
\hline $\begin{array}{l}\text { Akre et al. } \\
19 \text { (1999) }\end{array}$ & $\begin{array}{l}\text { Nested } \\
\text { case- } \\
\text { control }\end{array}$ & $\begin{array}{l}\text { Medical birth } \\
\text { record and } \\
\text { admission } \\
\text { records (Sweden) }\end{array}$ & $\begin{array}{l}\text { Cryptorchidism; } \\
\text { hypospadias }\end{array}$ & Interview & Unspecified & $\begin{array}{l}2,576 \text { (cryptor- } \\
\text { chidism); } \\
\text { 1,137 (hypos- } \\
\text { padias) }\end{array}$ & $\begin{array}{c}12,910 \\
\text { (cryptor- } \\
\text { chidism); } \\
5,687 \\
\text { (hypos- } \\
\text { padias) }\end{array}$ & $\begin{array}{c}\text { Adjusted: maternal } \\
\text { factors (age, height, } \\
\text { parity, preeclampsia) } \\
\text { and perinatal factors } \\
\text { (plurality, Apgar, other } \\
\text { defects); Matching: } \\
\text { sex, month and place } \\
\text { of birth }\end{array}$ \\
\hline $\begin{array}{l}\text { Alderman } \\
\text { et al. } 20 \\
(1991)\end{array}$ & $\begin{array}{l}\text { Case- } \\
\text { control }\end{array}$ & $\begin{array}{c}\text { Birth defects } \\
\text { registry, } \\
\text { Washington } \\
\text { State (United } \\
\text { States) }\end{array}$ & $\begin{array}{l}\text { Crooked foot at } \\
\text { birth }\end{array}$ & $\begin{array}{c}\text { Birth } \\
\text { certificate } \\
\text { data }\end{array}$ & Unspecified & 124 & 1,438 & $\begin{array}{l}\text { Adjusted or stratified: } \\
\text { sex of the child, } \\
\text { stillborn, plurality, } \\
\text { marital status }\end{array}$ \\
\hline $\begin{array}{l}\text { Alderman } \\
\text { et al. } 21 \\
(1994)\end{array}$ & $\begin{array}{l}\text { Case- } \\
\text { control }\end{array}$ & $\begin{array}{c}\text { Colorado } \\
\text { Craniosynostosis } \\
\text { Registry (United } \\
\text { States) }\end{array}$ & Craniosynostosis & $\begin{array}{l}\text { Phone } \\
\text { interview }\end{array}$ & Any period & 212 & 291 & $\begin{array}{l}\text { Adjusted or stratified: } \\
\text { maternal age, race, } \\
\text { multiparity, sex of } \\
\text { the child, type of } \\
\text { craniosynostosis period } \\
\text { of exposure }\end{array}$ \\
\hline $\begin{array}{l}\text { Ananijevic- } \\
\text { Pandey et } \\
\text { al. } 22 \text { (1992) }\end{array}$ & $\begin{array}{l}\text { Case- } \\
\text { control }\end{array}$ & $\begin{array}{l}\text { Belgrade Study } \\
\text { (Serbia) }\end{array}$ & $\begin{array}{c}\text { General } \\
\text { malformations }\end{array}$ & Interview & Unspecified & 113 & 195 & $\begin{array}{c}\text { Matching: sex, } \\
\text { gestational age, } \\
\text { maternal age, place of } \\
\text { birth }\end{array}$ \\
\hline $\begin{array}{l}\text { Aro et al. } 23 \\
\text { (1983) }\end{array}$ & $\begin{array}{l}\text { Case- } \\
\text { control }\end{array}$ & $\begin{array}{l}\text { The Finnish } \\
\text { registry of } \\
\text { congenital } \\
\text { malformations }\end{array}$ & Limb reduction & $\begin{array}{l}\text { Structured } \\
\text { question- } \\
\text { naire }\end{array}$ & Unspecified & 453 & 453 & $\begin{array}{l}\text { Adjusted: maternal } \\
\text { age, alcohol intake; } \\
\text { Matching: month/year } \\
\text { and place of birth }\end{array}$ \\
\hline $\begin{array}{l}\text { Bailey et al. } \\
24 \text { (1970) }\end{array}$ & Cohort & $\begin{array}{l}\text { Christchurch } \\
\text { Women's } \\
\text { Hospital (New } \\
\text { Zealand) }\end{array}$ & Birth defects & Interview & Unspecified & 58 & 1,116 & - \\
\hline $\begin{array}{l}\text { Batra et } \\
\text { al. } 25 \text { (2007) }\end{array}$ & $\begin{array}{l}\text { Case- } \\
\text { control }\end{array}$ & $\begin{array}{l}\text { Comprehensive } \\
\text { Hospital Abstract } \\
\text { Reporting } \\
\text { System, } \\
\text { Washington } \\
\text { State (United } \\
\text { States) }\end{array}$ & $\begin{array}{c}\text { Ventricular septal } \\
\text { defect }\end{array}$ & $\begin{array}{c}\text { Birth } \\
\text { certificate } \\
\text { data }\end{array}$ & Unspecified & 2,898 & 11,186 & Matching: year of birth \\
\hline $\begin{array}{l}\text { Beard et } \\
\text { al. } 26 \text { (1984) }\end{array}$ & $\begin{array}{l}\text { Case- } \\
\text { control }\end{array}$ & $\begin{array}{l}\text { Rochester Study, } \\
\text { Minnesota } \\
\text { (United States) }\end{array}$ & Cryptorchidism & - & Unspecified & 113 & 226 & $\begin{array}{c}\text { Adjusted: maternal age, } \\
\text { birth weight, parity, year } \\
\text { of birth }\end{array}$ \\
\hline
\end{tabular}

(continues) 
Table 1 (continued)

\begin{tabular}{|c|c|c|c|c|c|c|c|c|}
\hline \multirow[t]{2}{*}{$\begin{array}{l}\text { Reference } \\
\text { (year) }\end{array}$} & \multirow[t]{2}{*}{$\begin{array}{l}\text { Type of } \\
\text { study }\end{array}$} & \multirow[t]{2}{*}{$\begin{array}{l}\text { Site/Source } \\
\text { of data }\end{array}$} & \multirow[t]{2}{*}{ Type of defect } & \multicolumn{2}{|c|}{$\begin{array}{c}\text { Exposure (maternal } \\
\text { smoking) }\end{array}$} & \multirow[t]{2}{*}{ Case } & \multirow[t]{2}{*}{ Controls } & \multirow{2}{*}{$\begin{array}{c}\text { Control of confounders } \\
\text { (adjustment/ } \\
\text { matching) }\end{array}$} \\
\hline & & & & $\begin{array}{l}\text { Data } \\
\text { collection }\end{array}$ & $\begin{array}{l}\text { Stage of } \\
\text { pregnancy }\end{array}$ & & & \\
\hline $\begin{array}{l}\text { Beaty } \\
\text { et al. } 27 \\
(2008)\end{array}$ & $\begin{array}{l}\text { Case- } \\
\text { control }\end{array}$ & $\begin{array}{l}\text { Maryland State } \\
\text { Birth Defects } \\
\text { Reporting and } \\
\text { Information } \\
\text { System (United } \\
\text { States) }\end{array}$ & Oral fissures & Interview & Unspecified & 121 & 86 & - \\
\hline $\begin{array}{l}\text { Beaty } \\
\text { et al. } 28 \\
(2001)\end{array}$ & $\begin{array}{l}\text { Case- } \\
\text { control }\end{array}$ & $\begin{array}{l}\text { Maryland State } \\
\text { Birth Defects } \\
\text { Reporting and } \\
\text { Information } \\
\text { System (United } \\
\text { States) }\end{array}$ & Oral fissures & Interview & $\begin{array}{l}\text { Conception } \\
\text { and first } \\
\text { quarter }\end{array}$ & 135 & 152 & $\begin{array}{c}\text { Adjusted: maternal } \\
\text { age, maternal/paternal } \\
\text { schooling }\end{array}$ \\
\hline $\begin{array}{l}\text { Bell \& } \\
\text { Lumley } 29 \\
\text { (1989) }\end{array}$ & $\begin{array}{l}\text { Cross- } \\
\text { sectional }\end{array}$ & $\begin{array}{l}\text { Statistics of } \\
\text { perinatal } \\
\text { morbidity. } \\
\text { Victoria } \\
\text { (Austrália) }\end{array}$ & Birth defects & $\begin{array}{l}\text { Interview } \\
\text { or medical } \\
\text { records }\end{array}$ & $\begin{array}{l}\text { Second half of } \\
\text { pregnancy }\end{array}$ & 7 & 5,550 & - \\
\hline $\begin{array}{l}\text { Berkowitz } \\
\text { \& Lapinski } \\
30 \text { (1996) }\end{array}$ & $\begin{array}{l}\text { Case- } \\
\text { control }\end{array}$ & $\begin{array}{l}\text { Study of the } \\
\text { city of New York } \\
\text { (United States) }\end{array}$ & Cryptorchidism & - & Unspecified & 63 & 219 & $\begin{array}{l}\text { Matching: month/year } \\
\text { of birth, sex, place of } \\
\text { birth }\end{array}$ \\
\hline $\begin{array}{l}\text { Biggs et } \\
\text { al. } 31 \\
(2002)\end{array}$ & $\begin{array}{l}\text { Case- } \\
\text { control }\end{array}$ & $\begin{array}{c}\text { Birth certificate } \\
\text { data, } \\
\text { Washington } \\
\text { State (United } \\
\text { States) }\end{array}$ & Cryptorchidism & $\begin{array}{l}\text { Birth } \\
\text { certificate } \\
\text { data }\end{array}$ & Unspecified & 2,395 & 9,580 & $\begin{array}{l}\text { Matching: month/year } \\
\text { of birth, sex }\end{array}$ \\
\hline $\begin{array}{l}\text { Bille et } \\
\text { al. } 32 \\
(2007)\end{array}$ & $\begin{array}{l}\text { Nested } \\
\text { case- } \\
\text { control }\end{array}$ & $\begin{array}{c}\text { Danish National } \\
\text { Birth Cohort } \\
\text { Data }\end{array}$ & Oral fissures & $\begin{array}{l}\text { Question- } \\
\text { naire and } \\
\text { phone } \\
\text { interview }\end{array}$ & First quarter & 189 & 836 & $\begin{array}{c}\text { Adjusted: maternal age, } \\
\text { social class }\end{array}$ \\
\hline $\begin{array}{l}\text { Bird et al. } 6 \\
\text { (2009) }\end{array}$ & $\begin{array}{l}\text { Case- } \\
\text { control }\end{array}$ & $\begin{array}{l}\text { National } \\
\text { Birth Defects } \\
\text { Prevention Study } \\
\text { (United States) }\end{array}$ & Musculoskeletal & Interview & $\begin{array}{c}\text { Pre- } \\
\text { conception } \\
\text { exposure and } \\
\text { in the first } \\
\text { quarter }\end{array}$ & 653 & 4,967 & $\begin{array}{l}\text { Adjusted: place } \\
\text { of birth, folic acid } \\
\text { supplementation, BMI, } \\
\text { maternal diabetes }\end{array}$ \\
\hline $\begin{array}{l}\text { Bitsko } \\
\text { et al. } 33 \\
\text { (2007) }\end{array}$ & $\begin{array}{l}\text { Case- } \\
\text { control }\end{array}$ & $\begin{array}{c}\text { Birth Defects } \\
\text { Risk Factor } \\
\text { Surveillance, } \\
\text { lowa (United } \\
\text { States) }\end{array}$ & Birth defects & - & Unspecified & 142 & 243 & $\begin{array}{l}\text { Matching: month/year } \\
\text { of birth, place of birth }\end{array}$ \\
\hline $\begin{array}{l}\text { Blatter } \\
\text { et al. } 34 \\
(1996)\end{array}$ & $\begin{array}{l}\text { Case- } \\
\text { control }\end{array}$ & $\begin{array}{l}\text { Hospitals of the } \\
\text { Netherlands }\end{array}$ & CNS defects & $\begin{array}{l}\text { Question- } \\
\text { naire and } \\
\text { phone } \\
\text { interview }\end{array}$ & Unspecified & 274 & 314 & Matching: place of birth \\
\hline $\begin{array}{l}\text { Botto et } \\
\text { al. } 35 \\
(2001)\end{array}$ & $\begin{array}{l}\text { Case- } \\
\text { control }\end{array}$ & $\begin{array}{c}\text { Atlanta } \\
\text { Congenital } \\
\text { Defects Program } \\
\text { (United States) }\end{array}$ & Heart defects & $\begin{array}{l}\text { Phone } \\
\text { interview }\end{array}$ & $\begin{array}{c}\text { Pre- } \\
\text { conception } \\
\text { exposure and } \\
\text { in the first } \\
\text { quarter }\end{array}$ & 905 & 3,029 & $\begin{array}{l}\text { Matching: month/year } \\
\text { of birth, place of birth, } \\
\text { race }\end{array}$ \\
\hline $\begin{array}{l}\text { Bracken et } \\
\text { al. } 7 \text { (1978) }\end{array}$ & $\begin{array}{l}\text { Case- } \\
\text { control }\end{array}$ & $\begin{array}{l}\text { Hospitals of } \\
\text { Connecticut } \\
\text { (United States) }\end{array}$ & Birth defects & Interview & First quarter & 1,369 & 2,967 & - \\
\hline
\end{tabular}

(continues) 
Table 1 (continued)

\begin{tabular}{|c|c|c|c|c|c|c|c|c|}
\hline \multirow[t]{2}{*}{$\begin{array}{l}\text { Reference } \\
\text { (year) }\end{array}$} & \multirow[t]{2}{*}{$\begin{array}{l}\text { Type of } \\
\text { study }\end{array}$} & \multirow[t]{2}{*}{$\begin{array}{l}\text { Site/Source } \\
\text { of data }\end{array}$} & \multirow[t]{2}{*}{ Type of defect } & \multicolumn{2}{|c|}{$\begin{array}{l}\text { Exposure (maternal } \\
\text { smoking) }\end{array}$} & \multirow[t]{2}{*}{ Case } & \multirow[t]{2}{*}{ Controls } & \multirow{2}{*}{$\begin{array}{c}\text { Control of confounders } \\
\text { (adjustment/ } \\
\text { matching) }\end{array}$} \\
\hline & & & & $\begin{array}{l}\text { Data } \\
\text { collection }\end{array}$ & $\begin{array}{l}\text { Stage of } \\
\text { pregnancy }\end{array}$ & & & \\
\hline $\begin{array}{l}\text { Brouwers } \\
\text { et al. } 36 \\
\text { (2007) }\end{array}$ & $\begin{array}{l}\text { Case- } \\
\text { control }\end{array}$ & $\begin{array}{l}\text { Pediatric } \\
\text { urology center } \\
\text { (Netherlands) }\end{array}$ & Hypospadias & $\begin{array}{l}\text { Question- } \\
\text { naire }\end{array}$ & $\begin{array}{c}\text { Pre- } \\
\text { conception } \\
\text { exposure and } \\
\text { in the first } \\
\text { quarter }\end{array}$ & 583 & 251 & $\begin{array}{l}\text { Adjusted: maternal/ } \\
\text { paternal schooling, } \\
\text { place of birth, paternal } \\
\text { hypospadias, infertility } \\
\text { treatment, exposure } \\
\text { to DES, multiparity, } \\
\text { vitamin supplements } \\
\text { prior to conception, } \\
\text { exposure to pesticides, } \\
\text { use of medication by } \\
\text { the father; Matching: } \\
\text { month/year of birth, } \\
\text { place of birth, sex }\end{array}$ \\
\hline $\begin{array}{l}\text { Brouwers } \\
\text { et al. } 37 \\
(2010)\end{array}$ & $\begin{array}{l}\text { Case- } \\
\text { control }\end{array}$ & $\begin{array}{l}\text { University } \\
\text { Hospital, } \\
\text { Netherlands }\end{array}$ & Hypospadias & $\begin{array}{l}\text { Question- } \\
\text { naire }\end{array}$ & Unspecified & 305 & 629 & Adjusted: year of birth \\
\hline $\begin{array}{l}\text { Browne } \\
\text { et al. } 38 \\
(2007)\end{array}$ & $\begin{array}{l}\text { Case- } \\
\text { control }\end{array}$ & $\begin{array}{l}\text { National } \\
\text { Birth Defects } \\
\text { Prevention Study } \\
\text { (United States) }\end{array}$ & Heart defects & $\begin{array}{l}\text { Phone } \\
\text { interview }\end{array}$ & $\begin{array}{c}\text { Pre- } \\
\text { conception } \\
\text { exposure and } \\
\text { in the first } \\
\text { quarter }\end{array}$ & 403 & 131 & $\begin{array}{c}\text { Adjusted: race, place } \\
\text { of birth }\end{array}$ \\
\hline $\begin{array}{l}\text { Carbone } \\
\text { et al. } 39 \\
\text { (2007) }\end{array}$ & $\begin{array}{l}\text { Case- } \\
\text { control }\end{array}$ & $\begin{array}{l}\text { Ragusa Study } \\
\text { (Italy) }\end{array}$ & $\begin{array}{l}\text { Cryptorchidism; } \\
\text { hypospadias }\end{array}$ & - & Unspecified & 91 & 203 & $\begin{array}{l}\text { Matching: month/place } \\
\text { of birth, place of birth, } \\
\text { sex }\end{array}$ \\
\hline $\begin{array}{l}\text { Cardy } \\
\text { et al. } 40 \\
(2007)\end{array}$ & $\begin{array}{l}\text { Case- } \\
\text { control }\end{array}$ & $\begin{array}{l}\text { Talipes Study } \\
\text { (United } \\
\text { Kingdom) }\end{array}$ & $\begin{array}{l}\text { Congenital } \\
\text { equinovarus }\end{array}$ & Interview & Unspecified & 194 & 60 & $\begin{array}{l}\text { Adjusted: year of birth, } \\
\text { sex }\end{array}$ \\
\hline $\begin{array}{l}\text { Carmi- } \\
\text { chael \& } \\
\text { Shaw } 41 \\
(2000)\end{array}$ & $\begin{array}{l}\text { Case- } \\
\text { control }\end{array}$ & $\begin{array}{c}\text { California } \\
\text { Birth Defects } \\
\text { Monitoring } \\
\text { Program (United } \\
\text { States) }\end{array}$ & Anencephaly & $\begin{array}{c}\text { Phone } \\
\text { interview }\end{array}$ & $\begin{array}{c}\text { Pre- } \\
\text { conception } \\
\text { exposure and } \\
\text { in the first } \\
\text { quarter }\end{array}$ & 122 & 464 & - \\
\hline $\begin{array}{l}\text { Carmi- } \\
\text { chael et } \\
\text { al. } 42 \\
(2003)\end{array}$ & $\begin{array}{l}\text { Case- } \\
\text { control }\end{array}$ & $\begin{array}{c}\text { California } \\
\text { Birth Defects } \\
\text { Monitoring } \\
\text { Program (United } \\
\text { States) }\end{array}$ & $\begin{array}{c}\text { Malformations } \\
\text { (cardiovascular } \\
\text { defects and facial } \\
\text { cleft) }\end{array}$ & $\begin{array}{l}\text { Phone } \\
\text { interview }\end{array}$ & $\begin{array}{c}\text { Pre- } \\
\text { conception } \\
\text { exposure and } \\
\text { in the first } \\
\text { quarter }\end{array}$ & 696 & 734 & - \\
\hline $\begin{array}{l}\text { Carmi } \\
\text { chael et } \\
\text { al. } 43 \\
(2005)\end{array}$ & $\begin{array}{l}\text { Case- } \\
\text { control }\end{array}$ & $\begin{array}{l}\text { National } \\
\text { Birth Defects } \\
\text { Prevention Study } \\
\text { (United States) }\end{array}$ & Hypospadias & Interview & Any period & 437 & 1,225 & $\begin{array}{c}\text { Adjusted: maternal } \\
\text { age, race, maternal } \\
\text { schooling, parity, history } \\
\text { of subfertility }\end{array}$ \\
\hline $\begin{array}{l}\text { Carmi } \\
\text { chael et } \\
\text { al. } 44 \\
(2008)\end{array}$ & $\begin{array}{l}\text { Case- } \\
\text { control }\end{array}$ & $\begin{array}{l}\text { National } \\
\text { Birth Defects } \\
\text { Prevention Study } \\
\text { (United States) }\end{array}$ & Craniosynostosis & Interview & Any period & 531 & 5,008 & $\begin{array}{c}\text { Adjusted: maternal age, } \\
\text { race, maternal/paternal } \\
\text { schooling, parity, history } \\
\text { of subfertility, folic acid } \\
\text { intake, Maternal BMI, } \\
\text { place of the study }\end{array}$ \\
\hline
\end{tabular}

(continues) 
Table 1 (continued)

\begin{tabular}{|c|c|c|c|c|c|c|c|c|}
\hline \multirow[t]{2}{*}{$\begin{array}{l}\text { Reference } \\
\text { (year) }\end{array}$} & \multirow[t]{2}{*}{$\begin{array}{l}\text { Type of } \\
\text { study }\end{array}$} & \multirow[t]{2}{*}{$\begin{array}{l}\text { Site/Source } \\
\text { of data }\end{array}$} & \multirow[t]{2}{*}{ Type of defect } & \multicolumn{2}{|c|}{$\begin{array}{c}\text { Exposure (maternal } \\
\text { smoking) }\end{array}$} & \multirow[t]{2}{*}{ Case } & \multirow[t]{2}{*}{ Controls } & \multirow{2}{*}{$\begin{array}{c}\text { Control of confounders } \\
\text { (adjustment/ } \\
\text { matching) }\end{array}$} \\
\hline & & & & $\begin{array}{l}\text { Data } \\
\text { collection }\end{array}$ & $\begin{array}{l}\text { Stage of } \\
\text { pregnancy }\end{array}$ & & & \\
\hline $\begin{array}{l}\text { Caton } \\
\text { et al. } 45 \\
(2008)\end{array}$ & $\begin{array}{l}\text { Case- } \\
\text { control }\end{array}$ & $\begin{array}{c}\text { National } \\
\text { Birth Defects } \\
\text { Prevention Study } \\
\text { (United States) }\end{array}$ & Hypospadias & $\begin{array}{l}\text { Phone } \\
\text { interview }\end{array}$ & $\begin{array}{c}\text { Pre- } \\
\text { conception } \\
\text { exposure and } \\
\text { in the first } \\
\text { quarter }\end{array}$ & 755 & 2,044 & - \\
\hline $\begin{array}{l}\text { Cedergren } \\
\text { et al. } 8 \\
(2002)\end{array}$ & $\begin{array}{l}\text { Case- } \\
\text { control }\end{array}$ & $\begin{array}{l}\text { Southeastern } \\
\text { region of } \\
\text { Sweden }\end{array}$ & Heart defects & $\begin{array}{l}\text { Medical } \\
\text { records }\end{array}$ & $\begin{array}{l}\text { Beginning of } \\
\text { pregnancy }\end{array}$ & 264 & 515 & - \\
\hline $\begin{array}{l}\text { Chambers } \\
\text { et al. } 46 \\
\text { (2007) }\end{array}$ & $\begin{array}{l}\text { Case- } \\
\text { control }\end{array}$ & $\begin{array}{l}\text { Southern region } \\
\text { of California } \\
\text { (United States) }\end{array}$ & Gastroschisis & $\begin{array}{l}\text { Medical } \\
\text { records }\end{array}$ & First quarter & 102 & 117 & - \\
\hline $\begin{array}{l}\text { Chevrier } \\
\text { et al. } 47 \\
(2008)\end{array}$ & $\begin{array}{l}\text { Case- } \\
\text { control }\end{array}$ & $\begin{array}{l}\text { Hospitals of } \\
\text { France }\end{array}$ & Oral fissures & $\begin{array}{l}\text { Question- } \\
\text { naire }\end{array}$ & First quarter & 240 & 236 & $\begin{array}{c}\text { Adjusted: place of birth, } \\
\text { sex, race }\end{array}$ \\
\hline $\begin{array}{l}\text { Chew } \\
\text { et al. } 48 \\
\text { (1994) }\end{array}$ & Cohort & $\begin{array}{l}\text { Collaborative } \\
\text { perinatal project } \\
\text { (United States) }\end{array}$ & Eye defects & Interview & Unspecified & 1,658 & 37,133 & $\begin{array}{c}\text { Adjusted: maternal age, } \\
\text { race, birth weight, place } \\
\text { of birth }\end{array}$ \\
\hline $\begin{array}{l}\text { Christen- } \\
\text { sen et al. } 9 \\
(1999)\end{array}$ & $\begin{array}{l}\text { Case- } \\
\text { control }\end{array}$ & $\begin{array}{l}\text { Danish national } \\
\text { study }\end{array}$ & Oral fissures & Interview & First quarter & 296 & 551 & $\begin{array}{l}\text { Adjusted: maternal } \\
\text { alcohol intake, } \\
\text { periconcepcional } \\
\text { vitamin } \\
\text { supplementation, place } \\
\text { of birth, month/year of } \\
\text { birth }\end{array}$ \\
\hline $\begin{array}{l}\text { Christian- } \\
\text { son } 49 \\
(1980)\end{array}$ & Cohort & $\begin{array}{c}\text { Kaiser } \\
\text { Foundation } \\
\text { health plan } \\
\text { (United States) }\end{array}$ & $\begin{array}{l}\text { Anomalies in all } \\
\text { systems }\end{array}$ & Interview & First quarter & 2,547 & 12,138 & - \\
\hline $\begin{array}{l}\text { Chung \& } \\
\text { Myriantho- } \\
\text { poulos } 50 \\
(1975)\end{array}$ & Cohort & $\begin{array}{l}\text { Collaborative } \\
\text { perinatal project } \\
\text { (United States) }\end{array}$ & Inguinal hernia & - & Unspecified & 713 & 51,482 & - \\
\hline $\begin{array}{l}\text { Chung } \\
\text { et al. } 51 \\
(2000)\end{array}$ & $\begin{array}{l}\text { Case- } \\
\text { control }\end{array}$ & $\begin{array}{c}\text { Natality } \\
\text { database (United } \\
\text { States) }\end{array}$ & $\begin{array}{l}\text { Cleft lip; cleft } \\
\text { palate }\end{array}$ & $\begin{array}{l}\text { Interview } \\
\text { and } \\
\text { database }\end{array}$ & $\begin{array}{l}\text { The entire } \\
\text { pregnancy }\end{array}$ & 2,207 & 4,414 & $\begin{array}{l}\text { Adjusted: maternal } \\
\text { age, race, maternal/ } \\
\text { paternal schooling, } \\
\text { maternal hypertension, } \\
\text { birth weight, maternal } \\
\text { diabetes, sex }\end{array}$ \\
\hline $\begin{array}{l}\text { Cordier } \\
\text { et al. } 52 \\
\text { (1992) }\end{array}$ & $\begin{array}{l}\text { Case- } \\
\text { control }\end{array}$ & $\begin{array}{c}\text { Study in } \\
\text { hospitals of } \\
\text { Marseille and } \\
\text { Paris (France) }\end{array}$ & Major defects & Interview & Unspecified & 325 & 325 & Adjusted: place of birth \\
\hline $\begin{array}{l}\text { Correy } \\
\text { et al. } 53 \\
\text { (1991) }\end{array}$ & Cohort & $\begin{array}{c}\text { Cigarette } \\
\text { smoking, alcohol } \\
\text { consumption } \\
\text { and fetal } \\
\text { outcome in } \\
\text { Tasmania } \\
\text { (Australia) }\end{array}$ & $\begin{array}{l}\text { Malformations in } \\
\text { general }\end{array}$ & Interview & First quarter & 1,095 & 54,942 & - \\
\hline
\end{tabular}

(continues) 


\begin{tabular}{|c|c|c|c|c|c|c|c|c|}
\hline \multirow[t]{2}{*}{$\begin{array}{l}\text { Reference } \\
\text { (year) }\end{array}$} & \multirow[t]{2}{*}{$\begin{array}{l}\text { Type of } \\
\text { study }\end{array}$} & \multirow[t]{2}{*}{$\begin{array}{l}\text { Site/Source } \\
\text { of data }\end{array}$} & \multirow[t]{2}{*}{ Type of defect } & \multicolumn{2}{|c|}{$\begin{array}{l}\text { Exposure (maternal } \\
\text { smoking) }\end{array}$} & \multirow[t]{2}{*}{ Case } & \multirow[t]{2}{*}{ Controls } & \multirow{2}{*}{$\begin{array}{l}\text { Control of confounders } \\
\text { (adjustment/ } \\
\text { matching) }\end{array}$} \\
\hline & & & & $\begin{array}{l}\text { Data } \\
\text { collection }\end{array}$ & $\begin{array}{l}\text { Stage of } \\
\text { pregnancy }\end{array}$ & & & \\
\hline $\begin{array}{l}\text { Croen } \\
\text { et al. } 54 \\
(2000)\end{array}$ & $\begin{array}{l}\text { Case- } \\
\text { control }\end{array}$ & $\begin{array}{c}\text { California } \\
\text { Birth Defects } \\
\text { Monitoring } \\
\text { Program (United } \\
\text { States) }\end{array}$ & $\begin{array}{l}\text { Holoprosen- } \\
\text { cephaly }\end{array}$ & $\begin{array}{l}\text { Phone } \\
\text { interview }\end{array}$ & $\begin{array}{l}\text { Pre- } \\
\text { conception } \\
\text { exposure and } \\
\text { in the first } \\
\text { quarter }\end{array}$ & 48 & 106 & $\begin{array}{l}\text { Matching: month/year } \\
\text { of birth, place of birth, } \\
\text { sex }\end{array}$ \\
\hline $\begin{array}{l}\text { Czeizel \& } \\
\text { Vitez } 55 \\
(1981)\end{array}$ & $\begin{array}{l}\text { Case- } \\
\text { control }\end{array}$ & $\begin{array}{c}\text { Hungarian } \\
\text { congenital } \\
\text { abnormalities } \\
\text { registry }\end{array}$ & Omphalocele & Interview & Unspecified & 134 & 134 & $\begin{array}{l}\text { Matching: month/year } \\
\text { of birth, place of birth, } \\
\text { sex, pregnancy outcome }\end{array}$ \\
\hline $\begin{array}{l}\text { Czeizel \& } \\
\text { Nagy } 56 \\
(1986)\end{array}$ & $\begin{array}{l}\text { Case- } \\
\text { control }\end{array}$ & $\begin{array}{l}\text { Hungarian } \\
\text { congenital } \\
\text { abnormalities } \\
\text { registry }\end{array}$ & $\begin{array}{l}\text { Cleft lip; cleft } \\
\text { palate }\end{array}$ & Interview & $\begin{array}{l}\text { The entire } \\
\text { pregnancy }\end{array}$ & 1,088 & 752 & $\begin{array}{l}\text { Adjusted: maternal/ } \\
\text { paternal schooling, } \\
\text { parity; Matching: } \\
\text { month/year of birth, } \\
\text { place of birth, sex }\end{array}$ \\
\hline $\begin{array}{l}\text { Czeizel } \\
\text { et al. } 57 \\
(1994)\end{array}$ & $\begin{array}{l}\text { Case- } \\
\text { control }\end{array}$ & $\begin{array}{l}\text { Hungarian } \\
\text { congenital } \\
\text { abnormalities } \\
\text { registry }\end{array}$ & Limb reduction & $\begin{array}{l}\text { Question- } \\
\text { naire }\end{array}$ & $\begin{array}{l}\text { Pre- } \\
\text { conception } \\
\text { exposure and } \\
\text { the entire } \\
\text { pregnancy }\end{array}$ & 537 & 537 & $\begin{array}{l}\text { Matching: month/year } \\
\text { of birth, place of birth, } \\
\text { sex }\end{array}$ \\
\hline $\begin{array}{l}\text { Czeizel } \\
\text { et al. } 58 \\
(2004)\end{array}$ & $\begin{array}{l}\text { Case- } \\
\text { control }\end{array}$ & $\begin{array}{c}\text { Hungarian } \\
\text { congenital } \\
\text { abnormalities } \\
\text { registry }\end{array}$ & $\begin{array}{l}\text { Orofacial } \\
\text { clefts; limb } \\
\text { malformations }\end{array}$ & Interview & $\begin{array}{l}\text { The entire } \\
\text { pregnancy }\end{array}$ & 1,346 & 1,346 & $\begin{array}{l}\text { Matching: month/year } \\
\text { of birth, place of birth, } \\
\text { sex }\end{array}$ \\
\hline $\begin{array}{l}\text { Costa } \\
\text { et al. } 59 \\
(2006)\end{array}$ & $\begin{array}{l}\text { Case- } \\
\text { control }\end{array}$ & $\begin{array}{l}\text { Rio de Janeiro } \\
\text { hospital study } \\
\text { (Brazil) }\end{array}$ & Birth defects & $\begin{array}{l}\text { Question- } \\
\text { naires }\end{array}$ & Unspecified & 149 & 9,223 & - \\
\hline $\begin{array}{l}\text { Damgaard } \\
\text { et al. } 60 \\
(2008)\end{array}$ & Cohort & $\begin{array}{c}\text { University } \\
\text { hospitals of } \\
\text { Denmark and } \\
\text { Finland }\end{array}$ & Cryptorchidism & $\begin{array}{l}\text { Question- } \\
\text { naire and } \\
\text { interview }\end{array}$ & $\begin{array}{l}\text { The entire } \\
\text { pregnancy }\end{array}$ & 127 & 2,368 & $\begin{array}{c}\text { Adjusted: place of birth, } \\
\text { classe social; Matching: } \\
\text { sex }\end{array}$ \\
\hline $\begin{array}{l}\text { Davies } \\
\text { et al. } 61 \\
(1986)\end{array}$ & $\begin{array}{l}\text { Case- } \\
\text { control }\end{array}$ & $\begin{array}{l}\text { Addenbrookes } \\
\text { Hospital } \\
\text { Study (United } \\
\text { Kingdom) }\end{array}$ & Cryptorchidism & $\begin{array}{l}\text { Medical } \\
\text { records }\end{array}$ & Unspecified & 83 & 129 & $\begin{array}{l}\text { Matching: month/year } \\
\text { of birth, place of birth, } \\
\text { sex }\end{array}$ \\
\hline $\begin{array}{l}\text { De Roo } \\
\text { et al. } 10 \\
(2003)\end{array}$ & Cohort & $\begin{array}{l}\text { Washington } \\
\text { State Birth } \\
\text { Defects Registry } \\
\text { (United States) }\end{array}$ & Oral fissures & $\begin{array}{c}\text { Birth } \\
\text { certificate } \\
\text { data }\end{array}$ & $\begin{array}{l}\text { The entire } \\
\text { pregnancy }\end{array}$ & 608 & 297,530 & $\begin{array}{l}\text { Adjusted: race, maternal } \\
\text { age, marital status, sex }\end{array}$ \\
\hline $\begin{array}{l}\text { Dickinson } \\
\text { et al. }{ }^{11} \\
(2008)\end{array}$ & $\begin{array}{l}\text { Case- } \\
\text { control }\end{array}$ & $\begin{array}{l}\text { North Carolina } \\
\text { Birth Defects } \\
\text { Monitoring } \\
\text { Program (United } \\
\text { States) }\end{array}$ & $\begin{array}{c}\text { Crooked foot at } \\
\text { birth }\end{array}$ & $\begin{array}{l}\text { Birth } \\
\text { certificate } \\
\text { data }\end{array}$ & $\begin{array}{l}\text { The entire } \\
\text { pregnancy }\end{array}$ & 443 & 4,492 & $\begin{array}{l}\text { Adjusted: maternal } \\
\text { age, race, sex, time } \\
\text { until commencement of } \\
\text { antenatal care }\end{array}$ \\
\hline
\end{tabular}

(continues) 
Table 1 (continued)

\begin{tabular}{|c|c|c|c|c|c|c|c|c|}
\hline \multirow[t]{2}{*}{$\begin{array}{l}\text { Reference } \\
\text { (year) }\end{array}$} & \multirow[t]{2}{*}{$\begin{array}{l}\text { Type of } \\
\text { study }\end{array}$} & \multirow[t]{2}{*}{$\begin{array}{l}\text { Site/Source } \\
\text { of data }\end{array}$} & \multirow[t]{2}{*}{ Type of defect } & \multicolumn{2}{|c|}{$\begin{array}{c}\text { Exposure (maternal } \\
\text { smoking) }\end{array}$} & \multirow[t]{2}{*}{ Case } & \multirow[t]{2}{*}{ Controls } & \multirow{2}{*}{$\begin{array}{c}\text { Control of confounders } \\
\text { (adjustment/ } \\
\text { matching) }\end{array}$} \\
\hline & & & & $\begin{array}{c}\text { Data } \\
\text { collection }\end{array}$ & $\begin{array}{l}\text { Stage of } \\
\text { pregnancy }\end{array}$ & & & \\
\hline $\begin{array}{l}\text { Draper } \\
\text { et al. } 62 \\
(2008)\end{array}$ & $\begin{array}{l}\text { Case- } \\
\text { control }\end{array}$ & $\begin{array}{l}\text { Birth defects } \\
\text { registry in three } \\
\text { regions of the } \\
\text { United Kingdom }\end{array}$ & Gastroschisis & Interview & First quarter & 144 & 432 & $\begin{array}{l}\text { Adjusted: use of illicit } \\
\text { drugs by the mother, } \\
\text { use of vasoconstrictive } \\
\text { drugs, maternal BMI, } \\
\text { marital status, maternal } \\
\text { use of aspirin, parental } \\
\text { home ownership, } \\
\text { maternal diseases; } \\
\text { Matching: maternal age, } \\
\text { place of birth }\end{array}$ \\
\hline $\begin{array}{l}\text { Erickson } 63 \\
\text { (1991) }\end{array}$ & $\begin{array}{l}\text { Case- } \\
\text { control }\end{array}$ & $\begin{array}{c}\text { Atlanta Birth } \\
\text { Defects } \\
\text { Risk Factor } \\
\text { Surveillance } \\
\text { (United States) }\end{array}$ & $\begin{array}{l}\text { General } \\
\text { malformations }\end{array}$ & Interview & Unspecified & 4,908 & 3,024 & $\begin{array}{c}\text { Adjusted: race, place } \\
\text { of birth, month/year of } \\
\text { birth }\end{array}$ \\
\hline $\begin{array}{l}\text { Ericson } \\
\text { et al. } 64 \\
\text { (1979) }\end{array}$ & $\begin{array}{l}\text { Case- } \\
\text { control }\end{array}$ & $\begin{array}{l}\text { Swedish National } \\
\text { Board of Health }\end{array}$ & $\begin{array}{l}\text { CNS defects; } \\
\text { orofacial clefts }\end{array}$ & $\begin{array}{l}\text { Hospital } \\
\text { records }\end{array}$ & First quarter & 132 & 261 & $\begin{array}{l}\text { Matching: month/year } \\
\text { of birth, place of birth, } \\
\text { maternal age, parity }\end{array}$ \\
\hline $\begin{array}{l}\text { Evans } \\
\text { et al. } 65 \\
\text { (1979) }\end{array}$ & $\begin{array}{l}\text { Retrospec- } \\
\text { tive cohort }\end{array}$ & $\begin{array}{l}\text { Cardiff Births } \\
\text { Survey (United } \\
\text { Kingdom) }\end{array}$ & All birth defects & $\begin{array}{l}\text { Birth } \\
\text { records }\end{array}$ & Any period & 2,266 & 653,443 & - \\
\hline $\begin{array}{l}\text { Fredrick } \\
\text { et al. } 66 \\
\text { (1971) }\end{array}$ & $\begin{array}{l}\text { Case- } \\
\text { control }\end{array}$ & $\begin{array}{c}\text { Assessment } \\
\text { of perinatal } \\
\text { mortality (United } \\
\text { Kingdom) }\end{array}$ & $\begin{array}{l}\text { Congenital heart } \\
\text { diseases }\end{array}$ & $\begin{array}{l}\text { Question- } \\
\text { naire }\end{array}$ & $\begin{array}{l}\text { Second and } \\
\text { third quarter }\end{array}$ & 290 & 15,719 & - \\
\hline $\begin{array}{l}\text { Feldkamp } \\
\text { et al. } 12 \\
\text { (2008) }\end{array}$ & $\begin{array}{l}\text { Case- } \\
\text { control }\end{array}$ & $\begin{array}{l}\text { Utah Birth Defect } \\
\text { Network (United } \\
\text { States) }\end{array}$ & Gastroschisis & $\begin{array}{l}\text { Birth certi- } \\
\text { ficate }\end{array}$ & First quarter & 189 & 423,588 & - \\
\hline $\begin{array}{l}\text { Felix et } \\
\text { al. } 67 \\
(2008)\end{array}$ & $\begin{array}{l}\text { Case- } \\
\text { control }\end{array}$ & $\begin{array}{l}\text { Pediatric surgery } \\
\text { reference center, } \\
\text { Netherlands }\end{array}$ & $\begin{array}{c}\text { Esophageal } \\
\text { atresia; } \\
\text { diaphragmatic } \\
\text { hernia }\end{array}$ & $\begin{array}{l}\text { Question- } \\
\text { naire }\end{array}$ & $\begin{array}{c}\text { Pre- } \\
\text { conception } \\
\text { exposure and } \\
\text { in the first } \\
\text { quarter }\end{array}$ & 105 & 192 & $\begin{array}{c}\text { Adjusted: maternal age; } \\
\text { Matching: month/year } \\
\text { of birth, sex }\end{array}$ \\
\hline $\begin{array}{l}\text { Ferencz } \\
\text { et al. } 68 \\
(2008)\end{array}$ & $\begin{array}{l}\text { Case- } \\
\text { control }\end{array}$ & $\begin{array}{l}\text { Baltimore- } \\
\text { Washington } \\
\text { Infant Study } \\
\text { (United States) }\end{array}$ & $\begin{array}{l}\text { Cardiovascular } \\
\text { defects }\end{array}$ & $\begin{array}{l}\text { Question- } \\
\text { naire }\end{array}$ & Unspecified & 1,541 & 3,572 & - \\
\hline $\begin{array}{l}\text { Garcia } \\
\text { et al. } 69 \\
(1999)\end{array}$ & $\begin{array}{l}\text { Case- } \\
\text { control }\end{array}$ & $\begin{array}{c}\text { Data from } 8 \\
\text { public hospitals } \\
\text { of a community } \\
\text { in Valencia } \\
\text { (Spain) }\end{array}$ & Birth defects & $\begin{array}{l}\text { Phone } \\
\text { interview }\end{array}$ & $\begin{array}{c}\text { Pre- } \\
\text { conception } \\
\text { exposure and } \\
\text { in the first } \\
\text { quarter }\end{array}$ & 261 & 161 & $\begin{array}{l}\text { Matching: month/year } \\
\text { of birth, place of birth }\end{array}$ \\
\hline
\end{tabular}

(continues) 
Table 1 (continued)

\begin{tabular}{|c|c|c|c|c|c|c|c|c|}
\hline \multirow[t]{2}{*}{$\begin{array}{l}\text { Reference } \\
\text { (year) }\end{array}$} & \multirow[t]{2}{*}{$\begin{array}{l}\text { Type of } \\
\text { study }\end{array}$} & \multirow[t]{2}{*}{$\begin{array}{l}\text { Site/Source } \\
\text { of data }\end{array}$} & \multirow[t]{2}{*}{ Type of defect } & \multicolumn{2}{|c|}{$\begin{array}{l}\text { Exposure (maternal } \\
\text { smoking) }\end{array}$} & \multirow[t]{2}{*}{ Case } & \multirow[t]{2}{*}{ Controls } & \multirow{2}{*}{$\begin{array}{l}\text { Control of confounders } \\
\text { (adjustment/ } \\
\text { matching) }\end{array}$} \\
\hline & & & & $\begin{array}{c}\text { Data } \\
\text { collection }\end{array}$ & $\begin{array}{l}\text { Stage of } \\
\text { pregnancy }\end{array}$ & & & \\
\hline $\begin{array}{l}\text { Goldbaum } \\
\text { et al. } 70 \\
\text { (1990) }\end{array}$ & $\begin{array}{l}\text { Case- } \\
\text { control }\end{array}$ & $\begin{array}{l}\text { Birth records, } \\
\text { Washington } \\
\text { State (United } \\
\text { States) }\end{array}$ & Gastroschisis & $\begin{array}{l}\text { Birth } \\
\text { records }\end{array}$ & Unspecified & 62 & 617 & $\begin{array}{c}\text { Adjusted: month/year } \\
\text { of birth, sex, maternal } \\
\text { age, race, marital status, } \\
\text { maternal occupation, } \\
\text { rural/urban, pre- } \\
\text { natal care, previous } \\
\text { miscarriage, previous } \\
\text { induction of abortion, } \\
\text { paternal occupation; } \\
\text { Matching: month/year } \\
\text { of birth }\end{array}$ \\
\hline $\begin{array}{l}\text { Golding \& } \\
\text { Butler } 71 \\
\text { (1983) }\end{array}$ & $\begin{array}{l}\text { Case- } \\
\text { control }\end{array}$ & $\begin{array}{l}\text { Assessment } \\
\text { of perinatal } \\
\text { mortality (United } \\
\text { Kingdom) }\end{array}$ & Anencephaly & $\begin{array}{l}\text { Birth } \\
\text { records }\end{array}$ & $\begin{array}{l}\text { Beginning of } \\
\text { pregnancy }\end{array}$ & 483 & 19,172 & - \\
\hline $\begin{array}{l}\text { Grewal } \\
\text { et al. } 72 \\
\text { (2008) }\end{array}$ & $\begin{array}{l}\text { Case- } \\
\text { control }\end{array}$ & $\begin{array}{l}\text { Hospitals of } \\
\text { California } \\
\text { (United States) }\end{array}$ & All birth defects & Interview & $\begin{array}{c}\text { Pre- } \\
\text { conception } \\
\text { exposure and } \\
\text { in the first two } \\
\text { months }\end{array}$ & 1,351 & 620 & - \\
\hline $\begin{array}{l}\text { Haddow } \\
\text { et al. } 73 \\
\text { (1983) }\end{array}$ & Cohort & $\begin{array}{l}\text { Maternal serum } \\
\text { alpha-fetoprotein } \\
\text { screening } \\
\text { programs } \\
\text { (United States) }\end{array}$ & Gastroschisis & Interview & $\begin{array}{l}\text { Second } \\
\text { quarter }\end{array}$ & 21 & 59,919 & $\begin{array}{l}\text { Adjusted: maternal age, } \\
\text { month/year of birth }\end{array}$ \\
\hline $\begin{array}{l}\text { Hakin \& } \\
\text { Tielsch } 74 \\
\text { (1992) }\end{array}$ & $\begin{array}{l}\text { Case- } \\
\text { control }\end{array}$ & $\begin{array}{c}\text { Pediatric } \\
\text { Ophthalmology } \\
\text { Centers in } \\
\text { Baltimore } \\
\text { (United States) }\end{array}$ & $\begin{array}{l}\text { Esotropia; } \\
\text { exotropia }\end{array}$ & $\begin{array}{l}\text { Interview } \\
\text { and medical } \\
\text { data }\end{array}$ & $\begin{array}{l}\text { The entire } \\
\text { pregnancy }\end{array}$ & 377 & 377 & $\begin{array}{l}\text { Adjusted: maternal age, } \\
\text { paternal age, maternal } \\
\text { schooling, alcohol } \\
\text { intake, marital status, } \\
\text { race, birth weight, } \\
\text { Apgar, gestational age }\end{array}$ \\
\hline $\begin{array}{l}\text { Hearey } \\
\text { et al. } 75 \\
(1984)\end{array}$ & $\begin{array}{l}\text { Case- } \\
\text { control }\end{array}$ & $\begin{array}{l}\text { Antioch- } \\
\text { Pittsburg, } \\
\text { California } \\
\text { (United States) }\end{array}$ & CNS defects & $\begin{array}{l}\text { Medical } \\
\text { records }\end{array}$ & Unspecified & 9 & 27 & - \\
\hline $\begin{array}{l}\text { Heinonen } \\
76 \text { (1977) }\end{array}$ & $\begin{array}{l}\text { Case- } \\
\text { control }\end{array}$ & $\begin{array}{l}\text { Collaborative } \\
\text { perinatal project } \\
\text { (United States) }\end{array}$ & Malformations & $\begin{array}{l}\text { Medical } \\
\text { records }\end{array}$ & Unspecified & 1,393 & 4,889 & $\begin{array}{l}\text { Matching: month/year } \\
\text { of birth, place of birth, } \\
\text { sex }\end{array}$ \\
\hline $\begin{array}{l}\text { Hemminki } \\
\text { et al. } 77 \\
(1981)\end{array}$ & $\begin{array}{l}\text { Case- } \\
\text { control }\end{array}$ & $\begin{array}{l}\text { The Finnish } \\
\text { registry of } \\
\text { congenital } \\
\text { malformations }\end{array}$ & CNS defects & Interview & Unspecified & 3,300 & 3,300 & Matching: sex \\
\hline $\begin{array}{l}\text { Himmel- } \\
\text { berger } \\
\text { et al. } 78 \\
\text { (1978) }\end{array}$ & $\begin{array}{l}\text { Case- } \\
\text { control }\end{array}$ & $\begin{array}{c}\text { Survey of } \\
\text { American } \\
\text { Healthcare } \\
\text { Workers (United } \\
\text { States) }\end{array}$ & Defects & Interview & First quarter & 1,369 & 9,724 & $\begin{array}{c}\text { Adjusted: age, parity, } \\
\text { exposures to anesthetic } \\
\text { gases }\end{array}$ \\
\hline
\end{tabular}

(continues) 
Table 1 (continued)

\begin{tabular}{|c|c|c|c|c|c|c|c|c|}
\hline \multirow[t]{2}{*}{$\begin{array}{l}\text { Reference } \\
\text { (year) }\end{array}$} & \multirow[t]{2}{*}{$\begin{array}{l}\text { Type of } \\
\text { study }\end{array}$} & \multirow[t]{2}{*}{$\begin{array}{l}\text { Site/Source } \\
\text { of data }\end{array}$} & \multirow[t]{2}{*}{ Type of defect } & \multicolumn{2}{|c|}{$\begin{array}{c}\text { Exposure (maternal } \\
\text { smoking) }\end{array}$} & \multirow[t]{2}{*}{ Case } & \multirow[t]{2}{*}{ Controls } & \multirow{2}{*}{$\begin{array}{c}\text { Control of confounders } \\
\text { (adjustment/ } \\
\text { matching) }\end{array}$} \\
\hline & & & & $\begin{array}{c}\text { Data } \\
\text { collection }\end{array}$ & $\begin{array}{l}\text { Stage of } \\
\text { pregnancy }\end{array}$ & & & \\
\hline $\begin{array}{l}\text { Honein } \\
\text { et al. } 80 \\
(2000)\end{array}$ & $\begin{array}{l}\text { Case- } \\
\text { control }\end{array}$ & $\begin{array}{l}\text { Data from the } \\
\text { Atlanta Birth } \\
\text { Defects Study } \\
\text { (United States) }\end{array}$ & Craniosynostosis & Interview & $\begin{array}{l}\text { Pre- } \\
\text { conception } \\
\text { exposure and } \\
\text { in the first } \\
\text { quarter }\end{array}$ & 44 & 3,029 & $\begin{array}{c}\text { Adjusted: race, month/ } \\
\text { year of birth, place of } \\
\text { birth }\end{array}$ \\
\hline $\begin{array}{l}\text { Honein \& } \\
\text { Rasmussen } \\
81(2000)\end{array}$ & $\begin{array}{l}\text { Case- } \\
\text { control }\end{array}$ & $\begin{array}{l}\text { Data from the } \\
\text { Atlanta Birth } \\
\text { Defects Study } \\
\text { (United States) }\end{array}$ & $\begin{array}{l}\text { Crooked foot at } \\
\text { birth }\end{array}$ & Interview & $\begin{array}{l}\text { Pre- } \\
\text { conception } \\
\text { exposure and } \\
\text { in the first } \\
\text { quarter }\end{array}$ & 346 & 3,029 & Adjusted: sex, parity \\
\hline $\begin{array}{l}\text { Honein } \\
\text { et al. } 82 \\
(2001)\end{array}$ & $\begin{array}{l}\text { Case- } \\
\text { control }\end{array}$ & $\begin{array}{c}\text { National Vital } \\
\text { Statistics (United } \\
\text { States) }\end{array}$ & $\begin{array}{l}17 \text { defects: } \\
\text { CNS; digestive; } \\
\text { musculoskeletal; } \\
\text { urogenital; face } \\
\text { and neck }\end{array}$ & $\begin{array}{c}\text { Birth } \\
\text { certificate } \\
\text { data }\end{array}$ & Unspecified & $\begin{array}{c}24,014 \\
\text { (CNS: 4,352; } \\
\text { digestive: } \\
1.312 ; \\
\text { musculo- } \\
\text { skeletals: } \\
\text { 12,293; } \\
\text { urogenital: } \\
\text { 819; face and } \\
\text { neck: } 5,238)\end{array}$ & $6,134,773$ & $\begin{array}{l}\text { Adjusted: maternal age, } \\
\text { race, maternal schooling }\end{array}$ \\
\hline $\begin{array}{l}\text { Honein } \\
\text { et al. } 83 \\
(2007)\end{array}$ & $\begin{array}{l}\text { Case- } \\
\text { control }\end{array}$ & $\begin{array}{l}\text { National } \\
\text { Birth Defects } \\
\text { Prevention Study } \\
\text { (United States) }\end{array}$ & Oral fissures & $\begin{array}{l}\text { Phone } \\
\text { interview }\end{array}$ & $\begin{array}{l}\text { Pre- } \\
\text { conception } \\
\text { exposure and } \\
\text { in the first } \\
\text { quarter }\end{array}$ & 1,461 & 3,390 & $\begin{array}{l}\text { Adjusted: maternal age, } \\
\text { race, parity, alcohol } \\
\text { intake in the first } \\
\text { quarter, birth control } \\
\text { with folic acid, sex }\end{array}$ \\
\hline $\begin{array}{l}\text { Hoobs } \\
\text { et al. } 79 \\
(2006)\end{array}$ & $\begin{array}{l}\text { Case- } \\
\text { control }\end{array}$ & $\begin{array}{c}\text { Arkansas } \\
\text { Reproductive } \\
\text { Health } \\
\text { Monitoring } \\
\text { System (United } \\
\text { States) }\end{array}$ & Heart defects & Interview & $\begin{array}{l}\text { Pre- } \\
\text { conception } \\
\text { exposure } \\
\text { and in the } \\
\text { first primeiro } \\
\text { month of } \\
\text { pregnancy }\end{array}$ & 275 & 118 & - \\
\hline $\begin{array}{l}\text { Hougland } \\
\text { et al. } 84 \\
(2006)\end{array}$ & $\begin{array}{l}\text { Cross- } \\
\text { sectional }\end{array}$ & $\begin{array}{l}\text { Children's } \\
\text { Medical Center } \\
\text { (United States) }\end{array}$ & Gastroschisis & $\begin{array}{l}\text { Medical } \\
\text { records }\end{array}$ & Unspecified & 82 & 47,146 & - \\
\hline $\begin{array}{l}\text { Jensen } \\
\text { et al. } 85 \\
\text { (2007) }\end{array}$ & Cohort & $\begin{array}{l}\text { Birth cohort, } \\
\text { 1984-1987 } \\
\text { (Denmark) }\end{array}$ & Cryptorchidism & $\begin{array}{l}\text { Question- } \\
\text { naire and } \\
\text { medical } \\
\text { records }\end{array}$ & $\begin{array}{l}\text { The entire } \\
\text { pregnancy }\end{array}$ & 270 & 5,716 & $\begin{array}{l}\text { Adjusted: maternal age, } \\
\text { paternal age, infertility } \\
\text { treatment, parity, social } \\
\text { class, maternal alcohol } \\
\text { intake, birth weight, } \\
\text { gestational age, weight } \\
\text { of the placenta }\end{array}$ \\
\hline $\begin{array}{l}\text { Johansen } \\
\text { et al. } 86 \\
(2009)\end{array}$ & $\begin{array}{l}\text { Case- } \\
\text { control }\end{array}$ & $\begin{array}{l}\text { Norway medical } \\
\text { birth records }\end{array}$ & $\begin{array}{l}\text { Cleft lip; cleft } \\
\text { palate }\end{array}$ & $\begin{array}{l}\text { Question- } \\
\text { naire }\end{array}$ & First quarter & 573 & 763 & - \\
\hline $\begin{array}{l}\text { Jones } \\
\text { et al. } 87 \\
\text { (1998) }\end{array}$ & $\begin{array}{l}\text { Case- } \\
\text { control }\end{array}$ & $\begin{array}{l}\text { Oxford study } \\
\text { (United } \\
\text { Kingdom) }\end{array}$ & Cryptorchidism & $\begin{array}{l}\text { Medical } \\
\text { records }\end{array}$ & $\begin{array}{l}\text { Beginning of } \\
\text { pregnancy }\end{array}$ & 1,499 & 10,811 & $\begin{array}{l}\text { Matching: month/year } \\
\text { of birth, place of birth, } \\
\text { sex }\end{array}$ \\
\hline
\end{tabular}

(continues) 
Table 1 (continued)

\begin{tabular}{|c|c|c|c|c|c|c|c|c|}
\hline \multirow[t]{2}{*}{$\begin{array}{l}\text { Reference } \\
\text { (year) }\end{array}$} & \multirow[t]{2}{*}{$\begin{array}{l}\text { Type of } \\
\text { study }\end{array}$} & \multirow[t]{2}{*}{$\begin{array}{l}\text { Site/Source } \\
\text { of data }\end{array}$} & \multirow[t]{2}{*}{ Type of defect } & \multicolumn{2}{|c|}{$\begin{array}{l}\text { Exposure (maternal } \\
\text { smoking) }\end{array}$} & \multirow[t]{2}{*}{ Case } & \multirow[t]{2}{*}{ Controls } & \multirow{2}{*}{$\begin{array}{l}\text { Control of confounders } \\
\text { (adjustment/ } \\
\text { matching) }\end{array}$} \\
\hline & & & & $\begin{array}{l}\text { Data } \\
\text { collection }\end{array}$ & $\begin{array}{l}\text { Stage of } \\
\text { pregnancy }\end{array}$ & & & \\
\hline $\begin{array}{l}\text { Kallen } 88 \\
(1999)\end{array}$ & Cohort & $\begin{array}{l}\text { Swedish birth } \\
\text { defects registry }\end{array}$ & Craniosynostosis & Interview & First quarter & 303 & $1,413,585$ & $\begin{array}{c}\text { Stratified: place of birth, } \\
\text { maternal age, parity, } \\
\text { maternal schooling }\end{array}$ \\
\hline $\begin{array}{l}\text { Kallen } 89 \\
(2000)\end{array}$ & Cohort & $\begin{array}{l}\text { Swedish birth } \\
\text { defects registry } \\
\text { and birth } \\
\text { medical records } \\
\text { (1983-1996) }\end{array}$ & $\begin{array}{l}44 \text { defects: } \\
\text { CNS; heart; } \\
\text { face and neck; } \\
\text { musculoskeletal; } \\
\text { digestive; } \\
\text { urogenital; other }\end{array}$ & Interview & First quarter & $\begin{array}{c}\text { 27,670 (CNS: } \\
\text { 856; heart: } \\
\text { 13,266; } \\
\text { face and } \\
\text { neck: } 3,345 ; \\
\text { musculo- } \\
\text { skeletal: } \\
\text { 4,342; diges- } \\
\text { tive: } 1,241 ; \\
\text { urogenital: } \\
\text { 4,502; } \\
\text { other: } \\
\text { 118) }\end{array}$ & $1,413,811$ & $\begin{array}{c}\text { Adjusted: month/ } \\
\text { year of birth, maternal } \\
\text { age, parity, maternal } \\
\text { schooling }\end{array}$ \\
\hline $\begin{array}{l}\text { Kelsey } \\
\text { et al. } 90 \\
(1978)\end{array}$ & $\begin{array}{l}\text { Case- } \\
\text { control }\end{array}$ & $\begin{array}{l}\text { Birth data from } \\
5 \text { Connecticut } \\
\text { hospitals (United } \\
\text { States) }\end{array}$ & Malformations & Interview & First quarter & 1,370 & 2,968 & - \\
\hline $\begin{array}{l}\text { Khoury } \\
\text { et al. } 91 \\
(1989)\end{array}$ & $\begin{array}{l}\text { Case- } \\
\text { control }\end{array}$ & $\begin{array}{l}\text { Atlanta Birth } \\
\text { Defects Case- } \\
\text { Control Study } \\
\text { (United States) }\end{array}$ & $\begin{array}{c}\text { Cleft lip; cleft } \\
\text { palate }\end{array}$ & $\begin{array}{l}\text { Phone } \\
\text { interview }\end{array}$ & $\begin{array}{l}\text { Pre- } \\
\text { conception } \\
\text { and first } \\
\text { quarter } \\
\text { exposure }\end{array}$ & 345 & 2,809 & $\begin{array}{l}\text { Adjusted: maternal } \\
\text { age, schooling, } \\
\text { alcohol intake, use } \\
\text { of tranquilizers, use } \\
\text { of contraceptives, } \\
\text { pregnancy planning, } \\
\text { race }\end{array}$ \\
\hline $\begin{array}{l}\text { Krapels } \\
\text { et al. } 92 \\
(2006)\end{array}$ & $\begin{array}{l}\text { Case- } \\
\text { control }\end{array}$ & $\begin{array}{l}\text { Dutch university } \\
\text { medical centers }\end{array}$ & $\begin{array}{l}\text { Cleft lip with } \\
\text { or without cleft } \\
\text { palate }\end{array}$ & Interview & $\begin{array}{l}\text { Pre- } \\
\text { conception } \\
\text { exposure e } \\
\text { first quarter }\end{array}$ & 349 & 222 & - \\
\hline $\begin{array}{l}\text { Krauss } \\
\text { et al. } 93 \\
(2003)\end{array}$ & $\begin{array}{l}\text { Case- } \\
\text { control }\end{array}$ & $\begin{array}{l}\text { Missouri Birth } \\
\text { Defects Registry } \\
\text { (United States) }\end{array}$ & Microcephaly & Interview & Unspecified & 360 & 3,600 & - \\
\hline $\begin{array}{l}\text { Kricker } \\
\text { et al. } 93 \\
(1986)\end{array}$ & $\begin{array}{l}\text { Case- } \\
\text { control }\end{array}$ & $\begin{array}{c}\text { Two states of } \\
\text { Australia }\end{array}$ & Limb reduction & Interview & First quarter & 155 & 2,274 & $\begin{array}{l}\text { Matching: data of birth, } \\
\text { place of residency }\end{array}$ \\
\hline $\begin{array}{l}\text { Kuciene \& } \\
\text { Dulskiene } \\
95 \text { (2009) }\end{array}$ & $\begin{array}{l}\text { Case- } \\
\text { control }\end{array}$ & $\begin{array}{l}\text { Medical records } \\
\text { of hospitals and } \\
\text { clinics of the } \\
\text { city of Kaunas } \\
\text { (Lithuania) }\end{array}$ & Heart defects & Interview & Unspecified & 187 & 643 & - \\
\hline $\begin{array}{l}\text { Kullander } \\
\text { \& Kallen } 96 \\
\text { (1971) }\end{array}$ & Cohort & $\begin{array}{l}\text { Study in the } \\
\text { Malmö hospital } \\
\text { (Sweden) }\end{array}$ & Defects & $\begin{array}{l}\text { Question- } \\
\text { naire }\end{array}$ & First quarter & 192 & 5,548 & - \\
\hline $\begin{array}{l}\text { Kurahashi } \\
\text { et al. } 97 \\
(2005)\end{array}$ & $\begin{array}{l}\text { Case- } \\
\text { control }\end{array}$ & $\begin{array}{c}\text { Hokkaido } \\
\text { University } \\
\text { Hospital and } \\
\text { Chukyo Hospital } \\
\text { (Japan) }\end{array}$ & Hypospadias & $\begin{array}{l}\text { Question- } \\
\text { naire }\end{array}$ & Unspecified & 31 & 64 & - \\
\hline
\end{tabular}

(continues) 
Table 1 (continued)

\begin{tabular}{|c|c|c|c|c|c|c|c|c|}
\hline \multirow[t]{2}{*}{$\begin{array}{l}\text { Reference } \\
\text { (year) }\end{array}$} & \multirow[t]{2}{*}{$\begin{array}{l}\text { Type of } \\
\text { study }\end{array}$} & \multirow[t]{2}{*}{$\begin{array}{l}\text { Site/Source } \\
\text { of data }\end{array}$} & \multirow[t]{2}{*}{ Type of defect } & \multicolumn{2}{|c|}{$\begin{array}{c}\text { Exposure (maternal } \\
\text { smoking) }\end{array}$} & \multirow[t]{2}{*}{ Case } & \multirow[t]{2}{*}{ Controls } & \multirow{2}{*}{$\begin{array}{c}\text { Control of confounders } \\
\text { (adjustment/ } \\
\text { matching) }\end{array}$} \\
\hline & & & & $\begin{array}{c}\text { Data } \\
\text { collection }\end{array}$ & $\begin{array}{c}\text { Stage of } \\
\text { pregnancy }\end{array}$ & & & \\
\hline $\begin{array}{l}\text { Kurahashi } \\
\text { et al. } 98 \\
(2005)\end{array}$ & $\begin{array}{l}\text { Case- } \\
\text { control }\end{array}$ & $\begin{array}{c}\text { Hokkaido } \\
\text { University } \\
\text { Hospital and } \\
\text { Chukyo Hospital } \\
\text { (Japan) }\end{array}$ & Cryptorchidism & $\begin{array}{l}\text { Question- } \\
\text { naire }\end{array}$ & Unspecified & 96 & 116 & $\begin{array}{l}\text { Adjusted: maternal age, } \\
\text { maternal schooling, year } \\
\text { of birth }\end{array}$ \\
\hline $\begin{array}{l}\text { Lam \& } \\
\text { Torfs } 99 \\
(2006)\end{array}$ & $\begin{array}{l}\text { Case- } \\
\text { control }\end{array}$ & $\begin{array}{c}\text { California } \\
\text { Birth Defects } \\
\text { Monitoring } \\
\text { Program (United } \\
\text { States) }\end{array}$ & Gastroschisis & Interview & $\begin{array}{l}\text { Pre- } \\
\text { conception } \\
\text { exposure and } \\
\text { in the first } \\
\text { quarter }\end{array}$ & 55 & 94 & - \\
\hline $\begin{array}{l}\text { Leite \& } \\
\text { Koifman } \\
100 \text { (2009) }\end{array}$ & $\begin{array}{l}\text { Case- } \\
\text { control }\end{array}$ & $\begin{array}{l}\text { Hospitals of } \\
\text { Rio de Janeiro } \\
\text { (Brazil) }\end{array}$ & Oral fissures & Interview & $\begin{array}{c}\text { Pre- } \\
\text { conception } \\
\text { exposure and } \\
\text { in the first } \\
\text { quarter }\end{array}$ & 274 & 548 & - \\
\hline $\begin{array}{l}\text { Li et al. } 101 \\
\text { (1996) }\end{array}$ & $\begin{array}{l}\text { Case- } \\
\text { control }\end{array}$ & $\begin{array}{l}\text { Birth Defects } \\
\text { Registry, } \\
\text { Washington } \\
\text { State (United } \\
\text { States) }\end{array}$ & $\begin{array}{c}\text { Urinary tract } \\
\text { defects }\end{array}$ & Interview & $\begin{array}{l}\text { The entire } \\
\text { pregnancy }\end{array}$ & 118 & 369 & $\begin{array}{l}\text { Adjusted: family income, } \\
\text { paternal schooling, } \\
\text { periconceptional vitamin } \\
\text { supplementation, } \\
\text { maternal use of illicit } \\
\text { drugs, parity, place and } \\
\text { year of birth }\end{array}$ \\
\hline $\begin{array}{l}\text { Li et al. } 102 \\
\text { (2006) }\end{array}$ & $\begin{array}{l}\text { Case- } \\
\text { control }\end{array}$ & $\begin{array}{l}\text { Birth difects } \\
\text { surveillance } \\
\text { system in the } \\
\text { province of } \\
\text { Shanxi (China) }\end{array}$ & $\begin{array}{l}\text { Neural tube } \\
\text { defects }\end{array}$ & Interview & $\begin{array}{l}\text { Pre- } \\
\text { conception } \\
\text { exposure and } \\
\text { in the first } \\
\text { quarter }\end{array}$ & 158 & 226 & - \\
\hline $\begin{array}{l}\text { Lie et al. } \\
103 \text { (2008) }\end{array}$ & $\begin{array}{l}\text { Case- } \\
\text { control }\end{array}$ & $\begin{array}{c}\text { Birth records of } \\
\text { Norway }\end{array}$ & Oral fissures & $\begin{array}{l}\text { Question- } \\
\text { naire }\end{array}$ & First quarter & 573 & 763 & - \\
\hline $\begin{array}{l}\text { Lieff et } \\
\text { al. } 104 \\
(1999)\end{array}$ & $\begin{array}{l}\text { Case- } \\
\text { control }\end{array}$ & $\begin{array}{l}\text { Birth defects } \\
\text { study, Boston } \\
\text { University } \\
\text { (United States) }\end{array}$ & Oral fissures & Interviews & $\begin{array}{l}\text { The entire } \\
\text { pregnancy }\end{array}$ & 1,479 & 2,295 & - \\
\hline $\begin{array}{l}\text { Linn et } \\
\text { al. } 105 \\
\text { (1983) }\end{array}$ & $\begin{array}{l}\text { Case- } \\
\text { control }\end{array}$ & $\begin{array}{l}\text { Women's } \\
\text { hospital, Boston } \\
\text { (United States) }\end{array}$ & Defects & Interview & Unspecified & 579 & 11,861 & $\begin{array}{c}\text { Adjusted: parity, use } \\
\text { of oral contraceptive, } \\
\text { previous miscarriage, } \\
\text { social class, maternal/ } \\
\text { paternal age/, race, } \\
\text { maternal/paternal } \\
\text { schooling, maternal } \\
\text { religion }\end{array}$ \\
\hline $\begin{array}{l}\text { Little et } \\
\text { al. } 106 \\
(2004)\end{array}$ & $\begin{array}{l}\text { Case- } \\
\text { control }\end{array}$ & $\begin{array}{c}\text { Scotland, } \\
\text { Manchester } \\
\text { and Merseyside } \\
\text { (United } \\
\text { Kingdom) }\end{array}$ & Oral fissures & Interview & First quarter & 190 & 248 & $\begin{array}{l}\text { Adjusted: sex, race, } \\
\text { month of birth, maternal } \\
\text { schooling }\end{array}$ \\
\hline $\begin{array}{l}\text { Liu et } \\
\text { al. } 107 \\
(2009)\end{array}$ & $\begin{array}{l}\text { Case- } \\
\text { control }\end{array}$ & $\begin{array}{l}\text { City hospitals } \\
\text { in the province } \\
\text { of Shandong } \\
\text { (China) }\end{array}$ & Heart defects & Interview & $\begin{array}{c}\text { Pre- } \\
\text { conception } \\
\text { exposure and } \\
\text { in the first } \\
\text { quarter }\end{array}$ & 164 & 328 & - \\
\hline
\end{tabular}

(continues) 
Table 1 (continued)

\begin{tabular}{|c|c|c|c|c|c|c|c|c|}
\hline \multirow[t]{2}{*}{$\begin{array}{l}\text { Reference } \\
\text { (year) }\end{array}$} & \multirow[t]{2}{*}{$\begin{array}{l}\text { Type of } \\
\text { study }\end{array}$} & \multirow[t]{2}{*}{$\begin{array}{l}\text { Site/Source } \\
\text { of data }\end{array}$} & \multirow[t]{2}{*}{ Type of defect } & \multicolumn{2}{|c|}{$\begin{array}{c}\text { Exposure (maternal } \\
\text { smoking) }\end{array}$} & \multirow[t]{2}{*}{ Case } & \multirow[t]{2}{*}{ Controls } & \multirow{2}{*}{$\begin{array}{l}\text { Control of confounders } \\
\text { (adjustment/ } \\
\text { matching) }\end{array}$} \\
\hline & & & & $\begin{array}{c}\text { Data } \\
\text { collection }\end{array}$ & $\begin{array}{l}\text { Stage of } \\
\text { pregnancy }\end{array}$ & & & \\
\hline $\begin{array}{l}\text { Lorente } \\
\text { et al. } 108 \\
\text { (2000) }\end{array}$ & $\begin{array}{l}\text { Case- } \\
\text { control }\end{array}$ & $\begin{array}{c}\text { European } \\
\text { registry of } \\
\text { congenital } \\
\text { anomalies } \\
\text { (France, Italy, } \\
\text { Netherlands and } \\
\text { United Kingdom) }\end{array}$ & Oral fissures & Interview & First quarter & 161 & 1,134 & $\begin{array}{c}\text { Adjusted: place of birth, } \\
\text { maternal age, maternal } \\
\text { alcohol intake, social } \\
\text { class; Matching: month/ } \\
\text { year of birth, place of } \\
\text { birth }\end{array}$ \\
\hline $\begin{array}{l}\text { Lowe } 109 \\
\text { (1959) }\end{array}$ & Cohort & $\begin{array}{l}\text { Maternity, } \\
\text { Birmingham } \\
\text { Hospital (United } \\
\text { Kingdom) }\end{array}$ & Malformations & $\begin{array}{l}\text { Question- } \\
\text { naire }\end{array}$ & Any period & 23 & 1,800 & - \\
\hline $\begin{array}{l}\text { Lubs } 110 \\
(1973)\end{array}$ & $\begin{array}{l}\text { Retrospec- } \\
\text { tive cohort }\end{array}$ & $\begin{array}{l}\text { Yale Hospital } \\
\text { Study, New } \\
\text { Haven (United } \\
\text { States) }\end{array}$ & Major anomalies & Interview & Unspecified & 102 & 4,067 & - \\
\hline $\begin{array}{l}\text { Lumley } \\
\text { et al. } 111 \\
\text { (1985) }\end{array}$ & Cohort & $\begin{array}{c}\text { Cigarette } \\
\text { smoking, alcohol } \\
\text { consumption } \\
\text { study in } \\
\text { Tasmania } \\
\text { (Australia) }\end{array}$ & Malformations & Interview & Unspecified & 251 & 10,112 & $\begin{array}{l}\text { Adjusted: maternal age, } \\
\text { maternal alcohol intake, } \\
\text { parity, social class }\end{array}$ \\
\hline $\begin{array}{l}\text { MacBird } \\
\text { et al. } 112 \\
\text { (2009) }\end{array}$ & $\begin{array}{l}\text { Case- } \\
\text { control }\end{array}$ & $\begin{array}{l}\text { National } \\
\text { Birth Defects } \\
\text { Prevention Study } \\
\text { (United States) }\end{array}$ & Omphalocele & Interview & Any period & 168 & 4,967 & $\begin{array}{l}\text { Adjusted: place of birth, } \\
\text { maternal diabetes, } \\
\text { maternal BMI, folic acid } \\
\text { intake materna }\end{array}$ \\
\hline $\begin{array}{l}\text { Malik et al. } \\
113 \text { (2008) }\end{array}$ & $\begin{array}{l}\text { Case- } \\
\text { control }\end{array}$ & $\begin{array}{l}\text { National } \\
\text { Birth Defects } \\
\text { Prevention Study } \\
\text { (United States) }\end{array}$ & Heart defects & Interview & Any period & 3,067 & 3,947 & $\begin{array}{c}\text { Adjusted: sex, race, } \\
\text { maternal age, maternal } \\
\text { BMI, folic acid and } \\
\text { periconceptional } \\
\text { vitamines intake, alcohol } \\
\text { and caffeine maternal } \\
\text { intake, family history } \\
\text { of malformation, place } \\
\text { of birth }\end{array}$ \\
\hline $\begin{array}{l}\text { Malloy } \\
\text { et al. } 114 \\
\text { (1989) }\end{array}$ & $\begin{array}{l}\text { Case- } \\
\text { control }\end{array}$ & $\begin{array}{l}\text { Missouri Birth } \\
\text { Defects Registry } \\
\text { (United States) }\end{array}$ & Malformations & $\begin{array}{c}\text { Birth } \\
\text { certificate }\end{array}$ & Unspecified & 10,223 & 277,844 & $\begin{array}{c}\text { Adjusted: maternal } \\
\text { age, race, marital } \\
\text { status, parity, maternal } \\
\text { schooling }\end{array}$ \\
\hline $\begin{array}{l}\text { Man \& } \\
\text { Chang } 115 \\
(2006)\end{array}$ & $\begin{array}{l}\text { Case- } \\
\text { control }\end{array}$ & $\begin{array}{c}\text { Natality } \\
\text { database (United } \\
\text { States) }\end{array}$ & Digital anomaly & Interview & Unspecified & 5,171 & 10,342 & $\begin{array}{l}\text { Adjusted: marital status, } \\
\text { maternal diseases, } \\
\text { maternal diabetes, } \\
\text { maternal hypertension, } \\
\text { previous premature } \\
\text { delivery, maternal } \\
\text { chronic disease, Rh } \\
\text { sensitivity }\end{array}$ \\
\hline $\begin{array}{l}\text { Mandira- } \\
\text { cioglu } \\
\text { et al. } 116 \\
(2004)\end{array}$ & $\begin{array}{l}\text { Case- } \\
\text { control }\end{array}$ & $\begin{array}{c}\text { Study in Izmir } \\
\text { hospital (Turkey) }\end{array}$ & $\begin{array}{c}\text { Neural tube } \\
\text { defects }\end{array}$ & Interview & Unspecified & 44 & 88 & $\begin{array}{c}\text { Matching: place of birth, } \\
\text { month/year of birth }\end{array}$ \\
\hline
\end{tabular}

(continues) 
Table 1 (continued)

\begin{tabular}{|c|c|c|c|c|c|c|c|c|}
\hline \multirow[t]{2}{*}{$\begin{array}{l}\text { Reference } \\
\text { (year) }\end{array}$} & \multirow[t]{2}{*}{$\begin{array}{l}\text { Type of } \\
\text { study }\end{array}$} & \multirow[t]{2}{*}{$\begin{array}{l}\text { Site/Source } \\
\text { of data }\end{array}$} & \multirow[t]{2}{*}{ Type of defect } & \multicolumn{2}{|c|}{$\begin{array}{c}\text { Exposure (maternal } \\
\text { smoking) }\end{array}$} & \multirow[t]{2}{*}{ Case } & \multirow[t]{2}{*}{ Controls } & \multirow{2}{*}{$\begin{array}{c}\text { Control of confounders } \\
\text { (adjustment/ } \\
\text { matching) }\end{array}$} \\
\hline & & & & $\begin{array}{c}\text { Data } \\
\text { collection }\end{array}$ & $\begin{array}{l}\text { Stage of } \\
\text { pregnancy }\end{array}$ & & & \\
\hline $\begin{array}{l}\text { Martinez- } \\
\text { Frias et } \\
\text { al. } 117 \\
(2008)\end{array}$ & $\begin{array}{l}\text { Case- } \\
\text { control }\end{array}$ & $\begin{array}{l}\text { Birth defects } \\
\text { study in Spain }\end{array}$ & Gastroschisis & $\begin{array}{l}\text { Phone } \\
\text { interview }\end{array}$ & $\begin{array}{l}\text { Pre- } \\
\text { conception } \\
\text { exposure and } \\
\text { in the first } \\
\text { quarter }\end{array}$ & 45 & 690 & $\begin{array}{l}\text { Matching: month/year } \\
\text { of birth, sex }\end{array}$ \\
\hline $\begin{array}{l}\text { McBride } \\
\text { et al. } 118 \\
\text { (1991) }\end{array}$ & $\begin{array}{l}\text { Case- } \\
\text { control }\end{array}$ & $\begin{array}{l}\text { Birth Defects } \\
\text { Registry } \\
\text { (Canada) }\end{array}$ & Cryptorchidism & $\begin{array}{l}\text { Phone } \\
\text { interview }\end{array}$ & $\begin{array}{l}\text { Pre- } \\
\text { conception } \\
\text { exposure and } \\
\text { in the first } \\
\text { quarter }\end{array}$ & 244 & 488 & $\begin{array}{l}\text { Adjusted: maternal } \\
\text { age, maternal/paternal } \\
\text { schooling, race, } \\
\text { maternal alcohol intake, } \\
\text { caffeine }\end{array}$ \\
\hline $\begin{array}{l}\text { McDonald } \\
\text { et al. } 119 \\
\text { (1992) }\end{array}$ & $\begin{array}{l}\text { Case- } \\
\text { control }\end{array}$ & $\begin{array}{l}\text { Assessment of } \\
\text { occupational } \\
\text { factors in } \\
\text { pregnancy } \\
\text { in Montreal } \\
\text { (Canada) }\end{array}$ & Birth defects & Interview & First quarter & 1,928 & 87,389 & Matching: sex \\
\hline $\begin{array}{l}\text { McGlynn } \\
\text { et al. } 120 \\
\text { (2006) }\end{array}$ & $\begin{array}{l}\text { Nested } \\
\text { case- } \\
\text { control }\end{array}$ & $\begin{array}{l}\text { Collaborative } \\
\text { perinatal project } \\
\text { (United States) }\end{array}$ & Cryptorchidism & Interview & Unspecified & 424 & 23,994 & - \\
\hline $\begin{array}{l}\text { Miller et } \\
\text { al. } 121 \\
\text { (2009) }\end{array}$ & $\begin{array}{l}\text { Case- } \\
\text { control }\end{array}$ & $\begin{array}{c}\text { National } \\
\text { Birth Defects } \\
\text { Prevention Study } \\
\text { (United States) }\end{array}$ & Anorectal atresia & $\begin{array}{l}\text { Phone } \\
\text { interview }\end{array}$ & $\begin{array}{l}\text { Pre- } \\
\text { conception } \\
\text { exposure and } \\
\text { in the first } \\
\text { quarter }\end{array}$ & 464 & 4,940 & - \\
\hline $\begin{array}{l}\text { Miller et } \\
\text { al. } 122 \\
\text { (2010) }\end{array}$ & $\begin{array}{l}\text { Case- } \\
\text { control }\end{array}$ & $\begin{array}{c}\text { National } \\
\text { Birth Defects } \\
\text { Prevention Study } \\
\text { (United States) }\end{array}$ & $\begin{array}{l}\text { Holoprosen- } \\
\text { cephaly }\end{array}$ & $\begin{array}{l}\text { Phone } \\
\text { interview }\end{array}$ & $\begin{array}{l}\text { Pre- } \\
\text { conception } \\
\text { exposure and } \\
\text { in the first } \\
\text { quarter }\end{array}$ & 59 & 4,999 & - \\
\hline $\begin{array}{l}\text { Mitchell } \\
\text { et al. } 123 \\
\text { (2001) }\end{array}$ & $\begin{array}{l}\text { Case- } \\
\text { control }\end{array}$ & $\begin{array}{l}\text { Danish case- } \\
\text { control study }\end{array}$ & Oral fissures & Interview & First quarter & 296 & 559 & $\begin{array}{l}\text { Matching: month/year } \\
\text { of birth, place of birth }\end{array}$ \\
\hline $\begin{array}{l}\text { Morales- } \\
\text { Suarez- } \\
\text { Varela } \\
\text { et al. } 124 \\
\text { (2006) }\end{array}$ & Cohort & $\begin{array}{l}\text { Danish national } \\
\text { birth cohort } \\
\text { Denmark }\end{array}$ & Birth defects & Interview & First quarter & 3,767 & 73,001 & $\begin{array}{l}\text { Adjusted: maternal age, } \\
\text { maternal alcohol intake }\end{array}$ \\
\hline $\begin{array}{l}\text { Morgana } \\
\text { et al. } 125 \\
\text { (2008) }\end{array}$ & $\begin{array}{l}\text { Case- } \\
\text { control } \\
\text { aninhado }\end{array}$ & $\begin{array}{l}\text { Child Health and } \\
\text { Development } \\
\text { Studies of } \\
\text { California } \\
\text { (United States) }\end{array}$ & Cryptorchidism & Interview & Unspecified & 84 & 250 & $\begin{array}{c}\text { Matching: race, month/ } \\
\text { year of birth, sex }\end{array}$ \\
\hline $\begin{array}{l}\text { Mori et } \\
\text { al. } 126 \\
\text { (1992) }\end{array}$ & $\begin{array}{l}\text { Case- } \\
\text { control }\end{array}$ & $\begin{array}{c}\text { University } \\
\text { Hospital of } \\
\text { Sapporo (Japan) }\end{array}$ & Cryptorchidism & Interview & $\begin{array}{l}\text { Beginning of } \\
\text { pregnancy }\end{array}$ & 104 & 104 & Matching: age, sex \\
\hline $\begin{array}{l}\text { Mossey } \\
\text { et al. } 127 \\
\text { (2007) }\end{array}$ & $\begin{array}{l}\text { Case- } \\
\text { control }\end{array}$ & $\begin{array}{l}\text { Regions of } \\
\text { England }\end{array}$ & Oral fissures & $\begin{array}{l}\text { Phone } \\
\text { interview }\end{array}$ & First quarter & 191 & 247 & - \\
\hline
\end{tabular}

(continues) 
Table 1 (continued)

\begin{tabular}{|c|c|c|c|c|c|c|c|c|}
\hline \multirow[t]{2}{*}{$\begin{array}{l}\text { Reference } \\
\text { (year) }\end{array}$} & \multirow[t]{2}{*}{$\begin{array}{l}\text { Type of } \\
\text { study }\end{array}$} & \multirow[t]{2}{*}{$\begin{array}{l}\text { Site/Source } \\
\text { of data }\end{array}$} & \multirow[t]{2}{*}{ Type of defect } & \multicolumn{2}{|c|}{$\begin{array}{l}\text { Exposure (maternal } \\
\text { smoking) }\end{array}$} & \multirow[t]{2}{*}{ Case } & \multirow[t]{2}{*}{ Controls } & \multirow{2}{*}{$\begin{array}{c}\text { Control of confounders } \\
\text { (adjustment/ } \\
\text { matching) }\end{array}$} \\
\hline & & & & $\begin{array}{l}\text { Data } \\
\text { collection }\end{array}$ & $\begin{array}{l}\text { Stage of } \\
\text { pregnancy }\end{array}$ & & & \\
\hline $\begin{array}{l}\text { Munoz } \\
\text { et al. } 128 \\
\text { (2006) }\end{array}$ & $\begin{array}{l}\text { Case- } \\
\text { control }\end{array}$ & $\begin{array}{l}\text { Neural tube } \\
\text { defects } \\
\text { epidemiological } \\
\text { surveillance } \\
\text { system (Mexico) }\end{array}$ & Anencephaly & Interview & $\begin{array}{l}\text { Pre- } \\
\text { conception } \\
\text { exposure } \\
\text { and in the } \\
\text { first month of } \\
\text { pregnancy }\end{array}$ & 151 & 151 & $\begin{array}{l}\text { Matching: month/year } \\
\text { of birth, place of birth }\end{array}$ \\
\hline $\begin{array}{l}\text { Mygind } \\
\text { et al. } 129 \\
\text { (2002) }\end{array}$ & $\begin{array}{l}\text { Cross- } \\
\text { sectional }\end{array}$ & Denmark & Birth defects & Interview & First quarter & 342 & 9,284 & $\begin{array}{c}\text { Adjusted: maternal age, } \\
\text { gestational age }\end{array}$ \\
\hline $\begin{array}{l}\text { Niebyl } \\
\text { et al. } 130 \\
\text { (1985) }\end{array}$ & $\begin{array}{l}\text { Case- } \\
\text { control }\end{array}$ & $\begin{array}{l}\text { Children's } \\
\text { Hospital, } \\
\text { Baltimore } \\
\text { (United States) }\end{array}$ & $\begin{array}{l}\text { Cleft lip; cleft } \\
\text { palate }\end{array}$ & Interview & Unspecified & 59 & 59 & $\begin{array}{l}\text { Matching: race, } \\
\text { maternal age }\end{array}$ \\
\hline $\begin{array}{l}\text { Noorgaard } \\
\text { et al. } 131 \\
\text { (2009) }\end{array}$ & $\begin{array}{l}\text { Case- } \\
\text { control }\end{array}$ & $\begin{array}{l}\text { National Patient } \\
\text { Regsitry of } \\
\text { Denmark }\end{array}$ & Hypospadias & Database & $\begin{array}{c}\text { Pre- } \\
\text { conception } \\
\text { exposure and } \\
\text { in the first } \\
\text { quarter }\end{array}$ & 1,591 & 14,900 & - \\
\hline $\begin{array}{l}\text { Oddsberg } \\
\text { et al. } 132 \\
\text { (2008) }\end{array}$ & $\begin{array}{l}\text { Case- } \\
\text { control }\end{array}$ & $\begin{array}{l}\text { Swedish Registry } \\
\text { of Birth Defects }\end{array}$ & Esophagus atresia & $\begin{array}{l}\text { Prenatal } \\
\text { data }\end{array}$ & First quarter & 722 & 3,610 & \\
\hline $\begin{array}{l}\text { Ormond } \\
\text { et al. } 133 \\
\text { (2009) }\end{array}$ & $\begin{array}{l}\text { Case- } \\
\text { control }\end{array}$ & $\begin{array}{l}\text { Southeastern } \\
\text { England } \\
\text { Study (United } \\
\text { Kingdom) }\end{array}$ & Hypospadias & $\begin{array}{l}\text { Phone } \\
\text { interview }\end{array}$ & First quarter & 468 & 485 & $\begin{array}{l}\text { Adjusted: family income } \\
\text { gestational age, birth } \\
\text { weight, folic acid intake; } \\
\text { Matching: month/year } \\
\text { of birth, place of birth, } \\
\text { sex }\end{array}$ \\
\hline $\begin{array}{l}\text { Parikh } \\
\text { et al. } 134 \\
(2002)\end{array}$ & $\begin{array}{l}\text { Case- } \\
\text { control }\end{array}$ & $\begin{array}{c}\text { Birth records } \\
\text { of the State of } \\
\text { Colorado (United } \\
\text { States) }\end{array}$ & Renal agenesis & $\begin{array}{l}\text { Birth } \\
\text { certificate } \\
\text { data }\end{array}$ & Unspecified & 188 & 940 & $\begin{array}{l}\text { Matching: month/year } \\
\text { of birth }\end{array}$ \\
\hline $\begin{array}{l}\text { Parker } \\
\text { et al. } 135 \\
\text { (2009) }\end{array}$ & $\begin{array}{l}\text { Case- } \\
\text { control }\end{array}$ & $\begin{array}{l}\text { Birth Defects } \\
\text { Surveillance } \\
\text { Program (United } \\
\text { States) }\end{array}$ & $\begin{array}{l}\text { Crooked foot at } \\
\text { birth }\end{array}$ & $\begin{array}{l}\text { Birth } \\
\text { certificate } \\
\text { data }\end{array}$ & Unspecified & 6,139 & 61,390 & $\begin{array}{l}\text { Adjusted: race, maternal } \\
\text { age, parity, maternal/ } \\
\text { paternal schooling; } \\
\text { Matching: month/year } \\
\text { of birth, place of birth }\end{array}$ \\
\hline $\begin{array}{l}\text { Pierik et } \\
\text { al. } 136 \\
(2004)\end{array}$ & $\begin{array}{l}\text { Nested } \\
\text { case- } \\
\text { control }\end{array}$ & $\begin{array}{l}\text { Cohorte of } \\
\text { infants in the city } \\
\text { of Rotterdam } \\
\text { (Netherlands) }\end{array}$ & $\begin{array}{l}\text { Cryptorchidism; } \\
\text { hypospadias }\end{array}$ & Interview & Unspecified & 134 & 313 & - \\
\hline $\begin{array}{l}\text { Porter } \\
\text { et al. } 137 \\
\text { (2006) }\end{array}$ & $\begin{array}{l}\text { Case- } \\
\text { control }\end{array}$ & $\begin{array}{l}\text { Hospitais, } \\
\text { Washington } \\
\text { State (United } \\
\text { States) }\end{array}$ & Hypospadias & $\begin{array}{l}\text { Birth } \\
\text { certificate } \\
\text { data }\end{array}$ & Unspecified & 2,006 & 10,084 & $\begin{array}{l}\text { Matching: month/year } \\
\text { of birth, sex }\end{array}$ \\
\hline $\begin{array}{l}\text { Preiksaet } \\
\text { al. } 138 \\
(2006)\end{array}$ & Cohort & $\begin{array}{l}\text { Hospital-based } \\
\text { study in the city } \\
\text { of Panevęžys } \\
\text { (Lithuania) }\end{array}$ & Cryptorchidism & $\begin{array}{l}\text { Question- } \\
\text { naire }\end{array}$ & Unspecified & 69 & 1,135 & Matching: sex \\
\hline
\end{tabular}

(continues) 
Table 1 (continued)

\begin{tabular}{|c|c|c|c|c|c|c|c|c|}
\hline \multirow[t]{2}{*}{$\begin{array}{l}\text { Reference } \\
\text { (year) }\end{array}$} & \multirow[t]{2}{*}{$\begin{array}{l}\text { Type of } \\
\text { study }\end{array}$} & \multirow[t]{2}{*}{$\begin{array}{l}\text { Site/Source } \\
\text { of data }\end{array}$} & \multirow[t]{2}{*}{ Type of defect } & \multicolumn{2}{|c|}{$\begin{array}{c}\text { Exposure (maternal } \\
\text { smoking) }\end{array}$} & \multirow[t]{2}{*}{ Case } & \multirow[t]{2}{*}{ Controls } & \multirow{2}{*}{$\begin{array}{c}\text { Control of confounders } \\
\text { (adjustment/ } \\
\text { matching) }\end{array}$} \\
\hline & & & & $\begin{array}{c}\text { Data } \\
\text { collection }\end{array}$ & $\begin{array}{l}\text { Stage of } \\
\text { pregnancy }\end{array}$ & & & \\
\hline $\begin{array}{l}\text { Queissur- } \\
\text { Luft et } \\
\text { al. } 139 \\
(2002)\end{array}$ & Cohort & $\begin{array}{l}\text { Birth defects } \\
\text { monitoring } \\
\text { system of Mainz } \\
\text { (Germany) }\end{array}$ & $\begin{array}{l}\text { Major birth } \\
\text { defects }\end{array}$ & Interview & Unspecified & 2,144 & 28,796 & - \\
\hline $\begin{array}{l}\text { Ramirez } \\
\text { et al. } 13 \\
\text { (2007) }\end{array}$ & $\begin{array}{l}\text { Case- } \\
\text { control }\end{array}$ & $\begin{array}{l}\text { Population- } \\
\text { based study } \\
\text { in California } \\
\text { (United States) }\end{array}$ & Oral fissures & $\begin{array}{c}\text { Phone } \\
\text { interview }\end{array}$ & $\begin{array}{l}\text { Pre- } \\
\text { conception } \\
\text { exposure and } \\
\text { in the first } \\
\text { quarter }\end{array}$ & 431 & 299 & - \\
\hline $\begin{array}{l}\text { Rantakallio } \\
140 \text { (1978) }\end{array}$ & $\begin{array}{l}\text { Nested } \\
\text { case- } \\
\text { control }\end{array}$ & $\begin{array}{l}\text { Birth cohort, } \\
\text { Northern Finland }\end{array}$ & Malformations & Interview & Unspecified & 95 & 3,549 & $\begin{array}{l}\text { Matching: parity, } \\
\text { marital status, maternal } \\
\text { age, place of birth, } \\
\text { multiparity }\end{array}$ \\
\hline $\begin{array}{l}\text { Reefhuis } \\
\text { et al. } 141 \\
\text { (1998) }\end{array}$ & $\begin{array}{l}\text { Case- } \\
\text { control }\end{array}$ & $\begin{array}{c}\text { EUROCAT Study } \\
\text { (Europe) }\end{array}$ & $\begin{array}{l}\text { Crooked foot at } \\
\text { birth }\end{array}$ & $\begin{array}{l}\text { Interview } \\
\text { and hospital } \\
\text { records }\end{array}$ & Any period & 2,905 & 7,829 & $\begin{array}{c}\text { Adjusted: maternal age, } \\
\text { place of birth, parity, } \\
\text { month/year of birth }\end{array}$ \\
\hline $\begin{array}{l}\text { Robitaille } \\
\text { et al. } 142 \\
(2009)\end{array}$ & $\begin{array}{l}\text { Case- } \\
\text { control }\end{array}$ & $\begin{array}{l}\text { National } \\
\text { Birth Defects } \\
\text { Prevention Study } \\
\text { (United States) }\end{array}$ & Limb reduction & $\begin{array}{l}\text { Phone } \\
\text { interview }\end{array}$ & Unspecified & 527 & 4,956 & - \\
\hline $\begin{array}{l}\text { Rodriguez- } \\
\text { Pinilla } \\
\text { et al. } 143 \\
\text { (2008) }\end{array}$ & $\begin{array}{l}\text { Case- } \\
\text { control }\end{array}$ & $\begin{array}{l}\text { Collaborative } \\
\text { birth defects } \\
\text { study (Spain) }\end{array}$ & Hypospadias & Interview & Unspecified & 2,393 & 12,465 & $\begin{array}{c}\text { Adjusted: maternal } \\
\text { age, maternal/paternal } \\
\text { schooling, maternal } \\
\text { epilepsy, maternal } \\
\text { chronic disease, } \\
\text { race, family history of } \\
\text { malformations, fever } \\
\text { during pregnancy, } \\
\text { maternal alcohol } \\
\text { intake mother, } \\
\text { periconceptional vitamin } \\
\text { supplementation, } \\
\text { maternal use of } \\
\text { medication; Matching: } \\
\text { month/year of birth, } \\
\text { place of birth, sex }\end{array}$ \\
\hline $\begin{array}{l}\text { Romitti } \\
\text { et al. } 144 \\
\text { (2007) }\end{array}$ & $\begin{array}{l}\text { Case- } \\
\text { control }\end{array}$ & $\begin{array}{l}\text { National } \\
\text { Birth Defects } \\
\text { Prevention Study } \\
\text { (United States) }\end{array}$ & $\begin{array}{c}\text { Cleft lip with } \\
\text { or without cleft } \\
\text { palate }\end{array}$ & $\begin{array}{c}\text { Phone } \\
\text { interview }\end{array}$ & $\begin{array}{l}\text { Pre- } \\
\text { conception } \\
\text { exposure and } \\
\text { in the first } \\
\text { quarter }\end{array}$ & 1,748 & 4,094 & - \\
\hline $\begin{array}{l}\text { Salemi } \\
\text { et al. } 145 \\
(2009)\end{array}$ & $\begin{array}{l}\text { Retrospe- } \\
\text { ctive cohort }\end{array}$ & $\begin{array}{l}\text { Florida Registry } \\
\text { of Birth Defects } \\
\text { (United States) }\end{array}$ & Gastroschisis & $\begin{array}{l}\text { Birth } \\
\text { records }\end{array}$ & Unspecified & 394 & 117,8147 & $\begin{array}{c}\text { Adjusted: maternal } \\
\text { age, marital status, } \\
\text { race, maternal/paternal } \\
\text { schooling, parity, place } \\
\text { of birth }\end{array}$ \\
\hline
\end{tabular}

(continues) 
Table 1 (continued)

\begin{tabular}{|c|c|c|c|c|c|c|c|c|}
\hline \multirow[t]{2}{*}{$\begin{array}{l}\text { Reference } \\
\text { (year) }\end{array}$} & \multirow[t]{2}{*}{$\begin{array}{l}\text { Type of } \\
\text { study }\end{array}$} & \multirow[t]{2}{*}{$\begin{array}{l}\text { Site/Source } \\
\text { of data }\end{array}$} & \multirow[t]{2}{*}{ Type of defect } & \multicolumn{2}{|c|}{$\begin{array}{l}\text { Exposure (maternal } \\
\text { smoking) }\end{array}$} & \multirow[t]{2}{*}{ Case } & \multirow[t]{2}{*}{ Controls } & \multirow{2}{*}{$\begin{array}{l}\text { Control of confounders } \\
\text { (adjustment/ } \\
\text { matching) }\end{array}$} \\
\hline & & & & $\begin{array}{c}\text { Data } \\
\text { collection }\end{array}$ & $\begin{array}{l}\text { Stage of } \\
\text { pregnancy }\end{array}$ & & & \\
\hline $\begin{array}{l}\text { Saxen } 146 \\
(1974)\end{array}$ & $\begin{array}{l}\text { Case- } \\
\text { control }\end{array}$ & $\begin{array}{l}\text { The Finnish } \\
\text { registry of } \\
\text { congenital } \\
\text { malformations }\end{array}$ & $\begin{array}{l}\text { Cleft lip with } \\
\text { or without cleft } \\
\text { palate }\end{array}$ & Interview & $\begin{array}{l}\text { The entire } \\
\text { pregnancy }\end{array}$ & 599 & 590 & $\begin{array}{l}\text { Matching: month/year } \\
\text { of birth, place of birth }\end{array}$ \\
\hline $\begin{array}{l}\text { Schmidt } \\
\text { et al. } 147 \\
\text { (2009) }\end{array}$ & $\begin{array}{l}\text { Case- } \\
\text { control }\end{array}$ & $\begin{array}{c}\text { National } \\
\text { Birth Defects } \\
\text { Prevention Study } \\
\text { (United States) }\end{array}$ & CNS defects & $\begin{array}{l}\text { Phone } \\
\text { interview }\end{array}$ & $\begin{array}{c}\text { Pre- } \\
\text { conception } \\
\text { exposure and } \\
\text { in the first } \\
\text { quarter }\end{array}$ & 768 & 4,143 & - \\
\hline $\begin{array}{l}\text { Seidman } \\
\text { et al. } 148 \\
(1990)\end{array}$ & $\begin{array}{l}\text { Cross- } \\
\text { sectional }\end{array}$ & $\begin{array}{c}\text { Hospitals of } \\
\text { Jerusalem (Israel) }\end{array}$ & Malformations & Interview & $\begin{array}{l}\text { The entire } \\
\text { pregnancy }\end{array}$ & 1,296 & 15,856 & - \\
\hline $\begin{array}{l}\text { Shaw et al. } \\
149 \text { (1992) }\end{array}$ & $\begin{array}{l}\text { Case- } \\
\text { control }\end{array}$ & $\begin{array}{c}\text { California } \\
\text { Birth Defects } \\
\text { Monitoring } \\
\text { Program (United } \\
\text { States) }\end{array}$ & $\begin{array}{c}\text { Cardiovascular } \\
\text { defects }\end{array}$ & $\begin{array}{l}\text { Phone } \\
\text { interview }\end{array}$ & $\begin{array}{c}\text { Pre- } \\
\text { conception } \\
\text { exposure and } \\
\text { in the first } \\
\text { quarter }\end{array}$ & 141 & 176 & $\begin{array}{l}\text { Adjusted: race, } \\
\text { maternal age, maternal/ } \\
\text { paternal schooling, } \\
\text { maternal alcohol intake; } \\
\text { Matching: month/year } \\
\text { of birth, place of birth }\end{array}$ \\
\hline $\begin{array}{l}\text { Shaw et } \\
\text { al. } 150 \\
(1996)\end{array}$ & $\begin{array}{l}\text { Case- } \\
\text { control }\end{array}$ & $\begin{array}{c}\text { California } \\
\text { Birth Defects } \\
\text { Monitoring } \\
\text { Program (United } \\
\text { States) }\end{array}$ & $\begin{array}{c}\text { Neural tube } \\
\text { defects }\end{array}$ & $\begin{array}{l}\text { Phone } \\
\text { interview }\end{array}$ & $\begin{array}{c}\text { Pre- } \\
\text { conception } \\
\text { exposure and } \\
\text { in the first } \\
\text { quarter }\end{array}$ & 538 & 539 & $\begin{array}{l}\text { Adjusted: } \\
\text { periconceptional vitamin } \\
\text { supplementation, race, } \\
\text { maternal schooling, } \\
\text { maternal age, maternal } \\
\text { alcohol intake }\end{array}$ \\
\hline $\begin{array}{l}\text { Shaw et } \\
\text { al. } 151 \\
(1996)\end{array}$ & $\begin{array}{l}\text { Case- } \\
\text { control }\end{array}$ & $\begin{array}{c}\text { California } \\
\text { Birth Defects } \\
\text { Monitoring } \\
\text { Program (United } \\
\text { States) }\end{array}$ & $\begin{array}{l}\text { Cleft lip with } \\
\text { or without cleft } \\
\text { palate }\end{array}$ & $\begin{array}{l}\text { Phone } \\
\text { interview }\end{array}$ & $\begin{array}{c}\text { Pre- } \\
\text { conception } \\
\text { exposure and } \\
\text { in the first } \\
\text { quarter }\end{array}$ & 728 & 731 & $\begin{array}{l}\text { Matching: month/year } \\
\text { of birth, place of birth }\end{array}$ \\
\hline $\begin{array}{l}\text { Shaw et } \\
\text { al. } 152 \\
(1999)\end{array}$ & $\begin{array}{l}\text { Case- } \\
\text { control }\end{array}$ & $\begin{array}{c}\text { California } \\
\text { Birth Defects } \\
\text { Monitoring } \\
\text { Program (United } \\
\text { States) }\end{array}$ & Malformations & $\begin{array}{c}\text { Phone } \\
\text { interview }\end{array}$ & $\begin{array}{c}\text { Pre- } \\
\text { conception } \\
\text { exposure and } \\
\text { in the first } \\
\text { quarter }\end{array}$ & 1,299 & 734 & $\begin{array}{l}\text { Matching: month/year } \\
\text { of birth, place of birth }\end{array}$ \\
\hline $\begin{array}{l}\text { Shaw et } \\
\text { al. } 153 \\
(2000)\end{array}$ & $\begin{array}{l}\text { Case- } \\
\text { control }\end{array}$ & $\begin{array}{c}\text { California } \\
\text { Birth Defects } \\
\text { Monitoring } \\
\text { Program (United } \\
\text { States) }\end{array}$ & $\begin{array}{c}\text { Multiple } \\
\text { congenital } \\
\text { anomalies }\end{array}$ & $\begin{array}{l}\text { Phone } \\
\text { interview }\end{array}$ & $\begin{array}{l}\text { Pre- } \\
\text { conception } \\
\text { exposure and } \\
\text { in the first } \\
\text { quarter }\end{array}$ & 112 & 194 & $\begin{array}{l}\text { Matching: month/year } \\
\text { of birth, place of birth }\end{array}$ \\
\hline $\begin{array}{l}\text { Shi et al. } \\
154 \text { (2007) }\end{array}$ & $\begin{array}{l}\text { Case- } \\
\text { control }\end{array}$ & $\begin{array}{l}\text { Case-control } \\
\text { study (United } \\
\text { States and } \\
\text { Denmark) }\end{array}$ & Orofacial cleft & Interview & $\begin{array}{l}\text { The entire } \\
\text { pregnancy }\end{array}$ & 1,378 & 1,435 & - \\
\hline $\begin{array}{l}\text { Shiono } \\
\text { et al. } 155 \\
(1986)\end{array}$ & Cohort & $\begin{array}{c}\text { Kaiser } \\
\text { Permanente } \\
\text { Birth Defects } \\
\text { Study (United } \\
\text { States) }\end{array}$ & $\begin{array}{c}\text { Major } \\
\text { malformations }\end{array}$ & Interview & Unspecified & 592 & 28,810 & $\begin{array}{c}\text { Adjusted: maternal age, } \\
\text { race, maternal alcohol } \\
\text { intake }\end{array}$ \\
\hline
\end{tabular}

(continues) 
Table 1 (continued)

\begin{tabular}{|c|c|c|c|c|c|c|c|c|}
\hline \multirow[t]{2}{*}{$\begin{array}{l}\text { Reference } \\
\text { (year) }\end{array}$} & \multirow[t]{2}{*}{$\begin{array}{l}\text { Type of } \\
\text { study }\end{array}$} & \multirow[t]{2}{*}{$\begin{array}{l}\text { Site/Source } \\
\text { of data }\end{array}$} & \multirow[t]{2}{*}{ Type of defect } & \multicolumn{2}{|c|}{$\begin{array}{c}\text { Exposure (maternal } \\
\text { smoking) }\end{array}$} & \multirow[t]{2}{*}{ Case } & \multirow[t]{2}{*}{ Controls } & \multirow{2}{*}{$\begin{array}{c}\text { Control of confounders } \\
\text { (adjustment/ } \\
\text { matching) }\end{array}$} \\
\hline & & & & $\begin{array}{c}\text { Data } \\
\text { collection }\end{array}$ & $\begin{array}{l}\text { Stage of } \\
\text { pregnancy }\end{array}$ & & & \\
\hline $\begin{array}{l}\text { Skelly } \\
\text { et al. } 156 \\
\text { (2002) }\end{array}$ & $\begin{array}{l}\text { Case- } \\
\text { control }\end{array}$ & $\begin{array}{c}\text { Hospitais, } \\
\text { Washington } \\
\text { State (United } \\
\text { States) }\end{array}$ & $\begin{array}{c}\text { Crooked foot at } \\
\text { birth }\end{array}$ & Interview & Unspecified & 239 & 356 & $\begin{array}{l}\text { Adjusted: maternal age, } \\
\text { race, family history of } \\
\text { birth defects }\end{array}$ \\
\hline $\begin{array}{l}\text { Slickers } \\
\text { et al. } 157 \\
\text { (2008) }\end{array}$ & $\begin{array}{l}\text { Case- } \\
\text { control }\end{array}$ & $\begin{array}{c}\text { National } \\
\text { Birth Defects } \\
\text { Prevention Study } \\
\text { (United States) }\end{array}$ & $\begin{array}{c}\text { Renal agenesis or } \\
\text { hypoplasia }\end{array}$ & Interview & $\begin{array}{c}\text { Pre- } \\
\text { conception } \\
\text { exposure and } \\
\text { in the first } \\
\text { quarter }\end{array}$ & 73 & 859 & - \\
\hline $\begin{array}{l}\text { Smedts } \\
\text { et al. } 158 \\
\text { (2009) }\end{array}$ & $\begin{array}{l}\text { Case- } \\
\text { control }\end{array}$ & $\begin{array}{l}\text { HAVEN Study } \\
\text { (Netherlands) }\end{array}$ & $\begin{array}{c}\text { Congenital heart } \\
\text { defects }\end{array}$ & $\begin{array}{l}\text { Question- } \\
\text { naire }\end{array}$ & $\begin{array}{c}\text { Pre- } \\
\text { conception } \\
\text { exposure and } \\
\text { in the first } \\
\text { quarter }\end{array}$ & 276 & 324 & - \\
\hline $\begin{array}{l}\text { Sorensen } \\
\text { et al. } 159 \\
(2002)\end{array}$ & $\begin{array}{l}\text { Case- } \\
\text { control }\end{array}$ & $\begin{array}{l}\text { North Justland, } \\
\text { Denmark }\end{array}$ & $\begin{array}{l}\text { Hypertrophic } \\
\text { pyloric stenosis }\end{array}$ & $\begin{array}{l}\text { Birth certifi- } \\
\text { cate data }\end{array}$ & Unspecified & 78 & 57,918 & - \\
\hline $\begin{array}{l}\text { Stein- } \\
\text { berger } \\
\text { et al. } 160 \\
(2002)\end{array}$ & $\begin{array}{l}\text { Case- } \\
\text { control }\end{array}$ & $\begin{array}{l}\text { Baltimore- } \\
\text { Washington } \\
\text { Infant Study } \\
\text { (United States) }\end{array}$ & Heart defects & Interview & Unspecified & 48 & 3,572 & $\begin{array}{l}\text { Matching: month/year } \\
\text { of birth, place of birth, } \\
\text { sex }\end{array}$ \\
\hline $\begin{array}{l}\text { Stoll et al. } \\
161 \text { (1997) }\end{array}$ & $\begin{array}{l}\text { Case- } \\
\text { control }\end{array}$ & $\begin{array}{c}\text { Strasbourg Study } \\
\text { (France) }\end{array}$ & Anal atresia & $\begin{array}{l}\text { Hospital } \\
\text { records }\end{array}$ & Unspecified & 108 & 225,644 & $\begin{array}{l}\text { Matching: sex, } \\
\text { gestational age }\end{array}$ \\
\hline $\begin{array}{l}\text { Stoll et al. } \\
162 \text { (2001) }\end{array}$ & $\begin{array}{l}\text { Case- } \\
\text { control }\end{array}$ & $\begin{array}{c}\text { Strasbourg Study } \\
\text { (France) }\end{array}$ & Musculoskeletal & $\begin{array}{l}\text { Hospital } \\
\text { records }\end{array}$ & Unspecified & 105 & 105 & $\begin{array}{l}\text { Matching: sex, } \\
\text { gestational age }\end{array}$ \\
\hline $\begin{array}{l}\text { Suarez } \\
\text { et al. } 163 \\
\text { (2008) }\end{array}$ & $\begin{array}{l}\text { Case- } \\
\text { control }\end{array}$ & $\begin{array}{l}\text { Texas neural } \\
\text { tube defects } \\
\text { project (United } \\
\text { States) }\end{array}$ & $\begin{array}{l}\text { Neural tube } \\
\text { defects }\end{array}$ & Interview & $\begin{array}{c}\text { Pre- } \\
\text { conception } \\
\text { exposure and } \\
\text { in the first } \\
\text { quarter }\end{array}$ & 175 & 221 & $\begin{array}{l}\text { Adjusted: maternal age, } \\
\text { schooling, maternal } \\
\text { BMI, use of folic acid }\end{array}$ \\
\hline $\begin{array}{l}\text { Szendrey } \\
\text { et al. } 164 \\
\text { (1985) }\end{array}$ & $\begin{array}{l}\text { Case- } \\
\text { control }\end{array}$ & $\begin{array}{l}\text { Hungarian Birth } \\
\text { Defects Registry }\end{array}$ & $\begin{array}{c}\text { Esophageal } \\
\text { atresia }\end{array}$ & Interview & Unspecified & 160 & 160 & $\begin{array}{l}\text { Matching: month/year } \\
\text { of birth, place of birth, } \\
\text { sex }\end{array}$ \\
\hline $\begin{array}{l}\text { Tamura } \\
\text { et al. } 165 \\
\text { (2006) }\end{array}$ & $\begin{array}{l}\text { Case- } \\
\text { control }\end{array}$ & $\begin{array}{c}\text { Study in the } \\
\text { Province of Cebu } \\
\text { (Philippines) }\end{array}$ & Facial clefts & Interview & Unspecified & 74 & 283 & - \\
\hline $\begin{array}{l}\text { Targett } \\
\text { et al. } 166 \\
\text { (1977) }\end{array}$ & Cohort & $\begin{array}{l}\text { Maternity of the } \\
\text { Mercy hospital } \\
\text { (Australia) }\end{array}$ & Major defects & Interview & Unspecified & 122 & 2,878 & - \\
\hline $\begin{array}{l}\text { Tata et al. } \\
167 \text { (2008) }\end{array}$ & $\begin{array}{l}\text { Case- } \\
\text { control }\end{array}$ & $\begin{array}{l}\text { Health network } \\
\text { database (United } \\
\text { Kingdom) }\end{array}$ & Birth defects & $\begin{array}{l}\text { Birth } \\
\text { records }\end{array}$ & $\begin{array}{l}\text { The entire } \\
\text { pregnancy }\end{array}$ & 3,995 & 23,156 & $\begin{array}{l}\text { Matching: month/year } \\
\text { of birth, place of birth, } \\
\text { multiparity }\end{array}$ \\
\hline $\begin{array}{l}\text { The et } \\
\text { al. } 168 \\
(2007)\end{array}$ & $\begin{array}{l}\text { Case- } \\
\text { control }\end{array}$ & $\begin{array}{l}\text { National } \\
\text { Birth Defects } \\
\text { Prevention Study } \\
\text { (United States) }\end{array}$ & Biliary atresia & $\begin{array}{l}\text { Phone } \\
\text { interview }\end{array}$ & Unspecified & 62 & 4,094 & - \\
\hline
\end{tabular}

(continues) 
Table 1 (continued)

\begin{tabular}{|c|c|c|c|c|c|c|c|c|}
\hline \multirow[t]{2}{*}{$\begin{array}{l}\text { Reference } \\
\text { (year) }\end{array}$} & \multirow[t]{2}{*}{$\begin{array}{l}\text { Type of } \\
\text { study }\end{array}$} & \multirow[t]{2}{*}{$\begin{array}{l}\text { Site/Source } \\
\text { of data }\end{array}$} & \multirow[t]{2}{*}{ Type of defect } & \multicolumn{2}{|c|}{$\begin{array}{c}\text { Exposure (maternal } \\
\text { smoking) }\end{array}$} & \multirow[t]{2}{*}{ Case } & \multirow[t]{2}{*}{ Controls } & \multirow{2}{*}{$\begin{array}{l}\text { Control of confounders } \\
\text { (adjustment/ } \\
\text { matching) }\end{array}$} \\
\hline & & & & $\begin{array}{c}\text { Data } \\
\text { collection }\end{array}$ & $\begin{array}{l}\text { Stage of } \\
\text { pregnancy }\end{array}$ & & & \\
\hline $\begin{array}{l}\text { Tikkanen \& } \\
\text { Heinonen } \\
169 \text { (1991) }\end{array}$ & $\begin{array}{l}\text { Case- } \\
\text { control }\end{array}$ & $\begin{array}{l}\text { The Finnish } \\
\text { registry of } \\
\text { congenital } \\
\text { malformations/ } \\
\text { children's cardiac } \\
\text { registry (Finland) }\end{array}$ & $\begin{array}{c}\text { Cardiovascular } \\
\text { defects }\end{array}$ & Interview & First quarter & 573 & 1,055 & - \\
\hline $\begin{array}{l}\text { To \& Tang } \\
170 \text { (1999) }\end{array}$ & $\begin{array}{l}\text { Case- } \\
\text { control }\end{array}$ & $\begin{array}{l}\text { Department of } \\
\text { Gynecology and } \\
\text { Obstetrics of } \\
\text { a Hong Kong } \\
\text { hospital (China) }\end{array}$ & Birth defects & $\begin{array}{l}\text { Prenatal } \\
\text { records }\end{array}$ & $\begin{array}{l}\text { Pre- } \\
\text { conception } \\
\text { exposure until } \\
\text { the second } \\
\text { quarter of } \\
\text { pregnancy }\end{array}$ & 1,678 & 57,714 & - \\
\hline $\begin{array}{l}\text { Torfs et } \\
\text { al. } 171 \\
\text { (1994) }\end{array}$ & $\begin{array}{l}\text { Case- } \\
\text { control }\end{array}$ & $\begin{array}{c}\text { California } \\
\text { Birth Defects } \\
\text { Monitoring } \\
\text { Program (United } \\
\text { States) }\end{array}$ & Gastroschisis & Interview & First quarter & 110 & 220 & Matching: maternal age \\
\hline $\begin{array}{l}\text { Tornquist } \\
\text { et al. } 172 \\
\text { (2002) }\end{array}$ & $\begin{array}{l}\text { Case- } \\
\text { control }\end{array}$ & $\begin{array}{c}\text { Registry of } \\
\text { visual impaired } \\
\text { children } \\
\text { (Sweden) }\end{array}$ & $\begin{array}{l}\text { Optic nerve } \\
\text { hypoplasia }\end{array}$ & Interview & $\begin{array}{l}\text { Beginning of } \\
\text { pregnancy }\end{array}$ & 125 & $2,109,316$ & $\begin{array}{c}\text { Matching: maternal age, } \\
\text { race }\end{array}$ \\
\hline $\begin{array}{l}\text { Torp- } \\
\text { Pedersen } \\
\text { et al. } 173 \\
\text { (2010) }\end{array}$ & Cohort & $\begin{array}{l}\text { Danish national } \\
\text { birth cohort }\end{array}$ & Strabismus & Interview & $\begin{array}{l}\text { The entire } \\
\text { pregnancy }\end{array}$ & 1,299 & 95,543 & $\begin{array}{l}\text { Adjusted: month/year } \\
\text { of birth, social class, } \\
\text { maternal age, caffeine }\end{array}$ \\
\hline $\begin{array}{l}\text { Tuohy } \\
\text { et al. } 174 \\
\text { (1993) }\end{array}$ & $\begin{array}{l}\text { Retrospec- } \\
\text { tive cohort }\end{array}$ & $\begin{array}{l}\text { Plunket National } \\
\text { Child Health } \\
\text { Study (New } \\
\text { Zealand) }\end{array}$ & Birth defects & $\begin{array}{l}\text { Medical } \\
\text { records }\end{array}$ & Unspecified & 169 & 3,759 & - \\
\hline $\begin{array}{l}\text { Under- } \\
\text { wood et } \\
\text { al. } 175 \\
\text { (1965) }\end{array}$ & $\begin{array}{l}\text { Retrospec- } \\
\text { tive cohort }\end{array}$ & $\begin{array}{l}\text { Hospitals of } \\
\text { South Carolina } \\
\text { (United States) }\end{array}$ & $\begin{array}{c}\text { Major } \\
\text { malformations }\end{array}$ & $\begin{array}{l}\text { Hospital } \\
\text { records }\end{array}$ & Unspecified & 68 & 16,090 & - \\
\hline $\begin{array}{l}\text { van den } \\
\text { Boogaard } \\
\text { et al. } 176 \\
\text { (2008) }\end{array}$ & $\begin{array}{l}\text { Case- } \\
\text { control }\end{array}$ & $\begin{array}{l}\text { Study of cleft } \\
\text { palate defects } \\
\text { (Netherlands) }\end{array}$ & $\begin{array}{c}\text { Cleft lip with } \\
\text { or without cleft } \\
\text { palate }\end{array}$ & $\begin{array}{l}\text { Question- } \\
\text { naire }\end{array}$ & $\begin{array}{l}\text { Pre- } \\
\text { conception } \\
\text { exposure and } \\
\text { in the first } \\
\text { quarter }\end{array}$ & 181 & 132 & - \\
\hline $\begin{array}{l}\text { van den } \\
\text { Eeden } \\
\text { et al. } 177 \\
(1990)\end{array}$ & $\begin{array}{l}\text { Case- } \\
\text { control }\end{array}$ & $\begin{array}{l}\text { Birth records, } \\
\text { Washington } \\
\text { State (United } \\
\text { States) }\end{array}$ & $\begin{array}{l}\text { General } \\
\text { malformations }\end{array}$ & $\begin{array}{l}\text { Medical } \\
\text { records }\end{array}$ & Unspecified & 3,163 & 4,323 & $\begin{array}{c}\text { Adjusted: maternal age, } \\
\text { parity. Matching: month/ } \\
\text { year of birth, sex }\end{array}$ \\
\hline $\begin{array}{l}\text { van Rooij } \\
\text { et al. } 178 \\
(2001)\end{array}$ & $\begin{array}{l}\text { Case- } \\
\text { control }\end{array}$ & $\begin{array}{l}\text { Population- } \\
\text { based study } \\
\text { in Nijimegen } \\
\text { (Netherlands) }\end{array}$ & $\begin{array}{c}\text { Cleft lip with } \\
\text { or without cleft } \\
\text { palate }\end{array}$ & $\begin{array}{l}\text { Question- } \\
\text { naire }\end{array}$ & $\begin{array}{l}\text { Pre- } \\
\text { conception } \\
\text { exposure and } \\
\text { in the first } \\
\text { quarter }\end{array}$ & 113 & 104 & - \\
\hline $\begin{array}{l}\text { van Rooij } \\
\text { et al. } 179 \\
(2002)\end{array}$ & $\begin{array}{l}\text { Case- } \\
\text { control }\end{array}$ & $\begin{array}{l}\text { Population- } \\
\text { based study } \\
\text { in Nijimegen } \\
\text { (Netherlands) }\end{array}$ & Malformations & $\begin{array}{l}\text { Phone } \\
\text { interview }\end{array}$ & Unspecified & 84 & 72 & - \\
\hline
\end{tabular}

(continues) 
Table 1 (continued)

\begin{tabular}{|c|c|c|c|c|c|c|c|c|}
\hline \multirow[t]{2}{*}{$\begin{array}{l}\text { Reference } \\
\text { (year) }\end{array}$} & \multirow[t]{2}{*}{$\begin{array}{l}\text { Type of } \\
\text { study }\end{array}$} & \multirow[t]{2}{*}{$\begin{array}{l}\text { Site/Source } \\
\text { of data }\end{array}$} & \multirow[t]{2}{*}{ Type of defect } & \multicolumn{2}{|c|}{$\begin{array}{c}\text { Exposure (maternal } \\
\text { smoking) }\end{array}$} & \multirow[t]{2}{*}{ Case } & \multirow[t]{2}{*}{ Controls } & \multirow{2}{*}{$\begin{array}{c}\text { Control of confounders } \\
\text { (adjustment/ } \\
\text { matching) }\end{array}$} \\
\hline & & & & $\begin{array}{c}\text { Data } \\
\text { collection }\end{array}$ & $\begin{array}{l}\text { Stage of } \\
\text { pregnancy }\end{array}$ & & & \\
\hline $\begin{array}{l}\text { Verkerk } \\
\text { et al. } 180 \\
\text { (1994) }\end{array}$ & $\begin{array}{l}\text { Case- } \\
\text { control }\end{array}$ & $\begin{array}{l}\text { Dutch } \\
\text { obstectrics study } \\
\text { (Netherlands) }\end{array}$ & Birth defects & $\begin{array}{l}\text { Medical } \\
\text { records }\end{array}$ & First quarter & 40 & 2,320 & - \\
\hline $\begin{array}{l}\text { Virtanen } \\
\text { et al. } 181 \\
\text { (2006) }\end{array}$ & $\begin{array}{l}\text { Case- } \\
\text { control }\end{array}$ & $\begin{array}{c}\text { Central } \\
\text { University } \\
\text { Hospital of Turku } \\
\text { (Finland) }\end{array}$ & Cryptorchidism & $\begin{array}{l}\text { Interview } \\
\text { and medical } \\
\text { records }\end{array}$ & Unspecified & 125 & 1,159 & Matching: sex \\
\hline $\begin{array}{l}\text { Wang } \\
\text { et al. } 182 \\
\text { (2009) }\end{array}$ & $\begin{array}{l}\text { Case- } \\
\text { control }\end{array}$ & $\begin{array}{l}\text { Study in the city } \\
\text { of Shenyang } \\
\text { (China) }\end{array}$ & $\begin{array}{c}\text { Cleft lip with } \\
\text { or without cleft } \\
\text { palate }\end{array}$ & Interview & $\begin{array}{l}\text { Pre- } \\
\text { conception } \\
\text { exposure } \\
\text { and in the } \\
\text { beginning of } \\
\text { pregnancy }\end{array}$ & 586 & 1,172 & - \\
\hline $\begin{array}{l}\text { Wasser- } \\
\text { man et } \\
\text { al. } 183 \\
(1996)\end{array}$ & $\begin{array}{l}\text { Case- } \\
\text { control }\end{array}$ & $\begin{array}{c}\text { California } \\
\text { Birth Defects } \\
\text { Monitoring } \\
\text { Program (United } \\
\text { States) }\end{array}$ & Limb reduction & $\begin{array}{l}\text { Phone } \\
\text { interview }\end{array}$ & First quarter & 178 & 481 & $\begin{array}{l}\text { Matching: month/year } \\
\text { of birth, place of birth }\end{array}$ \\
\hline $\begin{array}{l}\text { Watkins } \\
\text { et al. } 184 \\
\text { (1996) }\end{array}$ & $\begin{array}{l}\text { Case- } \\
\text { control }\end{array}$ & $\begin{array}{l}\text { Study of birth } \\
\text { defects in } \\
\text { Atlanta (United } \\
\text { States) }\end{array}$ & $\begin{array}{l}\text { Spina bifida; } \\
\text { Anencephaly }\end{array}$ & Interview & $\begin{array}{c}\text { Pre- } \\
\text { conception } \\
\text { exposure and } \\
\text { in the first } \\
\text { quarter }\end{array}$ & 307 & 2,755 & $\begin{array}{l}\text { Matching: month/year } \\
\text { of birth, place of birth, } \\
\text { race }\end{array}$ \\
\hline $\begin{array}{l}\text { Watkins } \\
\text { et al. } 185 \\
(2003)\end{array}$ & $\begin{array}{l}\text { Case- } \\
\text { control }\end{array}$ & $\begin{array}{c}\text { Atlanta Birth } \\
\text { Defects } \\
\text { Risk Factor } \\
\text { Surveillance } \\
\text { (United States) }\end{array}$ & Malformations & Interview & Unspecified & 644 & 330 & - \\
\hline $\begin{array}{l}\text { Werler } \\
\text { et al. } 186 \\
\text { (2003) }\end{array}$ & $\begin{array}{l}\text { Case- } \\
\text { control }\end{array}$ & $\begin{array}{l}29 \text { hospitals in } \\
\text { the United States } \\
\text { and Canada }\end{array}$ & $\begin{array}{l}\text { Malformations } \\
\text { (Gastroschisis and } \\
\text { intestinal atresia) }\end{array}$ & $\begin{array}{l}\text { Phone } \\
\text { interview }\end{array}$ & First quarter & 332 & 416 & $\begin{array}{c}\text { Adjusted: use of } \\
\text { vasoconstrictor drugs, } \\
\text { maternal/paternal } \\
\text { schooling, family } \\
\text { income maternal use of } \\
\text { medication, maternal } \\
\text { alcohol intake, use } \\
\text { of illicit drugs by the } \\
\text { mother, maternal age; } \\
\text { Matching: month/year } \\
\text { of birth, place of birth }\end{array}$ \\
\hline $\begin{array}{l}\text { Werler } \\
\text { et al. } 187 \\
\text { (2009) }\end{array}$ & $\begin{array}{l}\text { Case- } \\
\text { control }\end{array}$ & $\begin{array}{l}26 \text { cities in the } \\
\text { United States } \\
\text { and Canada }\end{array}$ & $\begin{array}{l}\text { Hemifacial } \\
\text { microsomia }\end{array}$ & $\begin{array}{l}\text { Phone } \\
\text { interview }\end{array}$ & First quarter & 230 & 678 & $\begin{array}{l}\text { Adjusted: maternal age, } \\
\text { maternal schooling, } \\
\text { family income, } \\
\text { parity, race, maternal } \\
\text { use of medication, } \\
\text { maternal diabetes and } \\
\text { hypertension }\end{array}$ \\
\hline $\begin{array}{l}\text { Werler } \\
\text { et al. } 188 \\
\text { (2009) }\end{array}$ & $\begin{array}{l}\text { Case- } \\
\text { control }\end{array}$ & $\begin{array}{l}\text { National } \\
\text { Birth Defects } \\
\text { Prevention Study } \\
\text { (United States) }\end{array}$ & $\begin{array}{l}\text { Transverse limb } \\
\text { reduction }\end{array}$ & $\begin{array}{l}\text { Phone } \\
\text { interview }\end{array}$ & $\begin{array}{c}\text { Pre- } \\
\text { conception } \\
\text { exposure and } \\
\text { in the first } \\
\text { quarter }\end{array}$ & 367 & 5,886 & - \\
\hline
\end{tabular}

(continues) 
Table 1 (continued)

\begin{tabular}{|c|c|c|c|c|c|c|c|c|}
\hline \multirow[t]{2}{*}{$\begin{array}{l}\text { Reference } \\
\text { (year) }\end{array}$} & \multirow[t]{2}{*}{$\begin{array}{l}\text { Type of } \\
\text { study }\end{array}$} & \multirow[t]{2}{*}{$\begin{array}{l}\text { Site/Source } \\
\text { of data }\end{array}$} & \multirow[t]{2}{*}{ Type of defect } & \multicolumn{2}{|c|}{$\begin{array}{l}\text { Exposure (maternal } \\
\text { smoking) }\end{array}$} & \multirow[t]{2}{*}{ Case } & \multirow[t]{2}{*}{ Controls } & \multirow{2}{*}{$\begin{array}{l}\text { Control of confounders } \\
\text { (adjustment/ } \\
\text { matching) }\end{array}$} \\
\hline & & & & $\begin{array}{l}\text { Data } \\
\text { collection }\end{array}$ & $\begin{array}{l}\text { Stage of } \\
\text { pregnancy }\end{array}$ & & & \\
\hline $\begin{array}{l}\text { Werler } \\
\text { et al. } 189 \\
(2009)\end{array}$ & $\begin{array}{l}\text { Case- } \\
\text { control }\end{array}$ & $\begin{array}{c}\text { National } \\
\text { Birth Defects } \\
\text { Prevention Study } \\
\text { (United States) }\end{array}$ & Gastroschisis & $\begin{array}{c}\text { Phone } \\
\text { interview }\end{array}$ & $\begin{array}{c}\text { Pre- } \\
\text { conception } \\
\text { exposure and } \\
\text { in the first } \\
\text { quarter }\end{array}$ & 514 & 3,277 & $\begin{array}{l}\text { Adjusted: maternal age, } \\
\text { maternal schooling, } \\
\text { family income, parity, } \\
\text { race, maternal use of } \\
\text { medication, place of } \\
\text { birth, maternal BMI, } \\
\text { maternal alcohol intake, } \\
\text { folic acid intake, use of } \\
\text { oral contraceptives }\end{array}$ \\
\hline $\begin{array}{l}\text { Williams } \\
\text { et al. } 14 \\
(2004)\end{array}$ & $\begin{array}{l}\text { Case- } \\
\text { control }\end{array}$ & $\begin{array}{l}\text { Atlanta Birth } \\
\text { Defects Case- } \\
\text { Control Study } \\
\text { (United States) }\end{array}$ & $\begin{array}{c}\text { Ventricular septal } \\
\text { defects }\end{array}$ & $\begin{array}{c}\text { Phone } \\
\text { interview }\end{array}$ & $\begin{array}{c}\text { Pre- } \\
\text { conception } \\
\text { exposure and } \\
\text { in the first } \\
\text { quarter }\end{array}$ & 122 & 3,029 & - \\
\hline $\begin{array}{l}\text { Wong- } \\
\text { Gibbons } \\
\text { et al. } 190 \\
\text { (2008) }\end{array}$ & $\begin{array}{l}\text { Case- } \\
\text { control }\end{array}$ & $\begin{array}{c}\text { National } \\
\text { Birth Defects } \\
\text { Prevention Study } \\
\text { (United States) }\end{array}$ & $\begin{array}{l}\text { Esophageal } \\
\text { atresia with or } \\
\text { without tracheoe- } \\
\text { sophageal fistula }\end{array}$ & $\begin{array}{c}\text { Phone } \\
\text { interview }\end{array}$ & $\begin{array}{l}\text { Pre- } \\
\text { conception } \\
\text { exposure and } \\
\text { in the first } \\
\text { quarter }\end{array}$ & 334 & 4,967 & $\begin{array}{l}\text { Adjusted: multiparity, } \\
\text { maternal age, race, } \\
\text { maternal/paternal } \\
\text { schooling, maternal } \\
\text { diabetes, infertility } \\
\text { treatment, maternal } \\
\text { alcohol intake, duration } \\
\text { of maternal smoking, } \\
\text { place of birth }\end{array}$ \\
\hline $\begin{array}{l}\text { Woods \& } \\
\text { Raju } 191 \\
\text { (2001) }\end{array}$ & Cohort & $\begin{array}{l}\text { Data of the } \\
\text { TriHealth health } \\
\text { system (United } \\
\text { States) }\end{array}$ & Malformations & Interview & Unspecified & 2,066 & 15,950 & $\begin{array}{l}\text { Adjusted: maternal age, } \\
\text { race, maternal diabetes }\end{array}$ \\
\hline $\begin{array}{l}\text { Wyszynski } \\
\& \text { Wu } 192 \\
(2002)\end{array}$ & $\begin{array}{l}\text { Case- } \\
\text { control }\end{array}$ & $\begin{array}{l}\text { Birth database } \\
\text { (United States) }\end{array}$ & Oral fissures & Database & First quarter & 2,029 & 4,050 & $\begin{array}{c}\text { Adjusted: maternal age; } \\
\text { Matching: month/year } \\
\text { of birth, place of birth, } \\
\text { sex, race }\end{array}$ \\
\hline $\begin{array}{l}\text { Yerush- } \\
\text { almy } 193 \\
(1971)\end{array}$ & Cohort & $\begin{array}{l}\text { Child Health and } \\
\text { Development } \\
\text { Studies (United } \\
\text { States) }\end{array}$ & Malformations & $\begin{array}{l}\text { Question- } \\
\text { naire }\end{array}$ & Unspecified & 1,329 & 11,754 & - \\
\hline $\begin{array}{l}\text { Yerush- } \\
\text { almy } 194 \\
(1973)\end{array}$ & Cohort & $\begin{array}{l}\text { Child Health and } \\
\text { Development } \\
\text { Studies (United } \\
\text { States) }\end{array}$ & $\begin{array}{l}\text { Congenital heart } \\
\text { disease }\end{array}$ & $\begin{array}{l}\text { Question- } \\
\text { naire }\end{array}$ & Unspecified & 115 & 14,616 & - \\
\hline $\begin{array}{l}\text { Yuan et } \\
\text { al. } 195 \\
(1995)\end{array}$ & $\begin{array}{l}\text { Case- } \\
\text { control }\end{array}$ & $\begin{array}{l}\text { Kanagawa } \\
\text { Birth Defects } \\
\text { Monitoring } \\
\text { Program (Japan) }\end{array}$ & Anal atresia & Interview & Unspecified & 84 & 176 & $\begin{array}{c}\text { Matching: maternal age, } \\
\text { sex, parity, month/year } \\
\text { of birth }\end{array}$ \\
\hline $\begin{array}{l}\text { Zeiger } \\
\text { et al. } 196 \\
\text { (2002) }\end{array}$ & $\begin{array}{l}\text { Case- } \\
\text { control }\end{array}$ & $\begin{array}{c}\text { Metropolitan } \\
\text { area of } \\
\text { Baltimore- } \\
\text { Washington } \\
\text { (United States) }\end{array}$ & $\begin{array}{l}\text { Craniosynos- } \\
\text { tosis }\end{array}$ & $\begin{array}{l}\text { Phone } \\
\text { interview }\end{array}$ & Unspecified & 42 & 182 & $\begin{array}{l}\text { Adjusted: race, sex; } \\
\text { Matching: sex }\end{array}$ \\
\hline
\end{tabular}

DES: diethylstilbestrol ; BMI: body mass index; CNS: central nervous system. 
Table 2

Association between maternal smoking during pregnancy and birth defects in children: results of the 188 studies with birth defect of any type.

\begin{tabular}{|c|c|c|c|c|}
\hline Reference (year) & Type of defect & OR & $95 \% \mathrm{Cl}$ & Weight (\%) * \\
\hline Adams et al. 18 (1989) & Conotruncal heart defect & 1.13 & $0.71-1.81$ & 0.35 \\
\hline Akre et al. 19 (1999) & Cryptorchidism & 1.19 & $1.06-1.33$ & 0.99 \\
\hline Alderman et al. 20 (1991) & Crooked foot at birth & 1.92 & $1.31-2.81$ & 0.46 \\
\hline Alderman et al. 21 (1994) & Craniosynostosis & 1.70 & $1.11-2.60$ & 0.40 \\
\hline Ananijevic-Pandey et al. 22 (1992) & General malformations & 1.58 & $0.96-2.60$ & 0.32 \\
\hline Aro et al. 23 (1983) & Limb reduction & 1.30 & $0.89-1.90$ & 0.46 \\
\hline Bailey et al. 24 (1970) & Birth defects & 0.75 & $0.43-1.32$ & 0.27 \\
\hline Batra et al. 25 (2007) & Ventricular septal defect & 0.93 & $0.83-1.04$ & 0.98 \\
\hline Beard et al. 26 (1984) & Genitourinary defect & 1.00 & $0.50-2.00$ & 0.19 \\
\hline Beaty et al. 27 (2008) & Oral fissures & 1.04 & $0.51-2.12$ & 0.19 \\
\hline Beaty et al. 28 (2001) & Oral fissures & 1.77 & $0.86-3.65$ & 0.18 \\
\hline Bell \& Lumley 29 (1989) & Birth defects & 0.80 & $0.44-1.46$ & 0.24 \\
\hline Berkowitz \& Lapinski 30 (1996) & Cryptorchidism & 1.24 & $0.59-2.61$ & 0.17 \\
\hline Biggs et al. 31 (2002) & Cryptorchidism & 1.24 & $1.11-1.38$ & 1.00 \\
\hline Bille et al. 32 (2007) & Oral fissures & 1.50 & $1.05-2.14$ & 0.50 \\
\hline Bird et al. 6 (2009) & Musculoskeletal & 1.44 & $1.04-2.00$ & 0.54 \\
\hline Bitsko et al. 33 (2007) & Birth defects & 1.61 & $1.00-2.60$ & 0.33 \\
\hline Blatter et al. 34 (1996) & Central nervous system defects & 0.95 & $0.68-1.32$ & 0.54 \\
\hline Botto et al. 35 (2001) & Heart defects & 1.11 & $0.95-1.30$ & 0.90 \\
\hline Bracken et al. 7 (1978) & Birth defects & 1.09 & $0.96-1.25$ & 0.95 \\
\hline Brouwers et al. 36 (2007) & Hypospadias & 0.90 & $0.61-1.32$ & 0.45 \\
\hline Brouwers et al. 37 (2010) & Hypospadias & 1.50 & $0.97-2.32$ & 0.39 \\
\hline Browne et al. 38 (2007) & Heart defects & 1.16 & $1.03-1.31$ & 0.98 \\
\hline Carbone et al. 39 (2007) & Cryptorchidism; hypospadias & 1.33 & $0.55-3.18$ & 0.13 \\
\hline Cardy et al. 40 (2007) & Congenital equinovarus & 1.37 & $0.72-2.61$ & 0.22 \\
\hline Carmichael et al. 42 (2003) & Cardiovascular defects and facial cleft & 1.70 & $1.35-2.14$ & 0.73 \\
\hline Carmichael \& Shaw 41 (2000) & Anencephaly & 0.81 & $0.49-1.33$ & 0.32 \\
\hline Carmichael et al. 44 (2008) & Craniosynostosis & 1.03 & $0.80-1.33$ & 0.68 \\
\hline Carmichael et al. 43 (2005) & Hypospadias & 1.00 & $0.76-1.31$ & 0.64 \\
\hline Caton et al. 45 (2008) & Hypospadias & 0.88 & $0.72-1.10$ & 0.77 \\
\hline Cedergren et al. 8 (2002) & Heart defects & 1.19 & $0.86-1.66$ & 0.54 \\
\hline Chambers et al. 46 (2007) & Gastroschisis & 1.37 & $0.63-2.96$ & 0.16 \\
\hline Chevrier et al. 47 (2008) & Oral fissures & 1.00 & $0.62-1.61$ & 0.55 \\
\hline Chew et al. 48 (1994) & Eye defects & 1.27 & $1.22-1.32$ & 1.10 \\
\hline Christensen et al. 9 (1999) & Oral fissures & 1.16 & $0.73-1.83$ & 0.37 \\
\hline Christianson 49 (1980) & Anomalies in all systems & 1.05 & $0.96-1.15$ & 1.03 \\
\hline Chung \& Myrianthopoulos 50 (1975) & Inguinal hernia & 1.45 & $1.25-1.68$ & 0.95 \\
\hline Chung et al. 51 (2000) & Cleft lip; cleft palate & 1.35 & $1.18-1.54$ & 0.92 \\
\hline Cordier et al. 52 (1992) & Major defects & 0.80 & $0.53-1.20$ & 0.42 \\
\hline Correy et al. 53 (1991) & Defects & 0.94 & $0.82-1.08$ & 0.94 \\
\hline Croen et al. 54 (2000) & Holoprosencephaly & 4.08 & $1.54-10.80$ & 0.11 \\
\hline Czeizel et al. 58 (2004) & Orofacial clefts; Congenital limb defects & 1.27 & $1.11-1.45$ & 0.95 \\
\hline Czeizel et al. 57 (1994) & Limb reduction & 1.68 & $1.26-2.24$ & 0.61 \\
\hline Czeizel \& Nagy 56 (1986) & Cleft lip; cleft palate & 1.08 & $0.86-1.36$ & 0.73 \\
\hline Czeizel \& Vitez 55 (1981) & Omphalocele & 1.14 & $0.64-2.01$ & 0.26 \\
\hline Costa et al. et al. 59 (2006) & Birth defects & 1.15 & $0.73-1.81$ & 0.36 \\
\hline Damgaard et al. 60 (2008) & Cryptorchidism & 0.88 & $0.53-1.47$ & 0.31 \\
\hline Davies et al. 61 (1986) & Cryptorchidism & 1.38 & $0.73-2.61$ & 0.22 \\
\hline De Roo et al. 10 (2003) & Oral fissures & 1.10 & $0.73-1.66$ & 0.41 \\
\hline
\end{tabular}

(continues) 
Table 2 (continued)

\begin{tabular}{|c|c|c|c|c|}
\hline Reference (year) & Type of defect & OR & $95 \% \mathrm{Cl}$ & Weight $(\%)$ * \\
\hline Dickinson et al. 11 (2008) & Crooked foot at birth & 1.39 & $1.06-1.82$ & 0.65 \\
\hline Draper et al. 62 (2008) & Gastroschisis & 1.70 & $1.11-2.61$ & 0.39 \\
\hline Erickson 63 (1991) & General malformations & 1.12 & $1.05-1.20$ & 1.07 \\
\hline Ericson et al. 64 (1979) & Central nervous system defects; orofacial clefts & 1.88 & $1.22-2.90$ & 0.39 \\
\hline Evans et al. 65 (1979) & All birth defects & 0.96 & $0.88-1.04$ & 1.04 \\
\hline Fredrick et al. 66 (1971) & Congenital heart diseases & 1.54 & $1.22-1.95$ & 0.72 \\
\hline Feldkamp et al. 12 (2008) & Gastroschisis & 2.56 & $1.75-3.75$ & 0.46 \\
\hline Felix et al. 67 (2008) & Esophageal atresia; diaphragmatic hernia & 0.58 & $0.30-1.13$ & 0.21 \\
\hline Ferencz et al. 68 (2008) & Cardiovascular defects & 1.02 & $0.92-1.13$ & 1.01 \\
\hline Garcia et al. 69 (1999) & Birth defects & 4.25 & $1.57-11.50$ & 0.10 \\
\hline Goldbaum et al. 70 (1990) & Gastroschisis & 2.00 & $1.05-3.80$ & 0.22 \\
\hline Golding \& Butler 71 (1983) & Anencephaly & 1.34 & $1.12-1.60$ & 0.85 \\
\hline Grewal et al. 72 (2008) & Defects & 0.81 & $0.57-1.17$ & 0.49 \\
\hline Haddow et al. 73 (1983) & Gastroschisis & 2.10 & $0.92-4.80$ & 0.14 \\
\hline Hakin \& Tielsch 74 (1992) & Esotropia; exotropia & 1.56 & $1.15-2.12$ & 0.58 \\
\hline Hearey et al. 75 (1984) & Central nervous system defects & 4.00 & $0.64-24.99$ & 0.03 \\
\hline Heinonen 76 (1977) & Defects & 0.94 & $0.8-1.054$ & 0.99 \\
\hline Hemminki et al. 77 (1981) & Central nervous system defects & 1.61 & $1.27-2.04$ & 0.72 \\
\hline Himmelberger et al. 78 (1978) & Defects & 1.32 & $1.14-1.53$ & 0.92 \\
\hline Honein et al. 82 (2001) & Defects & 1.25 & $1.13-1.38$ & 1.01 \\
\hline Honein et al. 83 (2007) & Oral fissures & 1.20 & $0.98-1.47$ & 0.79 \\
\hline Honein et al. 80 (2000) & Craniosynostosis & 1.92 & $1.01-3.65$ & 0.22 \\
\hline Honein \& Rasmussen 81 (2000) & Crooked foot at birth & 1.41 & $1.10-1.81$ & 0.69 \\
\hline Hoobs et al. 79 (2006) & Heart defects & 1.72 & $0.95-3.13$ & 0.25 \\
\hline Hougland et al. 84 (2006) & Gastroschisis & 2.61 & $1.49-4.57$ & 0.27 \\
\hline Jensen et al. 85 (2007) & Cryptorchidism & 1.08 & $0.84-1.39$ & 0.68 \\
\hline Johansen et al. 86 (2009) & Cleft lip; cleft palate & 1.52 & $1.21-1.91$ & 0.74 \\
\hline Jones et al. 87 (1998) & Cryptorchidism & 1.04 & $0.85-1.27$ & 0.80 \\
\hline Kallen 88 (1999) & Craniosynostosis & 1.45 & $1.12-1.87$ & 0.68 \\
\hline Kallen 89 (2000) & Defects & 1.03 & $1.00-1.06$ & 1.11 \\
\hline Kelsey e tal. 90 (1978) & Defects & 1.09 & $0.96-1.25$ & 0.70 \\
\hline Khoury et al. 91 (1989) & Cleft lip; cleft palate & 1.48 & $1.16-1.89$ & 0.43 \\
\hline Krapels et al. 92 (2006) & Cleft lip; cleft palate & 1.12 & $0.75-1.67$ & 0.41 \\
\hline Krauss et al. 93 (2003) & Microcephaly & 1.90 & $1.00-3.60$ & 0.22 \\
\hline Kricker et al. 93 (1986) & Limb reduction & 1.10 & $0.67-1.81$ & 0.32 \\
\hline Kuciene \& Dulskiene 95 (2009) & Heart defects & 1.48 & $0.82-2.67$ & 0.25 \\
\hline Kullander \& Kallen 96 (1971) & Defects & 1.14 & $0.85-1.52$ & 0.61 \\
\hline Kurahashi et al. 97 (2005) & Cryptorchidism & 1.04 & $0.50-2.12$ & 0.19 \\
\hline Kurahashi et al. 98 (2005) & Hypospadias & 1.04 & $0.24-4.45$ & 0.05 \\
\hline Lam \& Torfs 99 (2006) & Gastroschisis & 1.96 & $0.98-3.92$ & 0.20 \\
\hline Leite \& Koifman 100 (2009) & Oral fissures & 1.19 & $0.82-1.75$ & 0.43 \\
\hline Li et al. 102 (2006) & Neural tube defects & 1.44 & $0.35-5.85$ & 0.05 \\
\hline Li et al. 101 (1996) & Urinary tract defects & 2.30 & $1.18-4.49$ & 0.21 \\
\hline Lie et al. 103 (2008) & Oral fissures & 1.60 & $1.15-2.23$ & 0.53 \\
\hline Lieff et al. 104 (1999) & Defects & 1.27 & $1.10-1.46$ & 0.94 \\
\hline Linn et al. 105 (1983) & All defects & 0.93 & $0.71-1.21$ & 0.66 \\
\hline Little et al. 106 (2004) & Oral fissures & 2.00 & $1.29-3.10$ & 0.38 \\
\hline Liu et al. 107 (2009) & Heart defects & 5.13 & $0.98-26.71$ & 0.04 \\
\hline Lorente et al. 108 (2000) & Oral fissures & 1.42 & $0.92-2.20$ & 0.39 \\
\hline Lowe 109 (1959) & All defects & 1.30 & $0.57-2.99$ & 0.14 \\
\hline Lubs 110 (1973) & Major defects & 0.75 & $0.50-1.12$ & 0.43 \\
\hline
\end{tabular}

(continues) 
Table 2 (continued)

\begin{tabular}{|c|c|c|c|c|}
\hline Reference (year) & Type of defect & OR & $95 \% \mathrm{Cl}$ & Weight $(\%)$ * \\
\hline Lumley et al. 111 (1985) & All defects & 1.04 & $0.80-1.35$ & 0.67 \\
\hline MacBird et al. 112 (2009) & Omphalocele & 1.20 & $0.79-1.82$ & 0.41 \\
\hline Malik et al. 113 (2008) & Heart defects & 1.22 & $1.10-1.35$ & 1.01 \\
\hline Malloy et al. 114 (1989) & Defects & 0.98 & $0.94-1.03$ & 1.09 \\
\hline Man \& Chang 115 (2006) & Congenital digital anomaly & 1.31 & $1.18-1.45$ & 1.01 \\
\hline Mandiracioglu et al. 116 (2004) & Neural tube defects & 1.25 & $0.50-3.13$ & 0.12 \\
\hline Martinez-Frias et al. 117 (2008) & Gastroschisis & 1.81 & $0.96-3.41$ & 0.23 \\
\hline McBride et al. 118 (1991) & Cryptorchidism & 1.69 & $1.21-2.36$ & 0.53 \\
\hline McDonald et al. 119 (1992) & Birth defects & 1.07 & $0.98-1.17$ & 1.04 \\
\hline McGlynn et al. 120 (2006) & Cryptorchidism & 1.05 & $0.87-1.27$ & 0.82 \\
\hline Miller et al. 121 (2009) & Anorectal atresia & 1.15 & $0.91-1.45$ & 0.73 \\
\hline Miller et al. 122 (2010) & Holoprosencephaly & 0.90 & $0.47-1.71$ & 0.22 \\
\hline Mitchell et al. 123 (2001) & Oral fissures & 1.21 & $0.91-1.60$ & 0.62 \\
\hline Morales-Suarez-Varela et al. 124 & Birth defects & 1.10 & $1.00-1.20$ & 1.03 \\
\hline \multicolumn{5}{|l|}{$(2006)$} \\
\hline Morgana et al. 125 (2008) & Cryptorchidism & 0.71 & $0.46-1.10$ & 0.38 \\
\hline Mori et al. 126 (1992) & Cryptorchidism & 1.00 & $0.49-2.05$ & 0.18 \\
\hline Mossey et al. 127 (2007) & Oral fissures & 2.40 & $1.59-3.62$ & 0.42 \\
\hline Munoz et al. 128 (2006) & Anencephaly & 0.65 & $0.23-1.88$ & 0.09 \\
\hline Mygind et al. 129 (2002) & Birth defects & 1.19 & $0.94-1.51$ & 0.72 \\
\hline Niebyl et al. 130 (1985) & Cleft lip; cleft palate & 0.64 & $0.30-1.36$ & 0.17 \\
\hline Noorgaard et al. 131 (2009) & Hypospadias & 0.87 & $0.77-0.99$ & 0.96 \\
\hline Oddsberg et al. 132 (2008) & Esophageal atresia & 0.89 & $0.70-1.13$ & 0.71 \\
\hline Ormond et al. 133 (2009) & Hypospadias & 1.22 & $0.85-1.76$ & 0.48 \\
\hline Parikh et al. 134 (2002) & Renal agenesis & 1.49 & $0.99-2.25$ & 0.42 \\
\hline Parker et al. 135 (2009) & Crooked foot at birth & 1.53 & $1.18-1.99$ & 0.67 \\
\hline Pierik et al. 136 (2004) & Cryptorchidism; hypospadias & 1.45 & $0.92-2.29$ & 0.37 \\
\hline Porter et al. 137 (2006) & Hypospadias & 0.93 & $0.82-1.05$ & 0.97 \\
\hline Preiksa et al. 138 (2006) & Hypospadias & 1.58 & $0.94-2.65$ & 0.31 \\
\hline Queissur-Luft et al. 139 (2002) & Major birth defects & 1.00 & $0.83-1.20$ & 0.84 \\
\hline Ramirez et al. 13 (2007) & Oral fissures & 0.76 & $0.56-1.03$ & 0.58 \\
\hline Rantakallio 140 (1978) & All defects & 0.86 & $0.55-1.33$ & 0.38 \\
\hline Reefhuis et al. 141 (1998) & Crooked foot at birth & 1.21 & $1.13-1.29$ & 1.07 \\
\hline Robitaille et al. 142 (2009) & Limb reduction & 1.11 & $0.89-1.38$ & 0.76 \\
\hline Rodriguez-Pinilla et al. 143 (2008) & Hypospadias & 0.86 & $0.77-0.96$ & 1.00 \\
\hline Romitti et al. 144 (2007) & Cleft lip; cleft palate & 1.37 & $1.20-1.57$ & 0.95 \\
\hline Salemi et al. 145 (2009) & Gastroschisis & 0.97 & $0.74-1.28$ & 0.64 \\
\hline Saxen 146 (1974) & Cleft lip; cleft palate & 2.32 & $1.46-3.68$ & 0.36 \\
\hline Schmidt et al. 147 (2009) & Central nervous system defects & 0.90 & $0.73-1.10$ & 0.80 \\
\hline Seidman et al. 148 (1990) & Malformations & 1.04 & $0.89-1.21$ & 0.90 \\
\hline Shaw et al. 149 (1992) & Cardiovascular defects & 1.13 & $0.61-2.09$ & 0.24 \\
\hline Shaw et al. 150 (1996) & Neural tube defects & 0.85 & $0.61-1.18$ & 0.53 \\
\hline Shaw et al. 151 (1996) & Cleft lip with or without cleft palate & 1.55 & $1.12-2.14$ & 0.55 \\
\hline Shaw et al. 152 (1999) & Neural tube defects & 1.31 & $1.06-1.62$ & 0.78 \\
\hline Shaw et al. 153 (2000) & Multiple defects & 0.98 & $0.48-2.01$ & 0.18 \\
\hline Shi et al. 154 (2007) & Cleft lip; cleft palate & 1.28 & $1.09-1.51$ & 0.89 \\
\hline Shiono et al. 155 (1986) & Malformations & 0.90 & $0.83-0.98$ & 1.04 \\
\hline Skelly et al. 156 (2002) & Crooked foot at birth & 2.21 & $1.51-3.23$ & 0.46 \\
\hline Slickers et al. 157 (2008) & Renal agenesis or hypoplasia & 2.12 & $1.27-3.51$ & 0.32 \\
\hline Smedts et al. 158 (2009) & Heart defects & 0.81 & $0.54-1.21$ & 0.43 \\
\hline Sorensen et al. 159 (2002) & Hypertrophic pyloric stenosis & 2.00 & $1.29-3.10$ & 0.38 \\
\hline
\end{tabular}

(continues) 
Table 2 (continued)

\begin{tabular}{|c|c|c|c|c|}
\hline Reference (year) & Type of defect & OR & $95 \% \mathrm{Cl}$ & Weight $(\%)$ * \\
\hline Steinberger et al. 160 (2002) & Heart defects & 2.49 & $1.23-5.03$ & 0.19 \\
\hline Stoll et al. 161 (1997) & Musculoskeletal & 1.18 & $0.61-2.26$ & 0.22 \\
\hline Stoll et al. 162 (2001) & Anal atresia & 1.36 & $0.72-2.56$ & 0.23 \\
\hline Suarez et al. 163 (2008) & Neural tube defects & 2.65 & $1.40-5.00$ & 0.22 \\
\hline Szendrey et al. 164 (1985) & Esophageal atresia & 0.82 & $0.49-1.36$ & 0.31 \\
\hline Tamura et al. 165 (2006) & Oral fissures & 0.84 & $0.28-2.56$ & 0.08 \\
\hline Targett et al. 166 (1977) & Major malformations & 1.33 & $0.92-1.92$ & 0.48 \\
\hline Tata et al. 167 (2008) & Birth defects & 0.99 & $0.92-1.06$ & 1.06 \\
\hline The et al. 168 (2007) & Biliary atresia & 0.70 & $0.34-1.43$ & 0.19 \\
\hline Tikkanen \& Heinonen 169 (1991) & Cardiovascular defects & 1.00 & $0.78-1.27$ & 0.70 \\
\hline To \& Tang 170 (1999) & Birth defects & 1.32 & $0.94-1.85$ & 0.53 \\
\hline Torfs et al. 171 (1994) & Gastroschisis & 1.51 & $0.93-2.46$ & 0.33 \\
\hline Tornquist et al. 172 (2002) & Optic nerve hypoplasia & 1.61 & $1.08-2.40$ & 0.43 \\
\hline Torp-Pedersen et al. 173 (2010) & Strabismus & 1.26 & $1.11-1.42$ & 0.97 \\
\hline Tuohy et al. 174 (1993) & Birth defects & 1.18 & $0.85-1.63$ & 0.54 \\
\hline Underwood et al. 175 (1965) & Major malformations & 0.78 & $0.46-1.33$ & 0.29 \\
\hline van den Boogaard et al. 176 (2008) & Cleft lip & 1.57 & $0.92-2.67$ & 0.29 \\
\hline van den Eeden et al. 177 (1990) & General malformations & 1.00 & $0.91-1.10$ & 1.02 \\
\hline van Rooij et al. 179 (2002) & Spina bifida/facial cleft & 1.92 & $0.90-4.12$ & 0.17 \\
\hline van Rooij et al. 178 (2001) & Cleft lip; cleft palate & 1.12 & $0.58-2.16$ & 0.21 \\
\hline Verkerk et al. 180 (1994) & Birth defects & 1.12 & $0.59-2.11$ & 0.22 \\
\hline Virtanen et al. 181 (2006) & Cryptorchidism & 0.41 & $0.23-0.72$ & 0.26 \\
\hline Wang et al. 182 (2009) & Cleft lip; cleft palate & 1.50 & $0.52-4.34$ & 0.09 \\
\hline Wasserman et al. 183 (1996) & Limb reduction & 1.14 & $0.77-1.69$ & 0.44 \\
\hline Watkins et al. 184 (1996) & Spina bifida; anencephaly & 1.09 & $0.85-1.39$ & 0.69 \\
\hline Watkins et al. 185 (2003) & Birth defects & 1.36 & $0.96-1.93$ & 0.50 \\
\hline Werler et al. 187 (2009) & Hemifacial microsomia & 1.62 & $0.86-3.06$ & 0.22 \\
\hline Werler et al. 189 (2009) & Gastroschisis & 1.50 & $1.18-1.90$ & 0.71 \\
\hline Werler et al. 186 (2003) & Gastroschisis; intestinal atresia & 1.31 & $0.96-1.78$ & 0.57 \\
\hline Werler et al. 188 (2009) & Transverse limb reduction & 1.10 & $0.85-1.42$ & 0.68 \\
\hline Williams et al. 14 (2004) & Ventricular septal defects & 1.26 & $0.86-1.84$ & 0.46 \\
\hline Wong-Gibbons et al. 190 (2008) & Esophageal atresia; tracheoesophageal fistula & 1.68 & $0.99-2.86$ & 0.29 \\
\hline Woods \& Raju 191 (2001) & Birth defects & 1.16 & $1.02-1.32$ & 0.95 \\
\hline Wyszynski \& Wu 192 (2002) & Oral fissures & 1.12 & $0.96-1.30$ & 0.91 \\
\hline Yerushalmy 193 (1971) & Birth defects & 0.51 & $0.45-0.58$ & 0.96 \\
\hline Yerushalmy 194 (1973) & Heart defects & 0.90 & $0.61-1.34$ & 0.45 \\
\hline Yuan et al. 195 (1995) & Anal atresia & 1.32 & $0.59-2.95$ & 0.15 \\
\hline Zeiger et al. 196 (2002) & Craniosynostosis & 0.75 & $0.29-1.95$ & 0.11 \\
\hline Meta-analysis & & 1.18 & $1.14-1.22$ & 100.00 \\
\hline
\end{tabular}

95\% Cl: 95\% confidence interval; OR: odds ratio.

* Weight of each study that contributed to the final result of the meta-analysis.

$\left(\chi^{2}=12.1 ; p=0.002\right)$. Post hoc sub-group analyses were performed according to the design of the investigation, control of confounders, and size of the sample (cases). The statistically significant dose-response relation was seen in sub-groups of studies that had controlled confounder factors and in studies where the number of cases ranged between 200 and 5,000 (Table 4). The design of the investigation did not substantially affect the results of the dose-response relation.

The cumulative meta-analysis showed a statistically significant association between maternal smoking during pregnancy and birth defects in children when 40 studies published until 1990, with a total of 26,827 were included in the analysis (OR: 1.09; 95\%CI: 1.001-1.19; $\mathrm{p}=0.035$ ). The 
Figure 3

Maternal smoking during pregnancy and birth defects in children according to the body systems involved.

\begin{tabular}{|c|c|c|c|c|c|c|}
\hline Systems & Studies & Cases & & ES [OR $(95 \% \mathrm{CI})]$ & p-value & $I^{2}$ (heterogeneity) \\
\hline Cardiovascular system & 29 & 32,340 & $\rightarrow$ & $1.11(1.03-1.19)$ & 0.001 & $58.7 \%$ \\
\hline Respiratory system & 6 & 634 & & $1.11(0.93-1.32)$ & 0.18 & $0.0 \%$ \\
\hline Digestive system & 22 & 7,046 & $\longrightarrow$ & $1.18(1.07-1.30)$ & $<0.001$ & $21.7 \%$ \\
\hline Urogenital system & 45 & 31,010 & . & $1.04(0.97-1.12)$ & 0.26 & $66.8 \%$ \\
\hline Nervous system & 35 & 15,510 & . & $1.09(0.98-1.21)$ & 0.06 & $53.5 \%$ \\
\hline Musculoskeletal system & 48 & 48,876 & $\longrightarrow$ & $1.27(1.16-1.39)$ & $<0.001$ & $78.5 \%$ \\
\hline Face and neck & 53 & 35,855 & 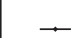 & $1.28(1.19-1.37)$ & $<0.001$ & $53.7 \%$ \\
\hline
\end{tabular}

Note: weights are of random effect analysis.

95\% $\mathrm{Cl}$ : 95\% confidence interval; ES: effect size; OR: odds ratio.

Table 3

Analysis of subgroups about the association between maternal smoking during pregnancy and birth defects in children.

\begin{tabular}{|c|c|c|c|c|}
\hline & OR & $95 \% \mathrm{Cl}$ & $12(\%)$ * & Difference among subgroups \\
\hline 1. Study design & & & & $\chi^{2}=21.2 ; p<0.00001$ \\
\hline Restrospective studies $(n=159)$ & 1.21 & $1.17-1.26$ & 69.70 & \\
\hline Prospective studies $(n=29)$ & 1.08 & $1.01-1.17$ & 90.20 & \\
\hline 2. Adjustment/matching according to the age of the mother & & & & $\chi^{2}=0.06 ; p=0.81$ \\
\hline No $(n=127)$ & 1.19 & $1.13-1.25$ & 76.50 & \\
\hline Yes $(n=61)$ & 1.18 & $1.13-1.24$ & 78.80 & \\
\hline 3. Sample size (cases) & & & & $\chi^{2}=16.5 ; p=0.0009$ \\
\hline$\leq 200(n=81)$ & 1.31 & $1.20-1.43$ & 49.60 & \\
\hline$>200-1,000(n=61)$ & 1.23 & $1.16-1.31$ & 60.90 & \\
\hline$>1,000-5,000(n=40)$ & 1.09 & $1.03-1.15$ & 89.00 & \\
\hline$>5,000(n=6)$ & 1.11 & $1.01-1.22$ & 91.30 & \\
\hline
\end{tabular}

95\% Cl: 95\% confidence interval; OR: odds ratio.

* 12 measures the heterogeneity of the results among the sutdies (> 75\% indicates significant heterogeneity).

OR $(95 \% \mathrm{CI})$ and the $\mathrm{p}$ value were respectively $1.16(1.10-1.23)$ and $<0.001$, when 87 studies published until 2000, with a total of 95,556 cases were included in the meta-analysis. The result of the meta-analysis remained almost unchanged when 101 studies (97,099 cases) published between 2001 and 2010 were included (Figure 5).

In the funnel plot (Figure 6), a slight asymmetry in the lower left corner was observed due to lack of studies, which suggested that studies with small samples demonstrating protective effects of maternal smoking against defects in children had not been published. The Egger test also showed evidence of the "small studies" effect, which suggests the presence of publication bias $(\mathrm{p}<0.001)$. 
Dose-response relation between maternal smoking and birth defects in children.

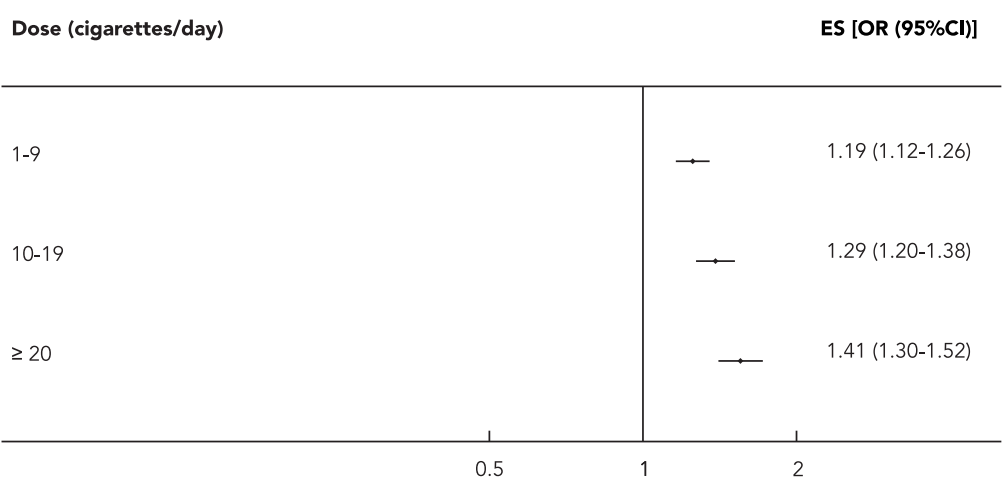

Note: weights are of random effect analysis.

Test for differences among sub-groups $\left(\chi^{2}=12 ; d f=2 ; p=0.002\right)$.

95\% Cl: 95\% confidence interval; ES: effect size; OR: odds ratio.

Table 4

Post hoc subgroup analysis amout the dose-response relation between maternal smoking during pregnancy and birth defects in children.

\begin{tabular}{|c|c|c|c|c|}
\hline & $\begin{array}{c}1-9 \text { cigarettes/day } \\
\text { OR }(95 \% \mathrm{Cl})\end{array}$ & $\begin{array}{c}10-19 \text { cigarettes/day } \\
\text { OR }(95 \% \mathrm{Cl})\end{array}$ & $\begin{array}{c}\geq 20 \text { cigarettes/day } \\
\text { OR }(95 \% \mathrm{Cl})\end{array}$ & $\begin{array}{l}\text { Difference among the } \\
3 \text { dose groups * }\end{array}$ \\
\hline \multicolumn{5}{|l|}{ 1. Study design } \\
\hline Retrospective studies $(n=49)$ & $1.25(1.18-1.33)$ & $1.31(1.22-1.39)$ & $1.47(1.33-1.61)$ & $\chi^{2}=7.95 ; p=0.002$ \\
\hline Prospective studies $(n=11)$ & $1.05(0.98-1.14)$ & $1.19(0.96-1.48)$ & $1.28(1.10-1.50)$ & $\chi^{2}=5.63 ; p=0.06$ \\
\hline \multicolumn{5}{|c|}{$\begin{array}{l}\text { 2. Adjustment/matching according to } \\
\text { the age of the mother }\end{array}$} \\
\hline No $(n=32)$ & $1.15(1.05-1.26)$ & $1.22(1.12-1.33)$ & $1.34(1.18-1.53)$ & $\chi^{2}=0.89 ; p=0.64$ \\
\hline Yes $(n=28)$ & $1.22(1.15-1.30)$ & $1.35(1.24-1.48)$ & $1.49(1.31-1.68)$ & $\chi^{2}=9.37 ; p=0.009$ \\
\hline \multicolumn{5}{|l|}{ 3. Sample size (cases) } \\
\hline$\leq 200(n=14)$ & $1.60(1.34-1.91)$ & $1.66(1.09-2.51)$ & $1.76(1.41-2.21)$ & $\chi^{2}=0.43 ; p=0.81$ \\
\hline$>200-1,000(n=28)$ & $1.21(1.10-1.34)$ & $1.39(1.26-1.54)$ & 1.45 (1.24-1.69) & $\chi^{2}=5.42 ; p=0.07$ \\
\hline$>1,000-5,000(n=14)$ & $1.10(0.93-1.30)$ & $1.19(1.09-1.31)$ & $1.42(1.25-1.61)$ & $\chi^{2}=7.14 ; p=0.03$ \\
\hline$>5,000(n=4)$ & $1.22(1.00-1.25)$ & $1.28(1.17-1.41)$ & $1.20(0.98-1.46)$ & $\chi^{2}=3.25 ; p=0.20$ \\
\hline
\end{tabular}

95\% Cl: 95\% confidence interval; OR: odds ratio.

* $p$-value $<0.10$ rather than 0.05 was considered statistically significant in the $\chi^{2}$ test due to the low statistic value, as there are only 3 dose groups.

\section{Discussion}

This systematic review with meta-analysis has shown that children of mothers who smoked during pregnancy are at a higher risk of presenting birth defects of any type. Significant associations between maternal smoking during preg- nancy and birth defects of the cardiovascular, digestive, musculoskeletal systems and of the face and neck were evidenced. Positive associations were also observed between maternal smoking and birth defects of the respiratory, nervous, and urogenital systems; however, these associations were not statistically significant. 
Cumulative meta-analysis about the association between maternal smoking during pregnancy and birth defects in children.

\begin{tabular}{|c|c|c|c|c|c|}
\hline Year & Studies & Cases & & ES [OR $(95 \% \mathrm{Cl})]$ & p-value \\
\hline 1959-1979 & 18 & 11,611 & & $1.08(0.91-1.29)$ & 0.34 \\
\hline Until 1990 & 40 & 36,827 & & $1.09(1.00-1.19)$ & 0.035 \\
\hline Until 2000 & 87 & 95,556 & $\rightarrow$ & $1.16(1.10-1.23)$ & $<0.001$ \\
\hline Until 2010 & 188 & 192,655 & $\leftarrow$ & $1.18(1.13-1.23)$ & $<0.001$ \\
\hline & & $\frac{1}{0.5}$ & & $\frac{1}{2}$ & \\
\hline
\end{tabular}

Note: weights are of random effect analysis.

95\% Cl: 95\% confidence interval; ES: effect size; OR: odds ratio.

Figure 6

Funnel plot.

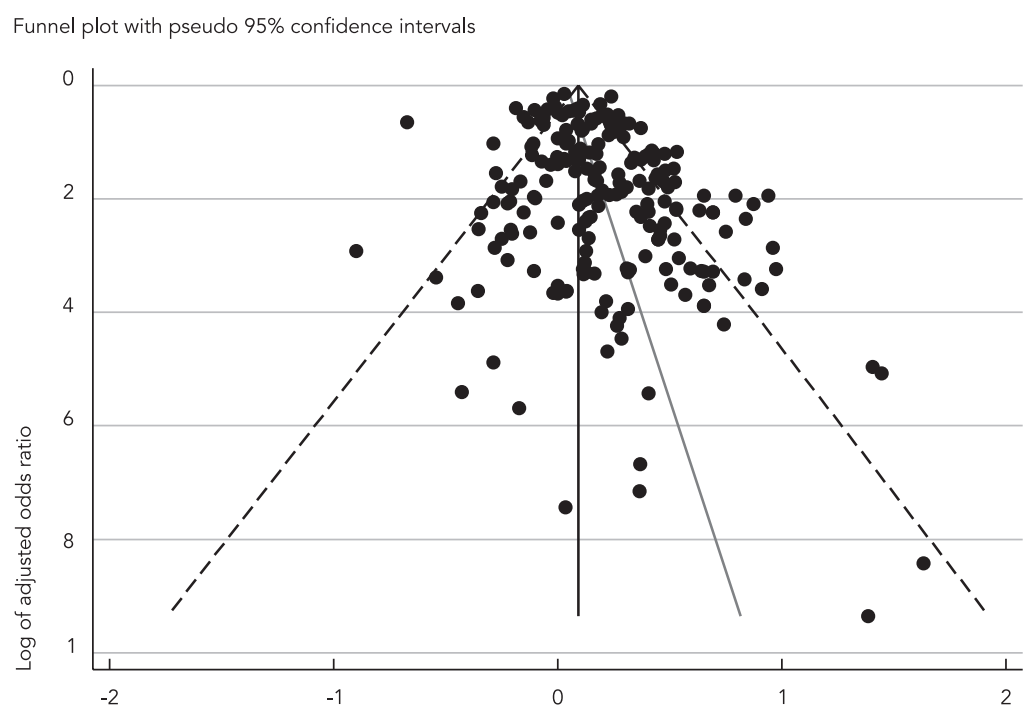

In this systematic review a statistically significant dose-response relation was alsou found between maternal smoking during pregnancy and the risk of birth defects in children; this means, the higher the number of cigarettes a day smoked by the mother, the higher the risk of having babies with some type of birth defects. It was also observed that all the three daily doses of 
cigarette-smoking were significantly associated with higher risk of birth defects compared to non-smoking, suggesting that the regular use of cigarettes by the pregnant woman, even in small amounts, may cause adverse impact in the development of the fetus.

The mechanisms of action of tobacco in the increase of abnormalities in babies are not accurately understood. It is believed that the vasoconstrictor effect of nicotine may reduce the uterine and placental blood flow 197. Carbon monoxide binds to the hemoglobin in such a way that less oxygen is available for the placenta. In addition, the endothelial injury caused by tobacco increases the rupture of blood vessels from neovascularization of the placenta, leading to a decrease in the blood flow to the fetus, causing hypoxia which will likely result in abnormal fetal morphogenesis 198. Therefore, exposure to toxins in tandem with hypoxia and cellular ischemia results in abnormal cellular proliferation.

Approximately one third of Brazilian adults were smokers by the end of the 1990s; there was, however, a reduction of about $50 \%$ (from $34 \%$ to $18.2 \%$ ) in the prevalence of smokers in this population between 1989 and 2008 199. A number of factors account for this reduction, including antitobacco policies and availability of smoking-cessation treatments. Smoking during pregnancy is of particular concern, as it is associated with many maternal-fetal outcomes, such as low-weight at birth, premature deliveries, perinatal deaths, and birth defects 200,201. In countries such as the United States and Canada, where anti-tobacco governmental policies are aggressive, and strong investments are made to control smoking during pregnancy, the prevalence of maternal smoking during pregnancy is currently around 10 to $12 \%$ 202,203. A recent study carried out in nine countries, including Latin America (Argentina, Brazil, Ecuador, Guatemala and Uruguay), Asia (India and Pakistan), and Africa (Democratic Republic of Congo and Zambia) showed higher prevalence of maternal smoking during pregnancy in Uruguay (18.3\%), followed by Argentina (10.3\%) and Brazil (6.1\%) 204. However, some local studies made in Brazil have shown a prevalence of active smoking of around $20 \%$ among pregnant women 201,205 , a proportion much higher than the reported in this international multicentric study. These data point the need for yet stronger actions against tobacco-use during pregnancy in Latin America, including Brazil.

There are a number of resources available to facilitate smoking cessation, such as anti-smoking patches, and anti-anxiety agents like bupropion 197 . These may be used prior to the patient become pregnant. For this reason, we stress the importance of pre-pregnancy counseling.
A systematic review has also shown an association between maternal smoking during pregnancy and birth defects in children 5 . Compared to that review, this one has included 20 additional studies $6,7,8,9,10,11,12,13,14,24,43,79,83,95,99,102,103,122$, 125,188 that have added about 10,000 cases of defects, and 800,000 of controls. Another difference between the two reviews is that 19 studies about abdominal wall defects were included in the meta-analysis of the gastro-intestinal system in the previous review, whereas these defects were classified as pertaining to the musculoskeletal system in this review. Despite these methodological differences, the results of these two reviews were similar in regards to the association between maternal smoking during pregnancy and defects of the cardiovascular, respiratory, digestive, nervous, urogenital and musculoskeletal systems. The meta-analysis from the previous review included 38 studies in which all defects were combined together did not show significant association between maternal smoking and birth defects (OR: 1.01; 95\%CI: 0.96-1.07). The metaanalysis of the current review has included all the 188 studies in which the defects were both combined or of a particular type, and evidenced a statistically significant association between maternal smoking during pregnancy and the risk of any type of birth defect in children (OR: 1.18; 95\%CI: 1.14-1.22).

The cumulative meta-analysis of this current review shows that there was already evidence of the association between maternal smoking during pregnancy and birth defects in children by analyzing the results of 40 studies published until 1990 that included a total of 26,827 cases of defects $(\mathrm{OR}=1.09 ; \mathrm{p}=0.035)$. The evidence of the association became more robust with the results of 87 studies published until 2000, with a total of 95,556 cases (OR $=1.16$; $\mathrm{p}<0.0001)$. Between 2000 and 2010, more than 100 studies were carried out with some 100,000 cases of defects; the inclusion of these studies, however, did not change significantly the results of the meta-analysis. These data indicate that findings about the association between maternal smoking during pregnancy and birth defects in children are convincing, and there is no need of further epidemiological studies to investigate this association.

Some methodological studies should be considered in interpreting the results of this systematic review. The heterogeneity of the results of the studies included in this review is to be expected, considering the differences in the research design, type of defect and method used for diagnosis, definition of maternal smoking and control of the effect of confounders. Some of the confounding factors were investigated 
through subgroup analyses, whose results suggest that the type of defect, the design of the research and the size of the sample are possible causes of heterogeneity. The quality of the studies included was not assessed individually due to limitations of the tools currently available 206; however, the potential influences of the methodological aspects of the studies (research design, sample size, control of the effect of confounders, and definition of exposure) in the results of the meta-analysis were investigated through the sub-group analyses. The influence of passive smoking in the association between maternal smoking during pregnancy and birth defects in children was not investigated due to lack of information in most of the original studies. Future studies should address this issue. The funnel plot and the Egger test suggest the presence of publication bias, due to non-publication of small studies that would demonstrate the protective effect of maternal smoking against defects in children. We believe that the number of this type of study is limited, and the lack of data from these studies does not significantly affect the results of the meta-analysis.

We conclude, from this systematic review with meta-analysis, that maternal smoking during pregnancy is associated with a higher risk of birth defects in children, and that this is a dosedependent association.

\section{Resumen}

Esta revisión sistemática se encargó de investigar la asociación entre el tabaquismo materno durante el embarazo y las malformaciones congénitas en los niños. Se realizó una búsqueda electrónica de los estudios de observación en las bases de datos de ovid MEDLINE (1950 hasta abril de 2010), LILACS y SciELO. 188 estudios con 13.564.914 participantes se incluyeron en esta revisión. Se encontraron asociaciones positivas significativas entre el tabaquismo materno y malformaciones de los sistemas: cardiovascular (OR: 1,11; IC95\%: 1.03-1.19), digestivo (OR: 1,18; IC95\%: 1,07-1,30), musculoesqueléticos (OR: 1,27; IC95\%: 1,16-1,39) y de cara y cuello (OR: 1,28; IC95\%: 1,19-1,37). La fuerza de la asociación entre el tabaquismo materno y los defectos de nacimiento, medidos por el OR (IC95\%) está significativamente relacionada con la cantidad de cigarrillos fumados diariamente $\left(\chi^{2}=12,1 ; p=0,002\right)$. Llegamos a la conclusión de que el tabaquismo materno durante el embarazo se asocia con un mayor riesgo de malformaciones congénitas en los niños y esta asociación es dosis-dependiente.

Hábito de Fumar; Embarazo; Anomalias Congénitas

\section{Contributors}

D. Nicoletti designed the investigation project and the writing of the article; she also participated in the selection and evaluation of the studies, extraction of data and interpretation of results. L. D. Appel, P. Siedersberger Neto and G. W. Guimarães participated in the selection and evaluation of the studies and the extraction of data; they conducted a critical review and approved the final version of the article. L. Zhang was responsible for the idea of the investigation and for data analysis and interpretation; he provided guidance in the design of the project and the writing of the article, and approved the final version of the article. 


\section{References}

1. Horovitz DDG, Llerena Jr. JC, Mattos RA. Atenção aos defeitos congênitos no Brasil: panorama atual. Cad Saúde Pública 2005; 21:1055-64.

2. Powell-Griner E, Woolbright A. Trends in infant deaths from congenital anomalies: results from England and Wales, Scotland, Sweden and the United States. Int J Epidemiol 1990; 19:391-8.

3. Neto PS, Zhang L, Nicoletti D, Munchen FB. Mortalidade infantil por malformações congênitas no Brasil. Rev AMRIGS 2012; 56:129-32.

4. Stillerman KP, Mattison DR, Giudice LC, Woodruff TJ. Environmental exposures and adverse pregnancy outcomes: a review of the science. Reprod Sci 2008; 15:631-50.

5. Hackshaw A, Rodeck C, Boniface S. Maternal smoking in pregnancy and birth defects: a systematic review based on 173687 malformed cases and 11.7 million controls. Hum Reprod Updat 2011; 17:589-604.

6. Bird TM, Robbins JM, Druschel C, Cleves MA, Yang S, Hobbs CA. Demographic and environmental risk factors for gastroschisis and omphalocele in the National Birth Defects Prevention Study. J Pediatr Surg 2009; 44:1546-51.

7. Bracken MB, Holford TR, White C, Kelsey JL. Role of oral contraception in congenital malformations of offspring. Int J Epidemiol 1978; 7:309-17.

8. Cedergren MI, Selbing AJ, Källén BAJ. Risk factors for cardiovascular malformation - a study based on prospectively collected data. Scan J Work Environ Health 2002; 28:12-7.

9. Christensen K, Olsen J, Norgaard-Pedersen B, Basso O, Stovring H, Milhollin-Johnson L, et al. Oral clefts, transforming growth factor alpha gene variants, and maternal smoking: a population-based case-control study in Denmark, 1991-1994. Am J Epidemiol 1999; 149:248-55.

10. DeRoo LA, Gaudino JA, Edmonds LD. Orofacial cleft malformations: associations with maternal and infant characteristics in Washington state. Birth Defects Res A Clin Mol Teratol 2003; 67: 637-42.

11. Dickinson KC, Meyer RE, Kotch J. Maternal smoking and the risk for clubfoot in infants. Birth Defects Res A Clin Mol Teratol 2008; 82:86-91.

12. Feldkamp ML, Alder SC, Carey JC. A case control population-based study investigating smoking as a risk factor for gastroschisis in Utah, 1997-2005. Birth Defects Res A Clin Mol Teratol 2008; 82: 768-75.

13. Ramirez D, Lammer EJ, Iovannisci DM, Laurent C, Finnell RH, Shaw GM. Maternal smoking during early pregnancy, GSTP1 and EPHX1 variants, and risk of isolated orofacial clefts. Cleft Palate Craniofac J 2007; 44:366-73.

14. Williams LJ, Correa A, Rasmussen S. Maternal lifestyle factors and risk for ventricular septal defects. Birth Defects Res A Clin Mol Teratol 2004; 70:59-64.

15. Centro Colaborador da OMS para a Classificação de Doenças em Português. Classificação estatística internacional de doenças e problemas relacionados à saúde. 10a revisão. http://www.datasus. gov.br/cid10/V2008/cid10.htm (accessed on 20/ Apr/2010).
16. Stroup DF, Berlin JA, Morton SC, Olkin I, Williamson GD, Rennie D, et al. Meta-analysis of observational studies in epidemiology: a proposal for reporting. JAMA 2000; 283:2008-12.

17. Higgins JPT, Thompson SG, Deeks JJ, Altman DG. Measuring inconsistency in meta-analysis. BMJ 2003; 327:557-60.

18. Adams MM, Mulinare J, Dooley K. Risk factors for conotruncal cardiac defects in Atlanta. J Am Coll Cardiol 1989; 14:432-42.

19. Akre O, Lipworth L, Cnattingius S, Sparen P, Ekbom A. Risk factor patterns for cryptorchidism and hypospadias. Epidemiology 1999; 10:364-9.

20. Alderman BW, Takahashi ER, LeMier MK. Risk indicators for talipes equinovarus in Washington State, 1987-1989. Epidemiology 1991; 2:289-92.

21. Alderman BW, Bradley CM, Greene C, Fernbach SK, Baron AE. Increased risk of craniosynostosis with maternal cigarette smoking during pregnancy. Teratology 1994; 50:13-8.

22. Ananijevic-Pandey J, Jarebinski M, Kastratovic B, Vlajinac H, Radojkovic Z, Brankovic D. Case-control study of congenital malformations. Eur J Epidemiol 1992; 8:871-4.

23. Aro T. Maternal diseases, alcohol consumption and smoking during pregnancy associated with reduction limb defects. Early Hum Dev 1983; 9: 49-57.

24. Bailey RR. The effect of maternal smoking on the infant birth weight. N Z Med J 1970; 71:293-4.

25. Batra M, Heike CL, Phillips RC, Weiss NS. Geographic and occupational risk factors for ventricular septal defects: Washington State, 1987-2003. Arch Pediatr Adolesc Med 2007; 161:89-95.

26. Beard CM, Melton LJ, O'Fallon WM, Noller KL, Benson RC. Cryptorchism and maternal estrogen exposure. Am J Epidemiol 1984; 120:707-16.

27. Beaty TH, Maestri NE, Hetmanski JB, Wyszynski DF, Vanderkolk CA, Simpson JC, et al. Testing for interaction between maternal smoking and TGFA genotype among oral cleft cases born in Maryland 1992-1996. Cleft Palate Craniofac J 1997; 34: 447-54.

28. Beaty TH, Wang H, Hetmanski JB, Fan YT, Zeiger JS, Liang KY, et al. A case-control study of nonsyndromic oral clefts in Maryland. Ann Epidemiol 2001; 11:434-42.

29. Bell R, Lumley J. Alcohol consumption, cigarette smoking and fetal outcome in Victoria, 1985. Community Health Stud 1989; 13:484-91.

30. Berkowitz GS, Lapinski RH. Risk factors for cryptorchidism: a nested case-control study. Paediatr Perinat Epidemiol 1996; 10:39-51.

31. Biggs ML, Baer A, Critchlow CW. Maternal, delivery, and perinatal characteristics associated with cryptorchidism: a population-based case-control study among births in Washington State. Epidemiology 2002; 13:197-204.

32. Bille C, Olsen J, Vach W, Knudsen VK, Olsen SF, Rasmussen $\mathrm{K}$, et al. Oral clefts and life style factors: a case-cohort study based on prospective Danish data. Eur J Epidemiol 2007; 22:173-81. 
33. Bitsko RH, Reefhuis J, Romitti PA, Moore CA, Honein MA. Periconceptional consumption of vitamins containing folic acid and risk for multiple congenital anomalies. Am J Med Genet A 2007; 143A:2397-405.

34. Blatter BM, Roeleveld N, Zielhuis GA, Gabreels FJ, Verbeek AL. Maternal occupational exposure during pregnancy and the risk of spina bifida. Occup Environ Med 1996; 53:80-6.

35. Botto LD, Lynberg MC, Erickson JD. Congenital heart defects, maternal febrile illness, and multivitamin use: a population-based study. Epidemiology 2001; 12:485-90.

36. Brouwers MM, Feitz WF, Roelofs LA, Kiemeney LA, de Gier RP, Roeleveld N. Risk factors for hypospadias. Eur J Pediatr 2007; 166:671-8.

37. Brouwers MM, van der Zanden LF, de Gier RP, Barten EJ, Zielhuis GA, Feitz WF, et al. Hypospadias: risk factor patterns and different phenotypes. BJU Int 2010; 105:254-62.

38. Browne ML, Bell EM, Druschel CM, Gensburg LJ, Mitchell AA, Lin AE, et al. Maternal caffeine consuption and risk of cardiovascular malformations. Birth Defects Res A Clin Mol Teratol 2007; 79: 533-43.

39. Carbone P, Giordano F, Nori F, Mantovani A, Taruscio D, Lauria L, et al. The possible role of endocrine disrupting chemicals in the aetiology of cryptorchidism and hypospadias: a populationbased case-control study in rural Sicily. Int J Androl 2007; 30:3-13.

40. Cardy AH, Barker S, Chesney D, Sharp L, Maffulli N, Miedzybrodzka Z. Pedigree analysis and epidemiological features of idiopathic congenital talipes equinovarus in the United Kingdom: a case-control study. BMC Musculoskelet Disord 2007; 8:62.

41. Carmichael SL, Shaw GM. Maternal life event stress and congenital anomalies. Epidemiology 2000; 11:30-5.

42. Carmichael SL, Nelson V, Shaw GM, Wasserman CR, Croen LA. Socio-economic status and risk of conotruncal heart defects and orofacial clefts. Paediatr Perinat Epidemiol 2003; 17:264-71.

43. Carmichael SL, Shaw GM, Laurent C, Lammer EJ, Olney RS. Hypospadias and maternal exposures to cigarette smoke. Pediatr Perinat Epidemiol 2005; 19:406-12.

44. Carmichael SL, Ma C, Rasmussen SA, Honein MA, Lammer EJ, Shaw GM. Craniosynostosis and maternal smoking. Birth Defects Res A Clin Mol Teratol 2008; 82:78-85.

45. Caton AR, Bell EM, Druschel CM, Werler MM, Mitchell AA, Browne ML, et al. Maternal hypertension, antihypertensive medication use, and the risk of severe hypospadias. Birth Defects Res A Clin Mol Teratol 2008; 82:34-40.

46. Chambers CD, Chen BH, Kalla K, Jernigan L, Jones KL. Novel risk factor in gastroschisis: change of paternity. Am J Med Genet A 2007; 143A:653-9.

47. Chevrier C, Bahuau M, Perret C, Iovannisci DM, Nelva A, Herman C, et al. Genetic susceptibilities in the association between maternal exposure to tobacco smoke and the risk of nonsyndromic oral cleft. Am J Med Genet A 2008; 146A:2396-406.
48. Chew E, Remaley NA, Tamboli A, Zhao J, Podgor MJ, Klebanoff M. Risk factors for esotropia and exotropia. Arch Ophthalmol 1994; 112:1349-55.

49. Christianson RE. The relationship between maternal smoking and the incidence of congenital anomalies. Am J Epidemiol 1980; 112:684-95.

50. Chung CS, Myrianthopoulos NC. Factors affecting risks of congenital malformations. I. Analysis of epidemiologic factors in congenital malformations. Report from the Collaborative Perinatal Project. Birth Defects Orig Artic Ser 1975; 11:1-22.

51. Chung KC, Kowalski CP, Kim HM, Buchman SR. Maternal cigarette smoking during pregnancy and the risk of having a child with cleft lip/palate. Plast Reconstr Surg 2000; 105:485-91.

52. Cordier S, Ha MC, Ayme S, Goujard J. Maternal occupational exposure and congenital malformations. Scand J Work Environ Health 1992; 18:11-7.

53. Correy JF, Newman NM, Collins JA, Burrows EA, Burrows RF, Curran JT. Use of prescription drugs in the first trimester and congenital malformations. Aust N Z J Obstet Gynaecol 1991; 31:340-4.

54. Croen LA, Shaw GM, Lammer EJ. Risk factors for cytogenetically normal holoprosencephaly in California: a population-based case-control study. Am J Med Genet 2000; 90:320-5.

55. Czeizel A, Vitez M. Etiological study of omphalocele. Hum Genet 1981; 58:390-5

56. Czeizel A, Nagy E. A recent aetiological study on facial clefting in Hungary. Acta Paediatr Hung 1986; 27:145-66

57. Czeizel AE, Kodaj I, Lenz W. Smoking during pregnancy and congenital limb deficiency. BMJ 1994; 308:1473-6.

58. Czeizel AE, Petik D, Puho E. Smoking and alcohol drinking during pregnancy. The reliability of retrospective maternal self-reported information. Cent Eur J Public Health 2004; 12:179-83.

59. Costa CMS, Gama SGN, Leal MC. Congenital malformations in Rio de Janeiro, Brazil: prevalence and associated factors. Cad Saúde Pública 2006; 22:2423-31.

60. Damgaard IN, Jensen TK; Nordic Cryptorchidism Study Group; Petersen JH, Skakkebaek NE, Toppari J, et al. Risk factors for congenital cryptorchidism in a prospective birth cohort study. PLoS One 2008; 3:e3051.

61. Davies TW, Williams DR, Whitaker RH. Risk factors for undescended testis. Int J Epidemiol 1986; 15:197-201.

62. Draper ES, Rankin J, Tonks A, Boyd P, Wellesley D, Tucker D, et al. Recreational drug use: a major risk factor for gastroschisis? Am J Epidemiol 2008; 167:485-91.

63. Erickson JD. Risk factors for birth defects: data from the Atlanta Birth Defects Case-Control Study. Teratology 1991; 43:41-51.

64. Ericson A, Kallen B, Westerholm P. Cigarette smoking as an etiologic factor in cleft lip and palate. Am J Obstet Gynecol 1979; 135:348-51.

65. Evans DR, Newcombe RG, Campbell H. Maternal smoking habits and congenital malformations: a population study. Br Med J 1979; 2:171-3.

66. Fedrick J, Alberman ED, Goldstein H. Possible teratogenic effect of cigarette smoking. Nature 1971; 231:529-30. 
67. Felix JF, van Dooren MF, Klaassens M, Hop WC, Torfs CP, Tibboel D. Environmental factors in the etiology of esophageal atresia and congenital diaphragmatic hernia: results of a case-control study. Birth Defects Res A Clin Mol Teratol 2008; 82: 98-105.

68. Ferencz C, Loffredo CA, Correa-Villasenor A. Genetic and environmental risk factors of major cardiovascular malformations: The Baltimore-Washington Infant Study 1981-1989. Armonk: Futura Publishing Co.; 1997.

69. Garcia AM, Fletcher T, Benavides FG, Orts E. Parental agricultural work and selected congenital malformations. Am J Epidemiol 1999; 149:64-74.

70. Goldbaum G, Daling J, Milham S. Risk factors for gastroschisis. Teratology 1990; 42:397-403.

71. Golding J, Butler NR. Maternal smoking and anencephaly. Br Med J (Clin Res Ed) 1983; 287:533-4

72. Grewal J, Carmichael SL, Ma C, Lammer EJ, Shaw GM. Maternal periconceptional smoking and alcohol consumption and risk for select congenital anomalies. Birth Defects Res A Clin Mol Teratol 2008; 82:519-26.

73. Haddow JE, Palomaki GE, Holman MS. Young maternal age and smoking during pregnancy as risk factors for gastroschisis. Teratology 1993; 47:225-8.

74. Hakim RB, Tielsch JM. Maternal cigarette smoking during pregnancy. A risk factor for childhood strabismus. Arch Ophthalmol 1992; 110:1459-62.

75. Hearey CD, Harris JA, Usatin MS, Epstein DM, Ury HK, Neutra RR. Investigation of a cluster of anencephaly and spina bifida. Am J Epidemiol 1984; 120:559-64.

76. Heinonen OP. Birth defects and drugs in pregnancy. Littleton: Publishing Sciences Group, Inc.; 1977.

77. Hemminki K, Mutanen P, Saloniemi I, Luoma K. Congenital malformations and maternal occupation in Finland: multivariate analysis. J Epidemiol Community Health 1981; 35:5-10.

78. Himmelberger DU, Brown Jr. BW, Cohen EN. Cigarette smoking during pregnancy and the occurrence of spontaneous abortion and congenital abnormality. Am J Epidemiol 1978; 108:470-9.

79. Hobbs CA, James SJ, Jernigan S, Melnyk S, Lu Y, Malik S, et al. Congenital heart defects, maternal homocysteine smoking, and the $677 \mathrm{C}>\mathrm{T}$ polymorphism in the methylenetetrahydroflate reductase gene: evaluating gene-environment interactions. Am J Obstet Gynecol 2006; 194:218-24.

80. Honein MA, Paulozzi LJ, Moore CA. Family history, maternal smoking, and clubfoot: an indication of a gene-environment interaction. Am J Epidemiol 2000; 152:658-65.

81. Honein MA, Rasmussen SA. Further evidence for an association between maternal smoking and craniosynostosis. Teratology 2000; 62:145-6.

82. Honein MA, Paulozzi LJ, Watkins ML. Maternal smoking and birth defects: validity of birth certificate data for effect estimation. Public Health Rep 2001; 116:327-35.

83. Honein MA, Rasmussen SA, Reefhuis J, Romitti PA, Lammer EJ, Sun L, et al. Maternal smoking and environmental tobacco smoke exposure and the risk of orofacial clefts. Epidemiology 2007; 18:226-33.
84. Hougland KT, Hanna AM, Meyers R, Null D. Increasing prevalence of gastroschisis in Utah. J Pediatr Surg 2005; 40:535-40.

85. Jensen MS, Toft G, Thulstrup AM, Bonde JP, Olsen J. Cryptorchidism according to maternal gestational smoking. Epidemiology 2007; 18:220-5.

86. Johansen AM, Wilcox AJ, Lie RT, Andersen LF, Drevon CA. Maternal consumption of coffee and caffeine-containing beverages and oral clefts: a population-based case-control study in Norway. Am J Epidemiol 2009; 169:1216-22.

87. Jones ME, Swerdlow AJ, Griffith M, Goldacre MJ. Prenatal risk factors for cryptorchidism: a record linkage study. Paediatr Perinat Epidemiol 1998; 12:383-96

88. Kallen K. Maternal smoking and craniosynostosis. Teratology 1999; 60:146-50.

89. Kallen K. Multiple malformations and maternal smoking. Paediatr Perinat Epidemiol 2000; 14: 227-33.

90. Kelsey JL, Dwyer T, Holford TR, Bracken MB. Maternal smoking and congenital malformations: an epidemiological study. J Epidemiol Community Health 1978; 32:102-7.

91. Khoury MJ, Gomez-Farias M, Mulinare J. Does maternal cigarette smoking during pregnancy cause cleft lip and palate in offspring? Am J Dis Child 1989; 143:333-7.

92. Krapels IP, Zielhuis GA, Vroom F, de Jong-van den Berg LT, Kuijpers-Jagtman AM, van der Molen AB, et al. Periconceptional health and lifestyle factors of both parents affect the risk of live-born children with orofacial clefts. Birth Defects Res A Clin Mol Teratol 2006; 76:613-20.

93. Krauss MJ, Morrissey AE, Winn HN, Amon E, Leet TL. Microcephaly: an epidemiologic analysis. Am J Obstet Gynecol 2003; 188:1484-9.

94. Kricker A, Elliott JW, Forrest JM, McCredie J. Congenital limb reduction deformities and use of oral contraceptives. Am J Obstet Gynecol 1986; 155:1072-8.

95. Kuciene R, Dulskiene V. Maternal socioeconomic and lifestyle factors during pregnancy and the risk of congenital heart defects. Medicina (Kaunas) 2009; 45:904-9.

96. Kullander S, Kallen B. A prospective study of smoking and pregnancy. Acta Obstet Gynecol Scand 1971; 50:83-94.

97. Kurahashi N, Kasai S, Shibata T, Kakizaki H, Nonomura K, Sata F, et al. Parental and neonatal risk factors for cryptorchidism. Med Sci Monit 2005; 11:CR274-83.

98. Kurahashi N, Sata F, Kasai S, Shibata T, Moriya K, Yamada $\mathrm{H}$, et al. Maternal genetic polymorphisms in CYP1A1, GSTM1 and GSTT1 and the risk of hypospadias. Mol Hum Reprod 2005; 11:93-8.

99. Lam PK, Torfs CP. Interaction between maternal smoking and malnutrition in infant risk of gastroschisis. Birth Defects Res A Clin Mol Teratol 2006; 76:182-6.

100. Leite IC, Koifman S. Oral clefts, consanguinity, parental tobacco and alcohol use: a case-control study in Rio de Janeiro, Brazil. Pesqui Odontol Bras 2009; 23:31-7. 
101. Li DK, Mueller BA, Hickok DE, Daling JR, Fantel AG, Checkoway H, et al. Maternal smoking during pregnancy and the risk of congenital urinary tract anomalies. Am J Public Health 1996; 86: 249-53.

102. Li Z, Ren A, Zhang L, Guo Z, Li Z. A populationbased case-control study of risk factors for neural tube defects in four high-prevalence areas of Shanxi province, China. Paediatr Perinat Epidemiol 2006; 20:43-53.

103. Lie RT, Wilcox AJ, Taylor J, Gjessing HK, Saugstad OD, Aabyholm F, et al. Maternal smoking and oral clefts. Epidemiology 2008; 19:606-15.

104. Lieff S, Olshan AF, Werler M, Strauss RP, Smith J, Mitchell A. Maternal cigarette smoking during pregnancy and risk of oral clefts in newborns. Am J Epidemiol 1999; 150:683-94.

105. Linn S, Schoenbaum SC, Monson RR, Rosner B, Stubblefield PG, Ryan KJ. Lack of association between contraceptive usage and congenital malformations in offspring. Am J Obstet Gynecol 1983; 147:923-8.

106. Little J, Cardy A, Arslan MT, Gilmour M, Mossey PA. Smoking and orofacial clefts: a United Kingdom-based case-control study. Cleft Palate Craniofac J 2004; 41:381-6.

107. Liu S, Liu J, Tang J, Ji J, Chen J, Liu C. Environmental risk factors for congenital heart disease in the Shandong Peninsula, China: a hospitalbased case-control study. J Epidemiol 2009; 19:122-30.

108. Lorente C, Cordier S, Goujard J, Aymé S, Bianchi F, Calzolari E, et al. Tobacco and alcohol use during pregnancy and risk of oral clefts. Am J Public Health 2000; 90:415-9.

109. Lowe CR. Effect of mothers' smoking habits on birth weight of their children. Br Med J 1959; 2:673-6.

110. Lubs ML. Racial differences in maternal smoking effects on the newborn infant. Am J Obstet Gynecol 1973; 115:66-76.

111. Lumley J, Correy JF, Newman NM, Curran JT. Cigarette smoking, alcohol consumption and fetal outcome in Tasmania 1981-82. Aust N Z J Obstet Gynaecol 1985; 25:33-40.

112. MacBird T, Robbins JM, Druschel C, Cleves MA, Yang S, Hobbs CA. Demographic and environmental risk factors for gastroschisis and omphalocele in the National Birth Defects Prevention Study. J Pediatr Surg 2009; 44:1546-51.

113. Malik S, Cleves MA, Honein MA, Romitti PA, Botto LD, Yang S, et al. Maternal smoking and congenital heart defects. Pediatrics 2008; 121:e810-6.

114. Malloy MH, Kleinman JC, Bakewell JM, Schramm WF, Land GH. Maternal smoking during pregnancy: no association with congenital malformations in Missouri 1980-83. Am J Public Health 1989; 79:1243-6.

115. Man LX, Chang B. Maternal cigarette smoking during pregnancy increases the risk of having a child with a congenital digital anomaly. Plast Reconst Surg 2006; 117:301-8.

116. Mandiracioglu A, Ulman I, Luleci E, Ulman C. The incidence and risk factors of neural tube defects in Izmir, Turkey: a nested case-control study. Turk J Pediatr 2004; 46:214-20.
117. Martinez-Frias ML, Rodriguez-Pinilla E, Prieto L. Prenatal exposure to salicylates and gastroschisis: a case-control study. Teratology 1997; 56: 241-3.

118. McBride ML, van den Steen N, Lamb CW, Gallagher RP. Maternal and gestational factors in cryptorchidism. Int J Epidemiol 1991; 20:964-70.

119. McDonald AD, Armstrong BG, Sloan M. Cigarette, alcohol, and coffee consumption and congenital defects. Am J Public Health 1992; 82:91-3.

120. McGlynn KA, Graubard BI, Klebanoff MA, Longnecker MP. Risk factors for cryptorchism among populations at differing risks of testicular cancer. Int J Epidemiol 2006; 35:787-95.

121. Miller EA, Manning SE, Rasmussen SA, Reefhuis J, Honein MA; National Birth Defects Prevention Study. Maternal exposure to tobacco smoke, alcohol and caffeine, and risk of anorectal atresia: National Birth Defects Prevention Study 19972003. Paediatr Perinat Epidemiol 2009; 23:9-17.

122. Miller EA, Rasmussen SA, Siega-Riz AM, Frías JL, Honein MA. Risk factors for non-syndromic holoprosencephaly in the national birth defects prevention study. Am J Med Genet C Semin Med Genet 2010; 154C:62-72.

123. Mitchell LE, Murray JC, O’Brien S, Christensen K. Evaluation of two putative susceptibility loci for oral clefts in the Danish population. Am J Epidemiol 2001; 153:1007-15.

124. Morales-Suárez-Varela MM, Bille C, Christensen $\mathrm{K}$, Olsen J. Smoking habits, nicotine use, and congenital malformations. Obstet Gynecol 2006; 107:51-7.

125. Morgana LM, Cohn BA, Cohen RD, Christianson RE. Maternal smoking, alcohol consumption, and caffeine consumption during pregnancy in relation to a son's risk of persistent cryptorchidism: a prospective study in the Child Health and Development Studies Cohort, 1959-1967. Am J Epidemiol 2008; 167:257-61.

126. Mori M, Davies TW, Tsukamoto T, Kumamoto Y, Fukuda K. Maternal and other factors of cryptorchidism: a case-control study in Japan. Kurume Med J 1992; 39:53-60.

127. Mossey PA, Davies JA, Little J. Prevention of orofacial clefts: does pregnancy planning have a role? Cleft Palate Craniofac J 2007; 44:244-50.

128. Munoz JB, Lacasana M, Aburto VHB, Sanchez LET, Garcia AMG, Carrillo LL. Socioeconomic factors and the risk of anencephaly in a Mexican population: a case-control study. Public Health Rep 2005; 120:39-45.

129. Mygind H, Thulstrup AM, Pedersen L, Larsen H. Risk of intrauterine growth retardation, malformations and other birth outcomes in children after topical use of corticosteroid in pregnancy. Acta Obstet Gynecol Scand 2002; 81:234-9.

130. Niebyl JR, Blake DA, Rocco LE, Baumgardner R, Mellits ED. Lack of maternal metabolic, endocrine, and environmental influences in the etiology of cleft lip with or without cleft palate. Cleft Palate J 1985; 22:20-8.

131. Nørgaard M, Wogelius P, Pedersen L, Rothman KJ, Sørensen HT. Maternal use of oral contraceptives during early pregnancy and risk of hypospadias in male offspring. Urology 2009; 74:583-7. 
132. Oddsberg J, Jia C, Nilsson E, Ye W, Lagergren J. Maternal tobacco smoking, obesity, and low socioeconomic status during early pregnancy in the etiology of esophageal atresia. J Pediatr Surg 2008; 43:1791-5.

133. Ormond G, Nieuwenhuijsen MJ, Nelson P, Toledano MB, Iszatt N, Geneletti S, et al. Endocrine disruptors in the workplace, hair spray, folate supplementation, and risk of hypospadias: casecontrol study. Environ Health Perspect 2009; 117:303-7.

134. Parikh CR, McCall D, Engelman C, Schrier RW. Congenital renal agenesis: case-control analysis of birth characteristics. Am J Kidney Dis 2002 39:689-94.

135. Parker SE, Mai CT, Strickland MJ, Olney RS, Rickard R, Marengo L, et al. Multistate study of the epidemiology of clubfoot. Birth Defects Res A Clin Mol Teratol 2009; 85:897-904.

136. Pierik FH, Burdorf A, Deddens JA, Juttmann RE, Weber RF. Maternal and paternal risk factors for cryptorchidism and hypospadias: a case-control study in newborn boys. Environ Health Perspect 2004; 112:1570-6.

137. Porter MP, Faizan MK, Grady RW, Mueller BA. Hypospadias in Washington State: maternal risk factors and prevalence trends. Pediatrics 2005; 115:e495-9.

138. Preiksa RT, Zilaitiene B, Matulevicius V, Skakkebaek NE, Petersen JH, Jorgensen N, et al. Higher than expected prevalence of congenital cryptorchidism in Lithuania: a study of 1204 boys at birth and 1 year follow-up. Hum Reprod 2005; 20:1928-32.

139. Queisser-Luft A, Stolz G, Wiesel A, Schlaefer K, Spranger J. Malformations in newborn: results based on 30,940 infants and fetuses from the Mainz congenital birth defect monitoring system (1990-1998). Arch Gynecol Obstet 2002; 266: 163-7.

140. Rantakallio P. Relationship of maternal smoking to morbidity and mortality of the child up to the age of five. Acta Paediatr Scand 1978; 67:621-31.

141. Reefhuis J, de Walle HE, Cornel MC. Maternal smoking and deformities of the foot: results of the EUROCAT Study. European Registries of Congenital Anomalies. Am J Public Health 1998; 88:1554-5.

142. Robitaille J, Carmichael SL, Shaw GM, Olney RS; National Birth Defects Prevention Study. Maternal nutrient intake and risks for transverse and longitudinal limb deficiencies: data from the National Birth Defects Prevention Study, 1997-2003. Birth Defects Res A Clin Mol Teratol 2009; 85: 773-9.

143. Rodríguez-Pinilla E, Mejías C, Prieto-Merino D, Fernández P, Martínez-Frias ML; ECEMC Working Group. Risk of hypospadias in newborn infants exposed to valproic acid during the first trimester of pregnancy: a case-control study in Spain. Drug Saf 2008; 31:537-43.

144. Romitti PA, Sun L, Honein MA, Reefhuis J, Correa A, Rasmussen SA. Maternal periconceptional alcohol consumption and risk of orofacial clefts. Am J Epidemiol 2007; 166:775-85.
145. Salemi JL, Pierre M, Tanner JP, Kornosky JL, Hauser KW, Kirby RS, et al. Maternal nativity as a risk factor for gastroschisis: a population-based study. Birth Defects Res A Clin Mol Teratol 2009; 85:890-6.

146. Saxen I. Cleft lip and palate in Finland: parental histories, course of pregnancy and selected environmental factors. Int J Epidemiol 1974; 3: 263-70.

147. Schmidt RJ, Romitti PA, Burns TL, Browne ML, Druschel CM, Olney RS. Maternal caffeine consumption and risk of neural tube defects. Birth Defects Res A Clin Mol Teratol 2009; 85:879-89.

148. Seidman DS, Ever-Hadani P, Gale R. Effect of maternal smoking and age on congenital anomalies. Obstet Gynecol 1990; 76:1046-50.

149. Shaw GM, Malcoe LH, Swan SH, Cummins SK, Schulman J. Congenital cardiac anomalies relative to selected maternal exposures and conditions during early pregnancy. Eur J Epidemiol 1992; 8:757-60.

150. Shaw GM, Wasserman CR, Lammer EJ, O'Malley CD, Murray JC, Basart AM, et al. Orofacial clefts, parental cigarette smoking, and transforming growth factor-alpha gene variants. Am J Hum Genet 1996; 58:551-61.

151. Shaw GM, Velie EM, Morland KB. Parental recreational drug use and risk for neural tube defects. Am J Epidemiol 1996; 144:1155-60.

152. Shaw GM, Wasserman CR, O'Malley CD, Nelson V, Jackson RJ. Maternal pesticide exposure from multiple sources and selected congenital anomalies. Epidemiology 1999; 10:60-6.

153. Shaw GM, Croen LA, Todoroff K, Tolarova MM. Periconceptional intake of vitamin supplements and risk of multiple congenital anomalies. Am J Med Genet 2000; 93:188-93.

154. Shi M, Christensen K, Weinberg CR, Romitti P, Bathum L, Lozada A, et al. Orofacial cleft risk is increased with maternal smoking and specific detoxification-gene variants. Am J Hum Genet 2007; 80:76-90.

155. Shiono PH, Klebanoff MA, Berendes HW. Congenital malformations and maternal smoking during pregnancy. Teratology 1986; 34:65-71.

156. Skelly AC, Holt VL, Mosca VS, Alderman BW. Talipes equinovarus and maternal smoking: a population-based case-control study in Washington state. Teratology 2002; 66:91-100.

157. Slickers JE, Olshan AF, Siega-Riz AM, Honein MA, Aylsworth AS. Maternal body mass index and lifestyle exposures and the risk of bilateral renal agenesis or hypoplasia: the National Birth Defects Prevention Study. Am J Epidemiol 2008; 168:1259-67.

158. Smedts HP, de Vries JH, Rakhshandehroo M, Wildhagen MF, Verkleij-Hagoort AC, Steegers EA, et al. High maternal vitamin $\mathrm{E}$ intake by diet or supplements is associated with congenital heart defects in the offspring. BJOG 2009; 116:416-23.

159. Sorensen HT, Norgard B, Pedersen L, Larsen H, Johnsen SP. Maternal smoking and risk of hypertrophic infantile pyloric stenosis: 10 year population based cohort study. BMJ 2002; 325:1011-2. 
160. Steinberger EK, Ferencz C, Loffredo CA. Infants with single ventricle: a population-based epidemiological study. Teratology 2002; 65:106-15.

161. Stoll C, Alembik Y, Roth MP, Dott B. Risk factors in congenital anal atresias. Ann Genet 1997; 40: 197-204.

162. Stoll C, Alembik Y, Dott B, Roth MP. Risk factors in congenital abdominal wall defects (omphalocele and gastroschisi): a study in a series of 265,858 consecutive births. Ann Genet 2001; 44:201-8.

163. Suarez L, Felkner M, Brender JD, Canfield M, Hendricks K. Maternal exposures to cigarette smoke, alcohol, and street drugs and neural tube defect occurrence in offspring. Matern Child Health J 2008; 12:394-401.

164. Szendrey T, Danyi G, Czeizel A. Etiological study on isolated esophageal atresia. Hum Genet 1985; 70:51-8.

165. Tamura T, Munger RG, Corcoran C, Bacayao JY, Nepomuceno B, Solon F. Plasma zinc concentrations of mothers and the risk of nonsyndromic oral clefts in their children: a case-control study in the Philippines. Birth Defects Res A Clin Mol Teratol 2005; 73:612-6.

166. Targett CS, Ratten GJ, Abell DA, Beischer NA. The influence of smoking on intrauterine fetal growth and on maternal oestriol excretion. Aust N Z J Obstet Gynecol 1977; 17:126-30.

167. Tata LJ, Lewis SA, McKeever TM, Smith CJ, Doyle P, Smeeth L, et al. Effect of maternal asthma, exacerbations and asthma medication use on congenital malformations in offspring: a UK population-based study. Thorax 2008; 63:981-7.

168. The NS, Honein MA, Caton AR, Moore CA, SiegaRiz AM, Druschel CM. Risk factors for isolated biliary atresia, National Birth Defects Prevention Study, 1997-2002. Am J Med Genet A 2007; 143A:2274-84.

169. Tikkanen J, Heinonen OP. Maternal exposure to chemical and physical factors during pregnancy and cardiovascular malformations in the offspring. Teratology 1991; 43:591-600.

170. To WW, Tang MH. The association between maternal smoking and fetal hydranencephaly. J Obstet Gynaecol Res 1999; 25:39-42.

171. Torfs CP, Velie EM, Oechsli FW, Bateson TF, Curry CJ. A population-based study of gastroschisis: demographic, pregnancy, and lifestyle risk factors. Teratology 1994; 50:44-53.

172. Tornqvist K, Ericsson A, Kallen B. Optic nerve hypoplasia: risk factors and epidemiology. Acta Ophthalmol Scand 2002; 80:300-4.

173. Torp-Pedersen T, Boyd HA, Poulsen G, Haargaard B, Wohlfahrt J, Holmes JM, et al. In-utero exposure to smoking, alcohol, coffee, and tea and risk of strabismus. Am J Epidemiol 2010; 171:868-75.

174. Tuohy PG, Counsell AM, Geddis DC. The Plunket National Child Health Study: birth defects and sociodemographic factors. N Z Med J 1993; 106:489-92.

175. Underwood P, Hester LL, Laffitte Jr. T, Gregg KV. The relationship of smoking to the outcome of pregnancy. Am J Obstet Gynecol 1965; 91:270-6.
176. van den Boogaard MJ, de Costa D, Krapels IP, Liu F, van Duijn C, Sinke RJ, et al. The MSX1 allele 4 homozygous child exposed to smoking at periconception is most sensitive in developing nonsyndromic orofacial clefts. Hum Genet 2008; 124:525-34.

177. van den Eeden SK, Karagas MR, Daling JR, Vaughan TL. A case-control study of maternal smoking and congenital malformations. Paediatr Perinat Epidemiol 1990; 4:147-55.

178. van Rooij IA, Wegerif MJ, Roelofs HM, Peters WH, Kuijpers-Jagtman AM, Zielhuis GA, et al. Smoking, genetic polymorphisms in biotransformation enzymes, and nonsyndromic oral clefting: a gene-environment interaction. Epidemiology 2001; 12:502-7.

179. van Rooij IA, Groenen PM, van Drongelen M, Te Morsche RH, Peters WH, Steegers-Theunissen RP. Orofacial clefts and spina bifida: N-acetyltransferase phenotype, maternal smoking, and medication use. Teratology 2002; 66:260-6.

180. Verkerk PH, Buitendijk SE, Verloove-Vanhorick SP. Differential misclassification of alcohol and cigarette consumption by pregnancy outcome. Int J Epidemiol 1994; 23:1218-25.

181. Virtanen HE, Tapanainen AE, Kaleva MM, Suomi AM, Main KM, Skakkebaek NE, et al. Mild gestational diabetes as a risk factor for congenital cryptorchidism. J Clin Endocrinol Metab 2006; 91:4862-5

182. Wang W, Guan P, Xu W, Zhou B. Risk factors for oral clefts: a population-based case-control study in Shenyang, China. Paediatr Perinat Epidemiol 2009; 23:310-20.

183. Wasserman CR, Shaw GM, O'Malley CD, Tolarova MM, Lammer EJ. Parental cigarette smoking and risk for congenital anomalies of the heart, neural tube, or limb. Teratology 1996; 53:261-7.

184. Watkins ML, Scanlon KS, Mulinare J, Khoury MJ. Is maternal obesity a risk factor for anencephaly and spina bifida? Epidemiology 1996; 7:507-12.

185. Watkins ML, Rasmussen SA, Honein MA, Botto LD, Moore CA. Maternal obesity and risk for birth defects. Pediatrics 2003; 111:1152-8.

186. Werler MM, Sheehan JE, Mitchell AA. Association of vasoconstrictive exposures with risks of gastroschisis and small intestinal atresia. Epidemiology 2003; 14:349-54.

187. Werler MM, Starr JR, Cloonan YK, Speltz ML. Hemifacial microsomia: from gestation to childhood. J Craniofac Surg 2009; 20 Suppl 1:664-9.

188. Werler MM, Bosco JLF, Shapira SK. Maternal vasoactive exposures, amniotic bands, and terminal transverse limb defects. Birth Defects Res A Clin Mol Teratol 2009; 85:52-7.

189. Werler MM, Mitchell AA, Moore CA, Honein MA Is there epidemiologic evidence to support vascular disruption as a pathogenesis of gastroschisis? Am J Med Genet A 2009; 149A:1399-406.

190. Wong-Gibbons DL, Romitti PA, Sun L, Moore CA, Reefhuis J, Bell EM, et al. Maternal periconceptional exposure to cigarette smoking and alcohol and esophageal atresia $+/$ - tracheo-esophageal fistula. Birth Defects Res A Clin Mol Teratol 2008; 82:776-84. 
191. Woods SE, Raju U. Maternal smoking and the risk of congenital birth defects: a cohort study. J Am Board Fam Pract 2001; 14:330-4.

192. Wyszynski DF, Wu T. Use of US birth certificate data to estimate the risk of maternal cigarette smoking for oral clefting. Cleft Palate Craniofac J 2002; 39:188-92.

193. Yerushalmy J. The relationship of parents' cigarette smoking to outcome of pregnancy - implications as to the problem of inferring causation from the observed associations. Am J Epidemiol 1971; 93:443-56.

194. Yerushalmy J. Congenital heart disease and maternal smoking habits. Nature 1973; 242:262-3.

195. Yuan P, Okazaki I, Kuroki Y. Anal atresia: effect of smoking and drinking habits during pregnancy. Jpn J Hum Genet 1995; 40:327-32.

196. Zeiger JS, Beaty TH, Hetmanski JB, Wang H, Scott $\mathrm{AF}$, Kasch L, et al. Genetic and environmental risk factors for sagittal craniosynostosis. J Craniofac Surg 2002; 13:602-6.

197. Leopércio W, Gigliotti A. Tabagismo e suas peculiaridades durante a gestação: uma revisão crítica. J Bras Pneumol 2004; 30:176-85.

198. Quinton AE, Cook CM, Peek MJ. The relationship between cigarette smoking, endothelial function and intrauterine growth restriction in human pregnancy. BJQG 2008; 115:780-4.

199. Szklo AS, de Almeida LM, Figueiredo VC, Autran M, Malta D, Caixeta R, et al. Snapshot of the striking decrease in cigarette smoking prevalence in Brazil between 1989 and 2008. Prev Med 2012; 54:162-7.

200. Salihu HM, Wilson RE. Epidemiology of parental smoking and perinatal outcomes. Early Hum Dev 2007; 83:713-20.
201. Zhang L, González-Chica DA, Cesar JA, Mendoza-Sassi RA, Beskow B, Larentis N, et al. Tabagismo materno durante a gestação e medidas antropométricas do recém-nascido: um estudo de base populacional no extremo sul do Brasil. Cad Saúde Pública 2011; 27:1768-76.

202. Tong VT, Dietz PM, Morrow B, D'Angelo DV, Farr SL, Rockhill KM, et al. Trends in smoking before, during, and after pregnancy: Pregnancy Risk Assessment Monitoring System, United States, 40 sites, 2000-2010. MMWR Surveill Summ 2013; 62:1-19.

203. Ontario Tobacco Research Unit. Indicators of smoke-free Ontario progress. Toronto: Ontario Tobacco Research Unit; 2010.

204. Bloch M, Althabe F, Onyamboko M, Kaseba-Sata C, Castilla EE, Freire S, et al. Tobacco use and secondhand smoke exposure during pregnancy: an investigative survey of women in 9 developing nations. Am J Public Health 2008; 98:1833-40.

205. Reis LG, da Silva CF, Trindade A, Abrahão M, da Silva VA. Quem são as mulheres tabagistas que param de fumar na gestação? Rev Bras Saúde Matern Infant 2008; 8:217-21.

206. Sanderson S, Iain D, Tatt ID, Higgins JPT. Tools for assessing quality and susceptibility to bias in observational studies in epidemiology: a systematic review and annotated bibliography. Int J Epidemiol 2007; 36:666-76.

Submitted on 15/Jun/2013

Final version resubmitted on 30/Jun/2014

Approved on 18/Aug/2014 